\title{
Microstructural Control and Characterization of Bi2V0.9Cu0.105.35 (BICUVOX) Ceramics
}

\author{
Soheil Razmyar \\ West Virginia University
}

Follow this and additional works at: https://researchrepository.wvu.edu/etd

\section{Recommended Citation}

Razmyar, Soheil, "Microstructural Control and Characterization of Bi2V0.9Cu0.105.35 (BICUVOX) Ceramics" (2011). Graduate Theses, Dissertations, and Problem Reports. 4771.

https://researchrepository.wvu.edu/etd/4771

This Thesis is protected by copyright and/or related rights. It has been brought to you by the The Research Repository @ WVU with permission from the rights-holder(s). You are free to use this Thesis in any way that is permitted by the copyright and related rights legislation that applies to your use. For other uses you must obtain permission from the rights-holder(s) directly, unless additional rights are indicated by a Creative Commons license in the record and/ or on the work itself. This Thesis has been accepted for inclusion in WVU Graduate Theses, Dissertations, and Problem Reports collection by an authorized administrator of The Research Repository @ WVU. For more information, please contact researchrepository@mail.wvu.edu. 


\title{
Microstructural Control and Characterization of $\mathrm{Bi}_{2} \mathrm{~V}_{0.9} \mathrm{Cu}_{0.1} \mathrm{O}_{5.35}$ (BICUVOX) Ceramics
}

\author{
Soheil Razmyar
}

Thesis submitted to the College of Engineering and Mineral Resources at West Virginia University in partial fulfillment of the requirements

for the degree of

\author{
Master of Science \\ in \\ Mechanical Engineering \\ Edward M. Sabolsky, Ph.D., Chair \\ Jacky C. Prucz, Ph.D. \\ Xueyan Song, Ph.D. \\ Department of Mechanical and Aerospace Engineering
}

Morgantown, West Virginia

2011

Keywords: SOFC, Solid Oxide Fuel Cell, Ionic Conductivity, BICUVOX

Copyright 2011 Soheil Razmyar 


\section{ABSTRACT \\ Microstructural Control and Characterization of $\mathrm{Bi}_{2} \mathrm{~V}_{\mathbf{0 . 9}} \mathrm{Cu}_{0.1} \mathrm{O}_{5.35}$ (BICUVOX) Ceramics}

\section{Soheil Razmyar}

The widespread commercialization of solid-oxide fuel cells (SOFCs) and solid-oxide electrolyte cells (SOECs) is primarily limited by material degradation issues related to the required high temperature operation $\left(>800^{\circ} \mathrm{C}\right)$. Applications of stabilized zirconia based electrolytes, which are the most commonly used oxide ion conductors, have been limited to this high temperature regime due to its low oxygen ion conductivity below $800^{\circ} \mathrm{C}$. Solid electrolytes made of the BIMEVOX compositional family of materials $\left(\mathrm{Bi}_{2} \mathrm{Me}_{\mathrm{x}} \mathrm{V}_{1-\mathrm{x}} \mathrm{O}_{5.5-\delta}\right.$ where $\mathrm{Me}=\mathrm{Cu}, \mathrm{Co}$, $\mathrm{Mg}, \mathrm{Ni}, \mathrm{Fe} . .$.$) exhibit high oxide ionic conductivity similar to YSZ at a low temperature (300-$ $\left.600^{\circ} \mathrm{C}\right)$. Among these materials copper-substituted bismuth vanadate $\left(\mathrm{Bi}_{2} \mathrm{~V}_{0.9} \mathrm{Cu}_{0.1} \mathrm{O}_{5.35}\right.$, BICUVOX), was reported to have the highest ionic conductivity at $400^{\circ} \mathrm{C}(0.02 \mathrm{~S} / \mathrm{cm})$. It's one of the most important drawbacks of using BICUVOX, as a SOFC electrolyte is the low mechanical strength, which makes it unusable for most electrolyte supported applications. This research aims at improving mechanical strength by careful control of synthesis processing and sintering processes, thus making BICUVOX a viable material option for intermediate temperature SOFC. A co-precipitation method was used to synthesize submicron BICUVOX powder. The powder was utilized to fabricate a thin $(<250 \mu \mathrm{m})$ BICUVOX electrolyte membrane, with $2.5 \mathrm{~cm}^{2}$ active area and high mechanical strength. The fabricated BICUVOX membranes were densified to $97 \%$ theoretical density at lower sintering temperature and shorter time $\left(675^{\circ} \mathrm{C} / 1 \mathrm{~h}\right)$, and shows fine grain size $(<1.5 \mu \mathrm{m})$ and high mechanical strength (159 MPa). 


\section{DEDICATION}

Dedicated to my dear God, without Him guiding my every step, nothing would be possible for me.

Dedicated to my loving, caring and industrious parents and brother, Nasrin, Rahmat, and Soroush Razmyar, and my grandparents, Mamani and Babaei (Marziyeh and Mohammad Morad Tehrani) who have always been making sacrifices along the way to help me achieve my goals. 


\section{ACKNOWLEDGEMENTS}

I would like to express my heartfelt deep appreciation to my advisor Dr. Edward Sabolsky for his mentoring, encouragement, and financial support throughout this project. His knowledge and wisdom were my resources, his hard work my inspiration and his persistence my motivation during the course of this work. His contributions are numerous and valuable. I also would like to express my eternal appreciation to Kathy Sabolsky for her valuable encouragement and assistance. Without her various levels of assistance in the lab, this work would have been impossible. I would like to thank the other committee members, Dr. Jacky C. Prucz and Dr. Xueyan Song who took the time from their very busy schedules to assist me. I would like to lay emphasis on thanks to Dr. Song for her valuable assistance for obtaining TEM images of my samples. A great deal of thanks is due to Trenton Larrabee, Charles Ndhlovu, and Sheldon Blckshire for all of their help with my XRD and BET works. I would also like to thank Santer Zachary for all of his help with the LabVIEW programming for conductivity tests. In particular, I would like to acknowledge Professor Bill Haller for all of his guidance and help during this work. Special thanks go to my dear uncle, Nader Tehrani, and his lovely family, for their endless support and encouragement. I would like to express my gratitude to my dear cousin Reza Abhari for being always there and providing unlimited support. Special thanks to my dear friends Albina Khabibulina, Nyakundi Michieka for their co-operation, support, idea and assistance throughout this project. Finally, I cannot express enough love and appreciation for my parents, grandparents, my supportive brother, and my caring uncles Mozaffar Tehrani and Nasser Razmyar and their lovely families in Charlotte, who have stood by me as mentors, friends, and as pillar of support. Everything I have achieved is because of them. 


\section{TABLE OF CONTENTS}

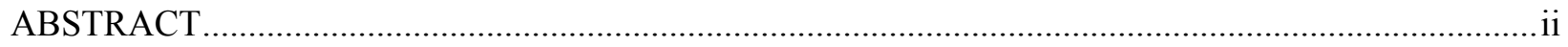

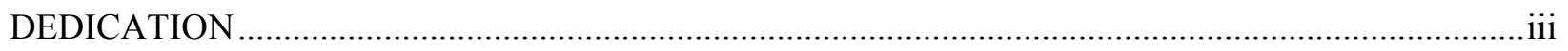

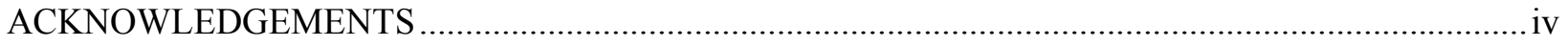

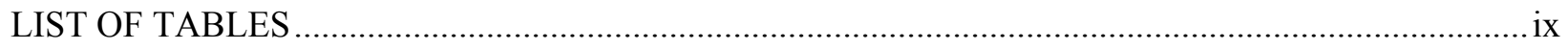

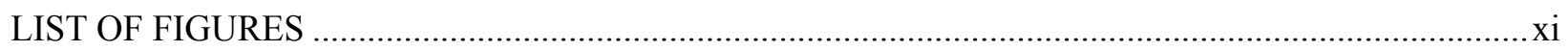

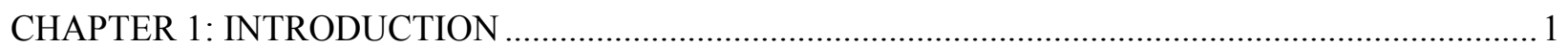

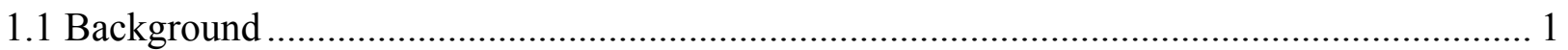

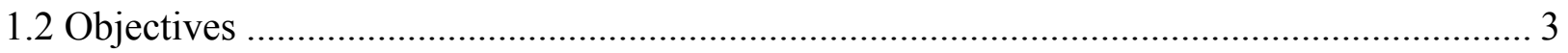

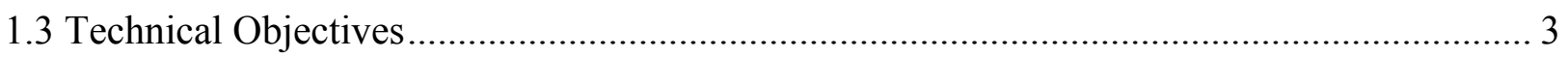

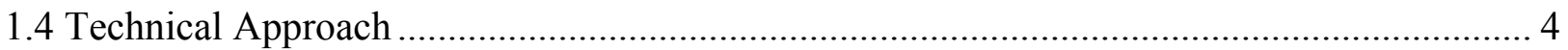

1.4.1 Enhance Sintering Kinetics for Lower Temperatures ......................................................... 4

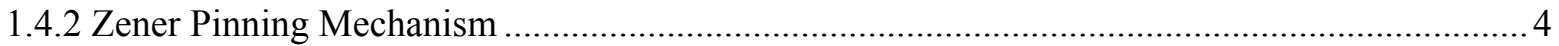

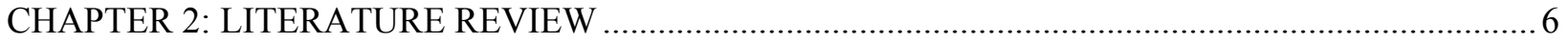

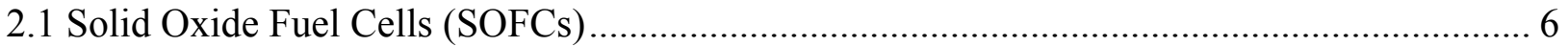

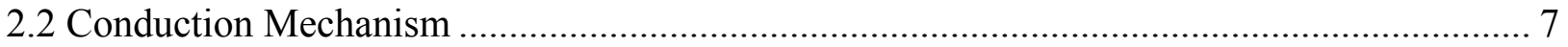

2.3 Conductivity-Crystal Structure Relationships ...................................................... 9

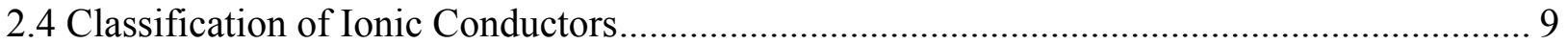


2.6 Doping and Mechanism of Improvement of Ionic Conductivity within Zirconia-Based Solid

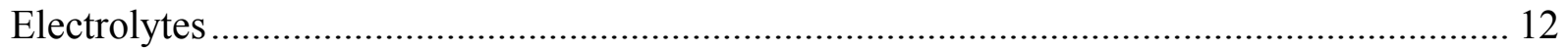

2.7 Dependence of Crystal Structure of Materials on Oxygen Ionic Conductivity ...................... 14

2.7.1 Oxygen Ionic Conductivity in Fluorite and Fluorite based Solid Electrolytes .......................... 15

2.7.2 Oxygen Ionic Conductivity in Pyrochlore based Solid Electrolytes............................................ 18

2.7.3 Oxygen Ionic Conductivity in Perovskite and Perovskite based Solid Electrolytes .................. 19

2.7.4 Oxygen Ionic Conductivity in Oxide Brownmillerite $\left(\mathrm{A}_{2} \mathrm{~B}_{2} \mathrm{O}_{5}\right)$ based Solid Electrolytes ........ 22

2.7.5 Oxide Ion Conductivity in $\mathrm{Bi}_{2} \mathrm{O}_{3}$ based Solid Electrolytes ..................................................... 24

2.7.6 Oxide Ion Conductivity in Bi-Layered Solid Electrolytes .......................................................27

2.7.7 Oxygen Ionic Conductivity in BIMEVOX based Solid Electrolytes.........................................2

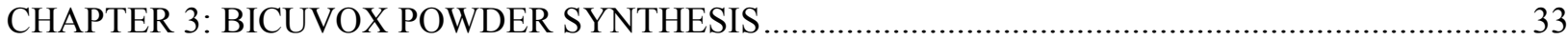

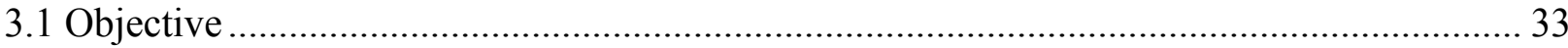

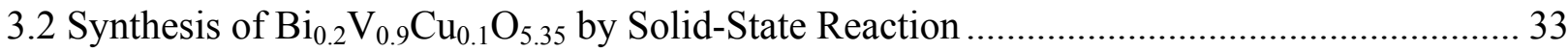

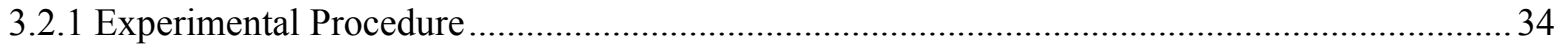

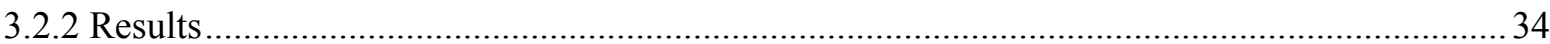

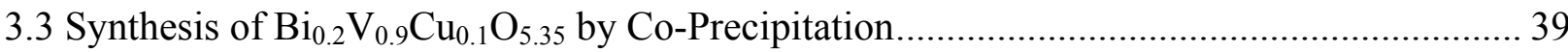

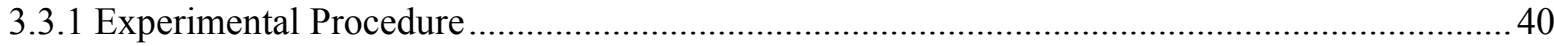

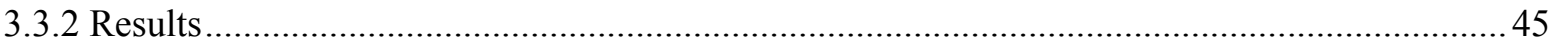

3.4 Synthesis of $\mathrm{Bi}_{0.2} \mathrm{~V}_{0.9} \mathrm{Cu}_{0.1} \mathrm{O}_{5.35}$ Templates by Molten Salt Synthesis (MSS) ........................ 50

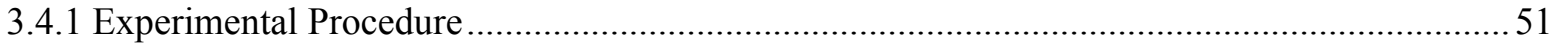

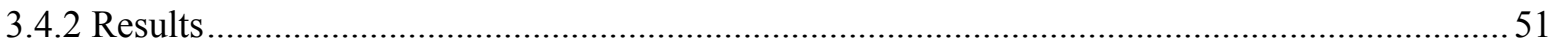




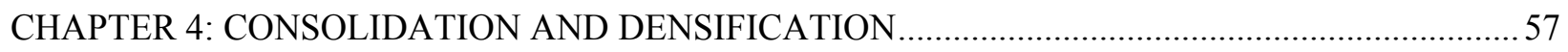

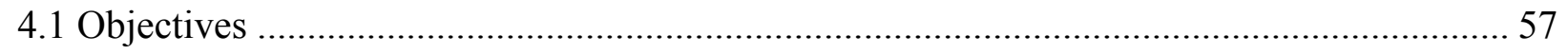

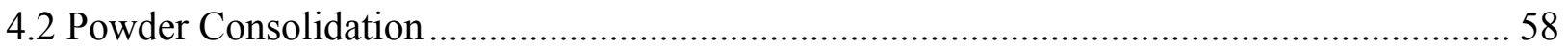

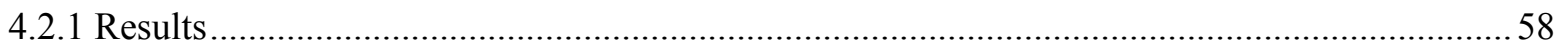

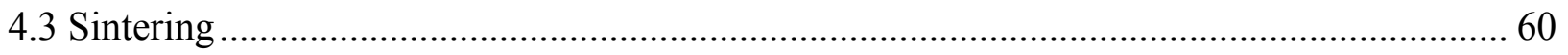

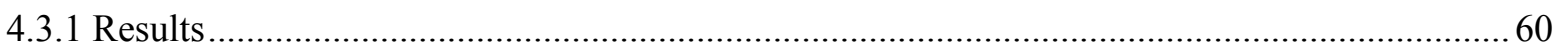

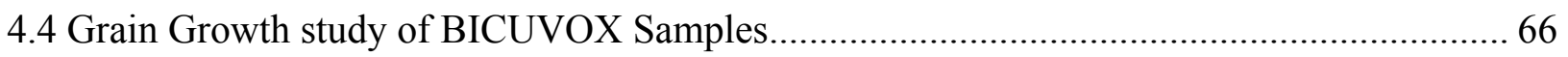

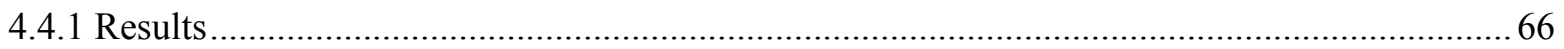

4.5 Control of Grain Growth through Boundary Pinning (Zenner Pinning)............................ 75

4.5.1 Synthesis of Gadolinium Doped Ceria (GDC, $\mathrm{Ce}_{0.90} \mathrm{Gd}_{0.10} \mathrm{O}_{1.95}$ ) by Hydrothermal Method ... 75

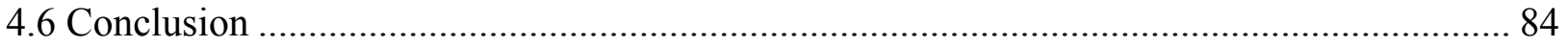

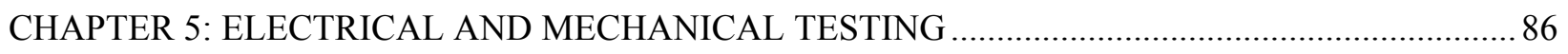

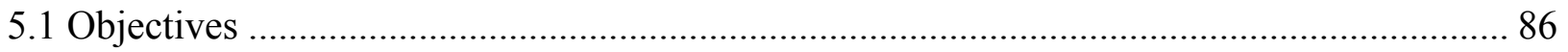

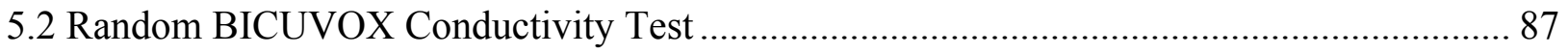

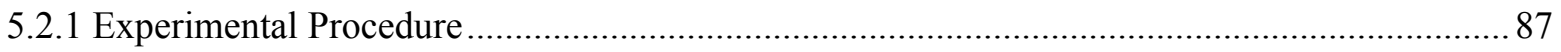

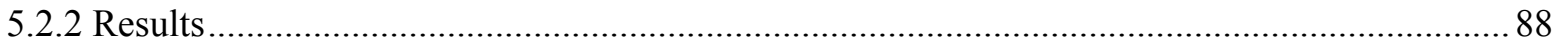

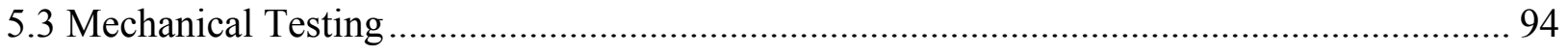

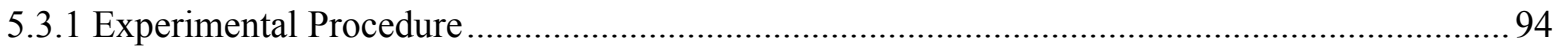

vii 
5.3.2 Results...

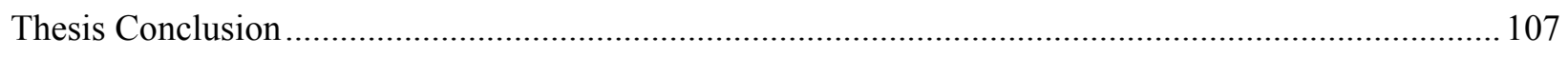

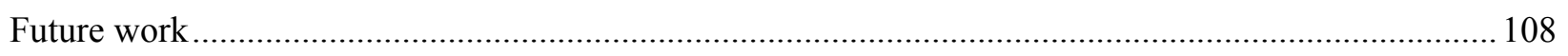




\section{LIST OF TABLES}

Table 1: $\mathrm{Bi}_{2} \mathrm{O}_{3}$ phases and related conductivity at different temperature 26

Table 2: BET surface area data obtained from calcined SSR powder at different temperatures.. 36

Table 3: The influence of different powder synthesis methods on particle size

Table 4: Density data and standard deviation of all sintering conditions 61

Table 5: Comparison of sintering conditions and achieved density data with repeated works .... 63

Table 6: Etching profile for different sintering conditions 67

Table 7: Comparison of obtained density and grain size with other sintering work 74

Table 8: Comparison of density and grain size obtained by co-precipitation method with other works. 92

Table 9: Comparison of conductivities and related densities of other works 93

Table 10: Comparison of alumina mechanical data of this work with the ones reported in ASTM

C 1499-03. 98

Table 11: Effects of sintering conditions and addition of GDC on mechanical properties of BICUVOX 99 
Table 12: Comparison of biaxial flexure strength of different oxide ceramics . 


\section{LIST OF FIGURES}

Figure 1: Schematic of a SOFC fuel cell.

Figure 2: Frenkel defect (left) for $\mathrm{AgCl}$ crystal, $\mathrm{Ag}^{+} \rightarrow \mathrm{V}_{\mathrm{Ag}^{+}} \mathrm{Ag}^{+}$, and Schottky defect (right)

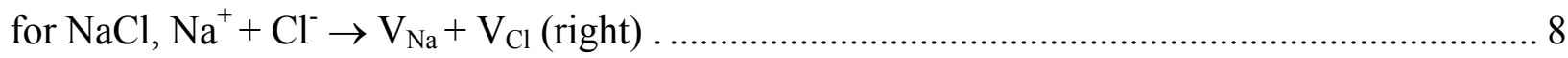

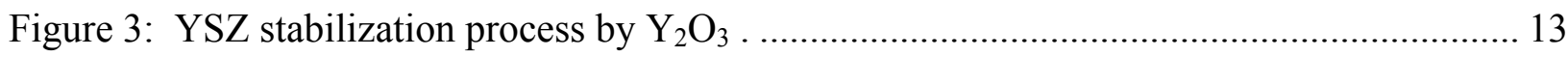

Figure 4: The fluorite $\left(\mathrm{AO}_{2}\right)$ oxide structure. The red spheres represent the A cation sites and the blue spheres the oxygen sites .

Figure 5: Unit cell of fluorite. The yellow atoms represent $4^{+}$cations and the red atoms represent $2^{-}$anions 15

Figure 6: Fluorite type structure of a) YSZ (yttria-stabilized zirconia), b) zirconium oxide (zirconia) c) calcia stabilized zirconia, d) cerium oxide (ceria) 17

Figure 7: Perovskite cubic unit cell with titanium atoms at the corners (gray), oxygen atoms at the midpoints of the edges (green and blue), and a calcium atom (purple) in the center. Dark shades are used to indicate layers further back 19

Figure 8: Each titanium atom is octahedrally coordinated with six oxygen atoms, with a calcium atom in the center 20

Figure 9: Perovskite type structure of a) $\mathrm{LaGaO}_{3}$.b) lanthanum scandate 22 
Figure 10: Perovskite has oxygen on the corners of each octahedral, an iron is in the center of each octahedral, and the dark circle is strontium. The strontiums together form cubes around the octahedral 23

Figure 11: Brownmillerite is $\mathrm{SrFeO}_{2.5}$. The yellow circles represent iron $\left(\mathrm{B}^{3+}\right)$, the red circles represent oxygen, and the boxes represent vacancies. Strontium is not shown ..... 24

Figure 12: Transformation temperatures for the different phases of $\mathrm{Bi}_{2} \mathrm{O}_{3}$. 25

Figure 13: Conductivity of different phases of $\mathrm{Bi}_{2} \mathrm{O}_{3}$ versus temperature 27

Figure 14: Aurivillius phases of $\mathrm{Bi}_{3} \mathrm{TiNbO}_{9}$ 28

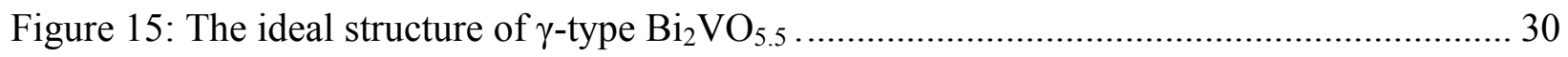

Figure 16: Oxide ion conductivity of selected $\mathrm{Bi}_{2} \mathrm{~V}_{1-\mathrm{x}} \mathrm{M}_{\mathrm{x}} \mathrm{O}_{5.5-1.5 \mathrm{x}}$ with $\mathrm{M}=\mathrm{Cu}, \mathrm{Co}, \mathrm{Ni}, \mathrm{Zn}$. 31

Figure 17: Comparison of ionic conductivity for ionic conductors with different crystal structure.

Figure 18: SEM micrograph of raw BICUVOX (SSR) powder (left) and calcined one at $200^{\circ} \mathrm{C}$

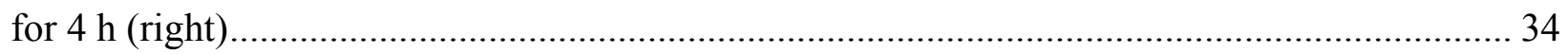

Figure 19: SEM micrograph of calcined BICUVOX powder (SSR) at $700^{\circ} \mathrm{C}$ for $4 \mathrm{~h}$. 35

Figure 20: X-ray pattern of BICUVOX pellet made by SSR method and sintered at $700^{\circ} \mathrm{C}$ for $4 \mathrm{~h}$ 37 
Figure 21: X-ray pattern of BICUVOX pellet made by SSR method and sintered at $750^{\circ} \mathrm{C}$ for $4 \mathrm{~h}$

Figure 22: Pourbaix diagram of the $\mathrm{Bi}-\mathrm{H}_{2} \mathrm{O}$ system 41

Figure 23: Pourbaix diagram of the $\mathrm{V}-\mathrm{H}_{2} \mathrm{O}$ system 42

Figure 24: Pourbaix diagram of the $\mathrm{Cu}-\mathrm{H}_{2} \mathrm{O}$ system . 43

Figure 25: Summary of Co-Precipitation Processes 45

Figure 26: XRD patterns of BICUVOX powder synthesized by co-precipitation method calcined at different temperatures. 46

Figure 27: BICUVOX powder obtained by co-precipitation method and calcined at $500^{\circ} \mathrm{C} / 2 \mathrm{~h}$ (left), BICUVOX powder obtain from SSR method; calcined at $500^{\circ} \mathrm{C} / 4 \mathrm{~h}$ and remilled for $4 \mathrm{~h}$ (right).

Figure 28: SEM images of MSS powders fired at (a) $680^{\circ} \mathrm{C} / 3 \mathrm{~h}$ contains $30 \%$ solid volume, (b) $700^{\circ} \mathrm{C} / 1 \mathrm{~h}$ contains $20 \%$ solid volume, (c) $700^{\circ} \mathrm{C} / 2 \mathrm{~h}$ contains $20 \%$ solid volume, (d) $700^{\circ} \mathrm{C} / 2 \mathrm{~h}$ contains $30 \%$ solid volume, (e) powder sieved by mesh 60 and fired at $700^{\circ} \mathrm{C} / 4 \mathrm{~h}$ contains $20 \%$ solid volume, (f) $700^{\circ} \mathrm{C} / 4 \mathrm{~h}$ contains $20 \%$ solid volume, (g) $700^{\circ} \mathrm{C} / 4 \mathrm{~h}$ contains $30 \%$ solid volume, (h) $700^{\circ} \mathrm{C} / 4 \mathrm{~h}$ contains $50 \%$ solid volume, (i) $700^{\circ} \mathrm{C} / 8 \mathrm{~h}$ contains $20 \%$ solid volume... 53

Figure 29: XRD pattern of the MSS BICUVOX powder treated at $700^{\circ} \mathrm{C} / 2 \mathrm{~h}(20 \% \mathrm{~S} . \mathrm{V})$. 54

xiii 
Figure 30: XRD pattern of the MSS BICUVOX powder treated at $700^{\circ} \mathrm{C} / 4 \mathrm{~h}(20 \% \mathrm{~S} . \mathrm{V})$

Figure 31: Effect of employed pressure during consolidation process on density of BICUVOX after sintering. 59

Figure 32: Densification characterization of BICUVOX related to time and temperature 62

Figure 33: SEM pictures of sintered samples at $625^{\circ} \mathrm{C}$ and $650^{\circ} \mathrm{C}$ for $2 \mathrm{~h}, 4 \mathrm{~h}$, and $8 \mathrm{~h}$ 64

Figure 34: SEM pictures of sintered samples at $700^{\circ} \mathrm{C} / 1 \mathrm{~h}$ and $750^{\circ} \mathrm{C} / 30 \mathrm{~min}$ 65

Figure 35: Effects of sintering time and temperature on BICUVOX grain size. 68

Figure 36: SEM pictures of sintered sample at $625^{\circ} \mathrm{C}, 675^{\circ} \mathrm{C}, 750^{\circ} \mathrm{C}$ and $800^{\circ} \mathrm{C}$ for $0 \mathrm{~h}$ and $4 \mathrm{~h} . .69$

Figure 37: SEM pictures of sintered sample at $625^{\circ} \mathrm{C}, 675^{\circ} \mathrm{C}, 750^{\circ} \mathrm{C}$ and $800^{\circ} \mathrm{C}$ for $0 \mathrm{~h}$ and 8 h.69

Figure 38 : Phase diagram of the system $\mathrm{Bi}_{2} \mathrm{O}_{3}-\mathrm{V}_{2} \mathrm{O}_{5}$. 70

Figure 39: Determination of sintering mechanism at different temperatures 72

Figure 40: A linear fit to the curve in the plot of $10 \times \mathrm{T}-1 \mathrm{vs} . \ln (\mathrm{dg}-1 \times \mathrm{t}-1)$ 73

Figure 41: XRD pattern of the calcined GDC at $800^{\circ} \mathrm{C}$ for $4 \mathrm{~h}$ 77

Figure 42: TEM image of the GDC powder prepared by hydrothermal method.... 77 
Figure 43: Density dependences of temperature at different $\mathrm{wt} \%$ addition of nano powder GDC

Figure 44: Comparison of the effects of nano powder GDC addition on density of BICUVOX ceramics 79

Figure 45: Grain size dependences temperature at different wt \% addition of nano GDC powder 80

Figure 46: Comparison of addition of different $w t \%$ nano powder GDC on grain size of BICUVOX ceramics 81

Figure 47: SEM image of effects of nano GDC addition on BICUVOX grain size for the sintered samples at $675^{\circ} \mathrm{C} / 4 \mathrm{~h}$ 82

Figure 48: SEM image of effects of nano GDC addition on BICUVOX grain size for the sintered samples at $700^{\circ} \mathrm{C} / 4 \mathrm{~h}$ 82

Figure 49: SEM image of effects of nano GDC addition on BICUVOX grain size for the sintered samples at $750^{\circ} \mathrm{C} / 4 \mathrm{~h}$. 83

Figure 50: SEM image of effects of nano GDC addition on BICUVOX grain size and density for the sintered samples at $800^{\circ} \mathrm{C} / 4 \mathrm{~h}$. 83

Figure 51: XRD pattern of the sintered conductivity bar at $675^{\circ} \mathrm{C} / 30 \mathrm{~min}$ 89 
Figure 52: Conductivity versus temperature for the sintered samples at different sintering condition and different $\mathrm{wt} \%$ of nano powder GDC 90

Figure 53: Comparison of obtained conductivity results with other work 93

Figure 54: A schematic of the concentric ring-on-ring loading configuration 95

Figure 55: Load cell and fixture set up for equibiaxial flexural strength test 97

Figure 56: A Weibull plot showing the distribution of flexural strength for specimens sintered at different conditions. 100

Figure 57: Illustrations of failure patterns in concentric ring test specimens 102

Figure 58: Fractured patterns of the tested samples. 102

Figure 59: Intergranular crack growth in fractured surface 103

Figure 60: Intragranular crack growth in fractured surface 104

Figure 61: Intragranular crack growth in top surface 104

Figure 62: Intergranular crack growth in top surface 105 


\section{CHAPTER 1: INTRODUCTION}

\subsection{Background}

Today our energy dependent society shows a tremendous interest in new sources of clean and highly efficient energy that can be substituted for fossil fuel in the future. Solid oxide fuel cells (SOFCs) are deemed to be a promising candidates to generate electricity with an environmentally friendly method that can satisfy today's society needs.

SOFCs is a highly efficient (40-60\% unassisted, up to $70 \%$ in pressurized hybrid system), clean, durable and relatively cost effective electrochemical device that produces electricity by oxidizing different kinds of fuels through its ceramic membrane. SOFCs use covers residential applications to power plants (distributed power generation), auxiliary power and also energy for automobiles, ships and space applications.

Solid electrolytes made of yttria-stabilized zirconia (YSZ) are the most common electrolyte for SOFCs applications. YSZ based SOFCs require operation at elevated temperature (800$1000^{\circ} \mathrm{C}$ ) in order to produce sufficient ionic conductivity. The widespread commercialization of SOFCs is primarily limited by materials degradation issues related to the high temperature operation. Research is required to develop the next generation of solid ionic electrolytes that display ionic conductivity exceeding $10^{-2} \mathrm{~S} / \mathrm{cm}$ at temperature $<800^{\circ} \mathrm{C}$. 
Solid electrolytes made of the BIMEVOX $\left(\mathrm{Bi}_{2} \mathrm{Me}_{\mathrm{x}} \mathrm{V}_{1-\mathrm{x}} \mathrm{O}_{5.5-\delta}\right.$ where $\mathrm{Me}=\mathrm{Cu}, \mathrm{Co}, \mathrm{Mg}, \mathrm{Ni}$, Fe...) compositional family of materials exhibit high oxide ionic conductivity, similar to YSZ at a lower temperature $\left(300-600^{\circ} \mathrm{C}\right)$. Among these materials, copper-substituted bismuth vanadate $\left(\mathrm{Bi}_{2} \mathrm{~V}_{0.9} \mathrm{Cu}_{0.1} \mathrm{O}_{5.35}\right)$, shows the highest ionic conductivity at $400^{\circ} \mathrm{C}(0.02 \mathrm{~S} / \mathrm{cm})$ [1]. Reduction at low oxygen partial pressure $\left(\mathrm{pO}_{2}<10^{-2}\right.$ atm $)$, high thermal expansion coefficient $\left(15 \times 10^{-6} /{ }^{\circ} \mathrm{C}\right)$, and extremely high chemical reactivity with many electrode systems are some of the problems faced by BICUVOX ceramic electrolytes [2]. One of the most important barriers for using BICUVOX as a SOFC electrolyte is its low mechanical strength.

Solid state reaction (SSR) is the typical approach for synthesis of BICUVOX powder. This method usually produces large grains size distribution $(>3 \mu \mathrm{m})$, which negatively influences the densification process and mechanical strength of the cells. Reported average density and grain size of the samples fabricated by SSR method are 95\% theoretical density and 5-10 $\mu \mathrm{m}$, respectively, which results in $83 \mathrm{MPa}$ mechanical strength [3,4]. In comparison YSZ substrates used for SOFC application have $400 \mathrm{MPa}$ mechanical strength [5]. 


\subsection{Objectives}

This research is aimed at investigating materials synthesis and processing conditions to increase the mechanical strength properties of BICUVOX, so the material may potentially be used in an actual commercial application. The long-range aim of this work is to fabricate a usable BICUVOX electrolyte membrane, which exhibits mechanical strength necessary for SOFC application and operates at temperatures $<800^{\circ} \mathrm{C}$. This work will specifically target the improvement of mechanical strength of BICUVOX electrolyte through a new powder synthesis method and careful control of densification process.

\subsection{Technical Objectives}

This project proposes the use of a co-precipitation and Zener pinning method to improve densification and grain growth processes for BICUVOX ceramics. Powder synthesis using coprecipitation method will result in powder particle size distribution of less than one micron. Smaller particle size powder will provide a higher driving force for the sintering process, where will result in completion the densification process at lower temperatures and limit grain growth.

Also, the suggested Zener pinning method using GDC nano powder, will prevent grain growth at higher sintering temperatures, therefore improve the mechanical strength of the fired BICUVOX specimens $>750^{\circ} \mathrm{C}$. 


\subsection{Technical Approach}

\subsubsection{Enhance Sintering Kinetics for Lower Temperatures}

Powder with smaller particle size distribution have a higher surface area, which can provide a strong thermodynamic driving force for sintering [6]. To achieve fully dense substrates at lower sintering temperature, it's necessary to control particle size distribution of powder and its sintering driving force. Depending upon packing efficiency of the finer powder, the reduction of interstitial particle spaces may be reduced, resulting in a reduction in ion transport distance. This reduces pore concentration and size, and consequently the sintering temperature. This research applies the co-precipitation [7] method to reduce BICUVOX particle size to less than a micron. It is expected that the sintering temperature will decrease to less than that achieved by SSR method $\left(750^{\circ} \mathrm{C}\right)$. Completion of densification process at lower temperature and shorter times will result in smaller grain size and higher mechanical strength.

\subsubsection{Zener Pinning Mechanism}

Zener pinning mechanism is also another applied method to this research which reduces the rate of grain growth and will improve the mechanical properties. In Zener pinning mechanism, the movement of grain boundaries through a polycrystalline material can be controlled with the dispersion of fine particles within its matrix. Applied dragging forces to the grain boundary by smaller particles will restrict the motion of grain boundaries resulting in limited grain growth [6]. 
This mechanism allows for diffusion through the bulk grains to the inter particle interstitial sites; thus, still permitting the sintering process to occur. This way porosity maybe removed between the grains and the grain boundary mobility may be decreased to eliminate trapping of pores within the grains. Consequently, the mechanical strength and ionic conductivity of the electrolyte will improve.

In this research, a concentration of hydrothermally synthesized nano-sized GDC $(10 \% \mathrm{Gd}-$ doped Ceria) powder will be added into the BICUVOX sub-micron matrix in order to control the grain size through boundary pinning (Zener pinning mechanism). The GDC nano-sized particles are dispersed at grain boundaries and allowing for the pinning grain boundary motion and grain growth. 


\section{CHAPTER 2: LITERATURE REVIEW}

\subsection{Solid Oxide Fuel Cells (SOFCs)}

The solid oxide fuel cell (Figure 1) is a highly efficient, clean, durable and relatively cost effective electrochemical device. The auxiliary power system, vehicle motor powder, stationary electric power and distributed generation are some of the SOFCs applications [8]. Two porous electrodes (anode and cathode) and a dense electrolyte placed between the electrodes are the main components of a cell. While air flows at the cathode side, cathode/electrolyte interface catalytically dissociates each oxygen molecule into two oxygen ions by accruing four electrons. Oxygen ions diffuse through the electrolyte and react with the fuel at the anode/electrolyte interface. Water, heat, and most importantly two electrons are the product of this reaction. Electrons can be used as a source of power to drive a load.

Resistance of the electrolyte is one of the drawbacks of this system, which needs to be reduced either by decreasing the thickness of the electrolyte or using materials with high ionic conductivity [9]. 


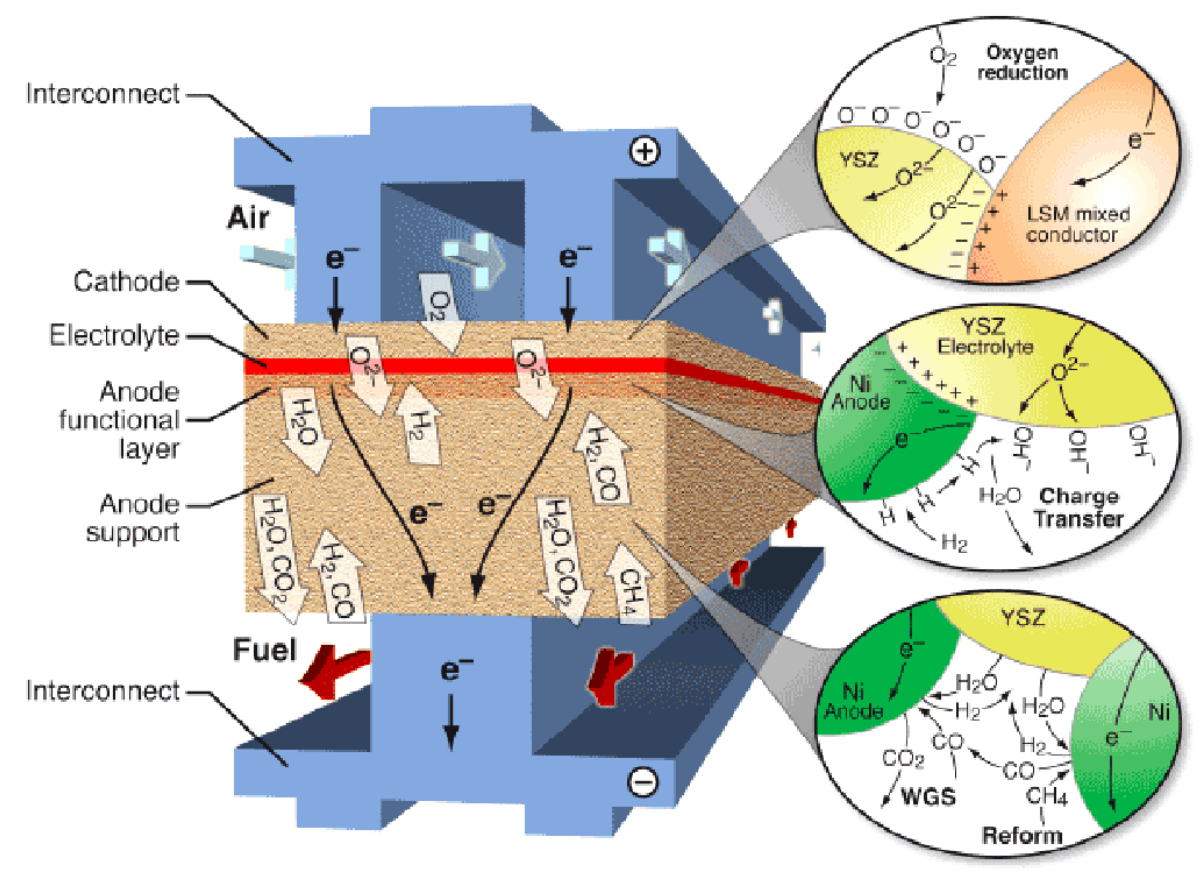

Figure 1: Schematic of a SOFC fuel cell [10].

\subsection{Conduction Mechanism}

Ionic conductivity is based upon the principle of ionic species being transported through a crystal lattice of a material by diffusion. Diversion of ions from their equilibrium state (at zero temperature) could happen by altering some factors such as temperature, pressure or the material's composition. This can result in the creation of a defect which helps to reduce the system energy. Schottky and Frenkel are two important types of stoichiometric lattice defects that have an important effect on ion transportation through the crystal structure.

The Frenkel defect (Eq.1) occurs due to thermal vibration and it usually happens when an atom or ion enters an interstitial site, creating a vacancy in the lattice [11]. 
$\mathrm{Mg}_{\mathrm{Mg}}^{\mathrm{x}}+\mathrm{O}_{\mathrm{O}}^{\mathrm{x}} \rightarrow \mathrm{O}_{\mathrm{i}}^{\prime \prime}+\mathrm{V}_{\mathrm{O}}^{\bullet}+\mathrm{Mg}_{\mathrm{Mg}}^{\mathrm{x}}$

Eq. 1

A Schottky defect (Eq. 2) occurs when a pair of anion-cations leaves their place and creates vacancies to maintain an overall neutral charge in the system [11].

$\phi \Leftrightarrow \mathrm{V}_{\mathrm{Ti}}^{\prime \prime \prime}+2 \mathrm{~V}_{\mathrm{O}}^{*}$

Eq. 2

$\phi \Leftrightarrow V_{\mathrm{Ba}}^{\prime \prime}+\mathrm{V}_{\mathrm{Ti}}^{\prime \prime \prime \prime}+3 \mathrm{~V}_{\mathrm{O}} \cdot$

Figure 2 shows Frenkel and Shottky defects in crystal structure of Ag and Na, respectively.
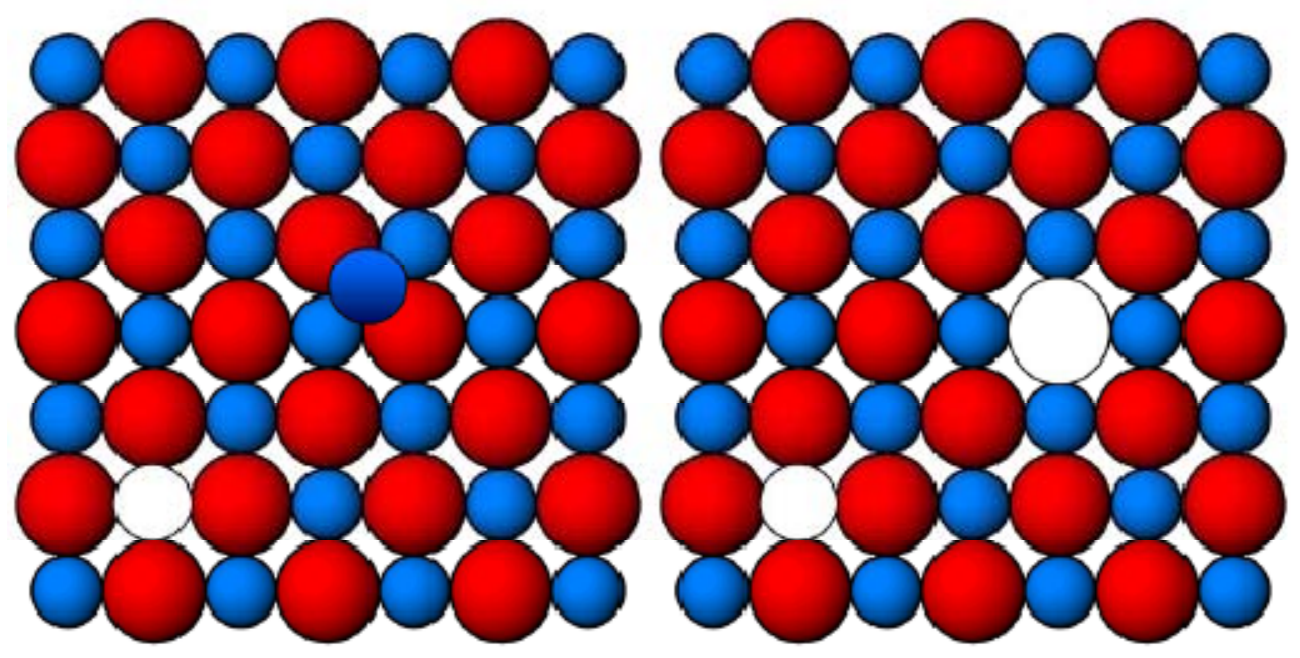

Figure 2: Frenkel defect (left) for $\mathrm{AgCl}$ crystal, $\mathrm{Ag}^{+} \rightarrow \mathrm{V}_{\mathrm{Ag}}+\mathrm{Ag}^{+}$, and Schottky defect (right) for $\mathrm{NaCl}, \mathrm{Na}^{+}+\mathrm{Cl}^{-} \rightarrow \mathrm{V}_{\mathrm{Na}}+\mathrm{V}_{\mathrm{Cl}}$ (right) $[12,13,14,15]$. 
Both Schottky and Frenkel defects create a vacancy in the crystal lattice which gives the option for nearby ions to move to vacant sites, creating more vacant sites behind. The more vacancies created within the unit cells, the more available open sites within the solid crystal structure for transport. This ion transportation (or vacancy migration) will contribute to ionic conductivity. The vacancy migration mechanism can be observed in sodium chloride $(\mathrm{NaCl})$ when ionic conductivity achieved by migration of ions to interstitial sites (Frenkel defect). This ionic transportation will continue through the whole interstitial sites within the unit cells which causes ionic conductivity. Interstitial migration is another mechanism, which contributes to ionic conductivity by movement of ions to interstitial sites resulting in long ion transportation within the crystal structure [16].

\subsection{Conductivity-Crystal Structure Relationships}

Some of the factors that influence the ionic conductivity of a solid electrolyte are related to symmetry of the unit cell, the position of immobile ions and the distribution of the vacant and occupied mobile-ion-sites within the unit cell. The mentioned factors determine structureconductivity [17].

\subsection{Classification of Ionic Conductors}

The number of defects per unit volume (the defect density) is a critical factor for ionic conductivity and it depends on crystal structure, temperature, number of impurity ions, and type of the chemical bonding. 
As Kumar et al. [16] indicated, ionic solids can be divided into three categories based on defect concentration in their crystal structure:

Type I: Poor ionic conductor usually refers to the materials which their crystal structures show low-defect concentration around $\sim 10^{18} \mathrm{~cm}^{-3}$ at room temperature, like sodium chloride or potassium chloride (vacancy migration is the dominant conduction mechanism).

Type II: Good ionic conductor usually refers to the materials which their crystal structures show defect concentration around $\sim 10^{20} \mathrm{~cm}^{-3}$ at room temperature. These types of ionic solids such as stabilized $\mathrm{ZrO}_{2}$ or $\mathrm{CaF}_{2}$ are able to show good conductivity at room temperature and high conductivity as the temperature increases (like type I, vacancy migration is the dominant mechanism for ionic conductivity).

$>$ Type III: This type of ionic solid usually shows a high concentration of defects, due to its liquid like structure of its mobile ions, usually $10^{22} \mathrm{~cm}^{-3}$. Na- $\beta$ - alumina and $\mathrm{RbAg}_{4} \mathrm{I}_{5}$ are considered as the best super ionic conductors, since ions within their crystal lattice are not tightly bonded at their position and they easily can jump to interstitials site and contribute to conductivity. Thus, interstitial or interstitially migration is considered as conduction mechanism for this type of superionic conductor. 


\subsection{Solid Electrolytes Types}

Charge can be carried by both anions and cations, but in the case of superionic conductors, diffusion is much faster by ions with smaller ionic radii (cations); thus, some cations such as $\mathrm{Li}^{+}, \mathrm{Na}^{+}, \mathrm{K}^{+}, \mathrm{Ag}^{+}$and $\mathrm{Cu}^{+}$are considered as charge carriers in superionic conductors. However, there are a few superionic conductors where anions such are $\mathrm{F}^{-}$and $\mathrm{O}^{-2}$ are the charge carriers.

The magnitude of the charge of ions also will affect ion diffusivity through the solid membrane. The ion with a larger charge either feels much higher coulombic attraction from its neighboring ions and needs higher activation energy to overcome the energy barrier to jump over the vacant sites through the crystal lattice. This explanation justifies the reason why most charge carriers in solid conductors are monovalent; therefore, those which are divalent like $\mathrm{O}^{-2}$ conductors, need to operate at very high temperature [16]. 


\subsection{Doping and Mechanism of Improvement of Ionic Conductivity within Zirconia-Based Solid Electrolytes}

Fundamental of oxygen vacancy creation is the neutralization of charges, which are coming from the addition of lower valence cations into the crystal system (acceptor doping). Some ceramic materials like $\mathrm{SrFeO}_{3}, \mathrm{LaMnO}_{3}$, and $\mathrm{ZrO}_{2}$ are able to create oxygen vacancies at high temperature $\left(\mathrm{T}>700{ }^{\circ} \mathrm{C}\right)$ by means of losing some of their oxygen and changing to nonstoichiometric compounds. At a specific concentration of oxygen vacancies, the oxygen vacancies can be found to arrange into anionic channels within the lattice, which can provide low energy paths for ionic diffusivity. A vacancy opens a free spot for oxygen ions to jump across (diffuse). This will create a long range of motion ions through the crystal lattice [17].

For fuel cell applications, solid electrolytes, fabricated from substituting lower valent metal

cations like $\mathrm{Mg}^{2+}, \mathrm{Ca}^{2+}$ and $\mathrm{Y}^{3+}$ for $\mathrm{Zr}^{4+}$ in $\mathrm{ZrO}_{2}$ crystal lattice, results in high oxygen ion conductivity. Yttria stabilized zirconia $\left(\mathrm{Zr}_{1-\mathrm{x}} \mathrm{Y}_{\mathrm{x}} \mathrm{O}_{2-\mathrm{x} / 2}\right)$ is typically used for an electrolyte membrane within a solid oxide fuel cell, since it shows high oxide ion conductivity at elevated temperature while being thermodynamically and structurally stable over broad temperature and pressure ranges. 
Eq.3 displays the Kröger-Vink notation for substituted zirconia, where $M_{Z r}^{\prime \prime}$ represents $\mathrm{M}^{+2}$ ion substitution in a $\mathrm{Zr}^{+4}$ sites and $O_{O}^{X}$ indicates an oxygen ion sitting on regular sites. Based on the simple calculation, it can be assumed that maximum ionic conductivity can be obtained when half of the oxygen sites are vacant. This is not true since there is always some interaction between doped cations and the created oxygen vacancies (to maintain overall charge neutrality) in the system. Therefore, the maximum conductivity can be achieved when a lower concentration of cations are doped into the crystal lattice. Figure 3 displays stabilization processes for synthesis of YSZ [18].

$\mathrm{ZrO}_{2} \stackrel{x M O}{\longrightarrow} x M_{\mathrm{Zr}}^{\prime \prime}+\mathrm{O}_{O}^{X}+x V_{O}^{\ddot{\prime}}$ Eq. 3

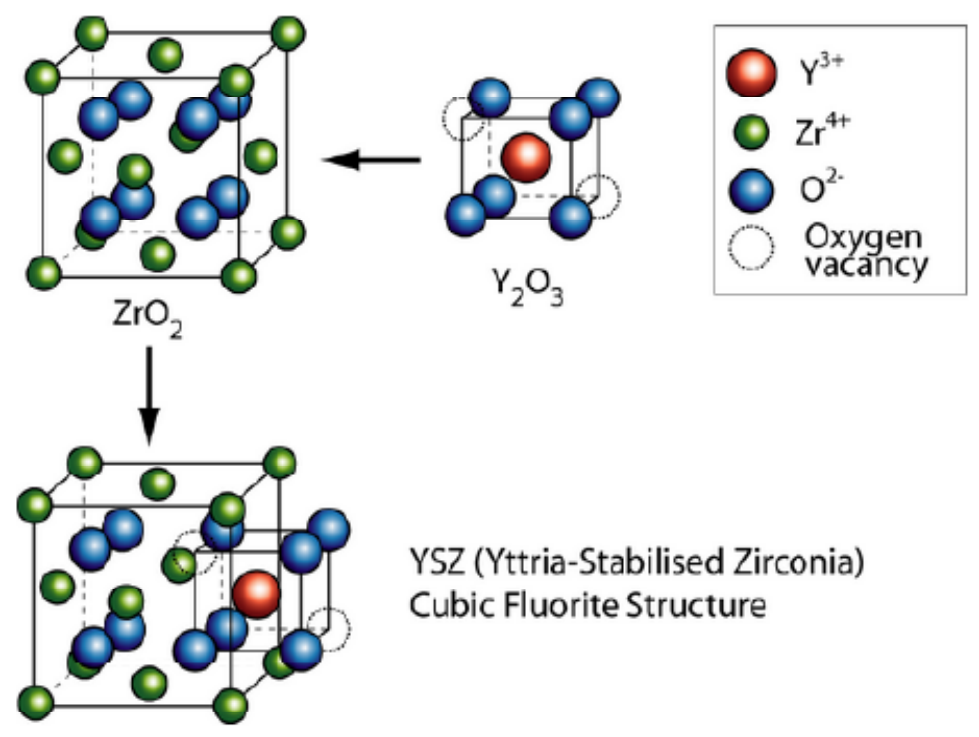

Figure 3: $\mathrm{YSZ}$ stabilization process by $\mathrm{Y}_{2} \mathrm{O}_{3}$ [19]. 


\subsection{Dependence of Crystal Structure of Materials on Oxygen Ionic}

\section{Conductivity}

Movement of oxygen ions through the crystal structure produces current flow. Low migration energy for ion movement from one site to other unoccupied site (less than $1 \mathrm{eV}$ ), and equivalency of number of occupied and unoccupied sites are two major points that should be provided for oxygen ion conductivity. However, this is not an issue for the materials with open crystal structures. The following subsections $(2.7 .1-2.7 .8)$ list the materials, which due to their crystal structure; have the most use for SOFCs applications.

In the end, the advantages and disadvantages will be discussed, and the BIVOX composition will be primarily focused upon. The reason for focusing on this compositional family is due to its high conductivity at moderate temperatures, which is related to its crystal structure. The oxide $\mathrm{Bi}_{4} \mathrm{~V}_{2} \mathrm{O}_{11}$ shows the Aurivillius structure ( $\left.\mathrm{n}=1\right)$ - alternating $\mathrm{Bi}_{2} \mathrm{O}_{2}{ }^{2+}$ and defective perovskite-like $\mathrm{VO}_{3.5}$ layers. The perovskite layer $\mathrm{VO}_{3.5}$ is oxygen deficient. Through the phase transition $(\alpha-$ $\mathrm{Bi}_{4} \mathrm{~V}_{2} \mathrm{O}_{11}$ to $\gamma-\mathrm{Bi}_{4} \mathrm{~V}_{2} \mathrm{O}_{11}$ ), oxygen vacancies are disordered and contribute to ionic conductivity [20]. 


\subsubsection{Oxygen Ionic Conductivity in Fluorite and Fluorite based Solid Electrolytes}

Fluorite is one of the crystal structures that show good ionic conductivity. The crystal lattice has $\mathrm{AO}_{2}$ formula and oxygen ions sits at simple cubic positions followed by alternative body centers positions occupied by cations which show coordination number of 8 (Fig. 4 and Fig.5) [21].

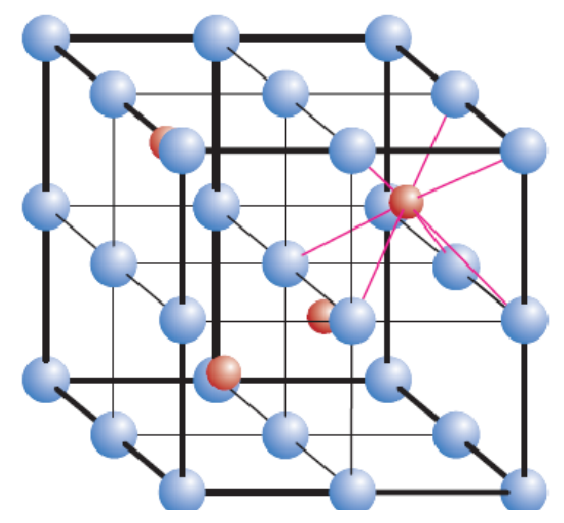

Figure 4: The fluorite $\left(\mathrm{AO}_{2}\right)$ oxide structure. The red spheres represent the A cation sites and the blue spheres the oxygen sites [21].

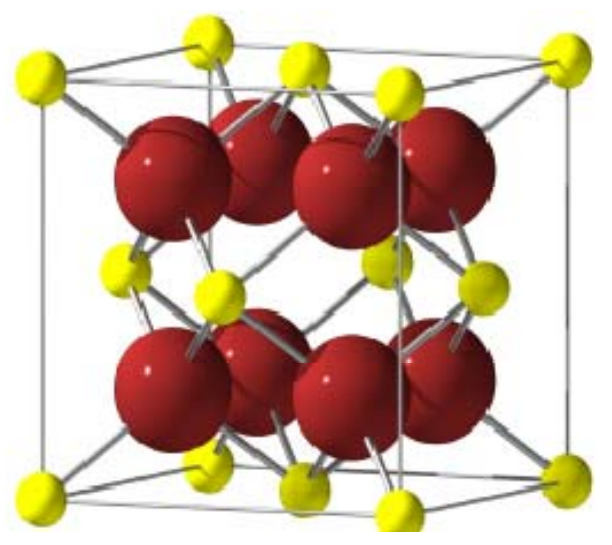

Figure 5: Unit cell of fluorite. The yellow atoms represent $4^{+}$cations and the red atoms represent $2^{-}$ anions [22]. 
The ability of accepting a high amount of lower valent metal ions (dopants) for the materials with fluorite structure results in very highly disordered materials. Rare earth or alkaline earth elements are usually used for substitution in fluorite crystal lattice.

For example, by substituting $10 \mathrm{~mol} \%$ of yttrium oxide into the fluorite structure of zirconium oxide $\left(\mathrm{ZrO}_{2}\right.$, zirconia), high ionic conductivity $(0.03 \mathrm{~S} / \mathrm{cm})$ at elevated temperature $\left(>800^{\circ} \mathrm{C}\right)$ for new composition of ytrria-stablized zirconia (YSZ, $\left.\mathrm{Zr}_{1-\mathrm{x}} \mathrm{Y}_{\mathrm{x}} \mathrm{O}_{2-\delta}\right)$ will be achieved. Besides the increasing ionic conductivity of doped zirconia (YSZ) at high temperature, doping can also benefit the stabilization of the cubic crystal structure from room temperature to high operating temperature. For example, zirconium oxide $\left(\mathrm{ZrO}_{2}\right)$ shows a monoclinic, tetragonal and cubic structure at room temperature, $1170^{\circ} \mathrm{C}$ and $2370^{\circ} \mathrm{C}$, respectively. The cubic fluorite structure can be stabilized up to $2680{ }^{\circ} \mathrm{C}$ (melting point) through a doping strategy.

Yttria $\left(\mathrm{Y}_{2} \mathrm{O}_{3}\right)$ is a common dopant, but other aliovalent oxides that show high solubility in zirconia, such as $\mathrm{SC}_{2} \mathrm{O}_{3}, \mathrm{CaO}, \mathrm{MgO}$ and various rare-earth oxides, can also be effectively utilized for the same strategy. Scandia-doped zirconia oxide $\mathrm{Zr}_{1-\mathrm{x}} \mathrm{Sc}_{\mathrm{x}} \mathrm{O}_{2-\delta}$ (SSZ), gadolinia-doped ceria $\mathrm{Ce}_{1-\mathrm{x}} \mathrm{Gd}_{\mathrm{x}} \mathrm{O}_{2-\delta}(\mathrm{GDC})$, samarium-doped ceria (SDC), and rare earth doped ceria are some of the materials with fluorite structure, which show high ionic conductivity at moderate to high temperatures, due to the close atomic radii of the host and dopant ions (Figure 6): 
a)
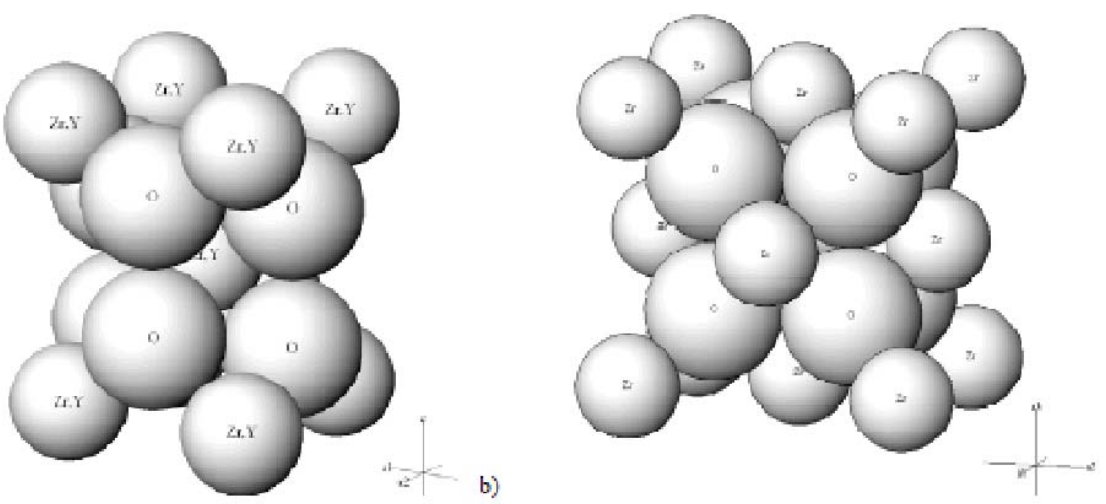

c)
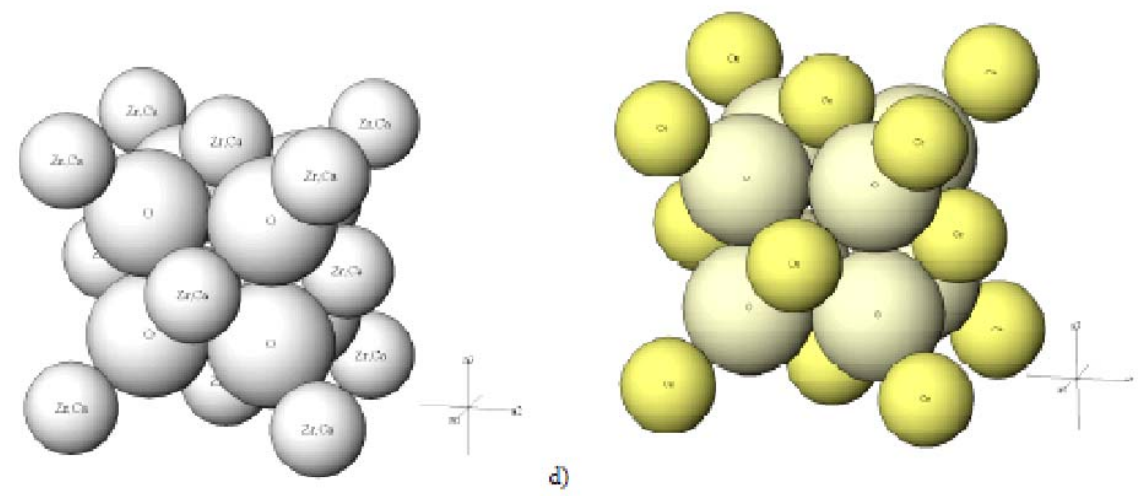

d)

Figure 6: Fluorite type structure of a) YSZ (yttria-stabilized zirconia), b) zirconium oxide (zirconia) c) calcia stabilized zirconia, d) cerium oxide (ceria) [23].

Although YSZ is not expensive and shows thermomechanical stability over a wide range of oxygen partial pressure, its conductivity has been limited to below $0.1 \mathrm{~S} / \mathrm{cm}$ at $1000^{\circ} \mathrm{C}$. Also at high temperatures, it reacts with lanthanum and strontium which exists in the perovskite electrodes used for SOFC applications and forms a resistive Zirconite layers [24]. 
Although doping with expensive $\mathrm{Sc}$ is one of the few methods to increase conductivity; this material is structurally unstable over long periods and will go through a phase transition. For example, ScSZ (10-15 mol \%), which has a rhombohedral structure, will go through phase transition above $600^{\circ} \mathrm{C}$ and transforms to a cubic structure. However, adding a small amount of other dopants, such as $\mathrm{Y}_{2} \mathrm{O}_{3}$, will stabilize the cubic structure at room temperature [24].

Ceria doped with rare earth metals is an excellent candidate for SOFCs electrolyte applications due to its higher conductivity at intermediate to high temperature, but it is more expensive and has low redox stability, which results in the reduction of $\mathrm{Ce}^{+4}$ to $\mathrm{Ce}^{+3}$, and it converts to $\mathrm{n}$-type electronic conductor in reducing conditions $\left(\mathrm{pO}_{2} \cong 1 \times 10^{-19} \mathrm{~atm}\right)$. The increased e conductivity reduces the fuel cell efficiency [24].

\subsubsection{Oxygen Ionic Conductivity in Pyrochlore based Solid Electrolytes}

Materials with the general formula $\mathrm{A}_{2} \mathrm{~B}_{2} \mathrm{O}_{6}$ and $\mathrm{A}_{2} \mathrm{~B}_{2} \mathrm{O}_{7}$ such as $(\mathrm{Gd}, \mathrm{Ca})_{2} \mathrm{Ti}_{2} \mathrm{O}_{7-\delta}$ fall into the pyrochlore structure category. Cations sites (A and B) usually are occupied by either rare-earth or transition metal and will be placed in the face-centered cubic position while anions take the interstitial sites. It can be assumed that pyrochlore structure is similar to a fluorite one which lost one eighth of the oxygen sites (vacant sites) [25].

Among the materials with pyrochlore structure, $\mathrm{Gd}_{2-\mathrm{x}} \mathrm{Ca}_{\mathrm{x}} \mathrm{Ti}_{2} \mathrm{O}$ 7-8 with $x \approx 0.20$, has shown the highest oxygen ionic conduction; however, it is still below that of the YSZ electrolyte. It can be used as either SOFCs thick-film electrolyte or protective layers onto $\mathrm{LaGaO}_{3}$-based or $\mathrm{CeO}_{2}$ based electrolytes. 


\subsubsection{Oxygen Ionic Conductivity in Perovskite and Perovskite based Solid Electrolytes}

Compounds with perovskite structure are represented with $\mathrm{ABO}_{3}$ formula, which is based on atomic arrangement in calcium titanate $\mathrm{CaTiO}_{3}$. Titanium, oxygen and calcium atoms occupy corners, center of 12 edges and center of simple cubic, respectively (Figure 7).

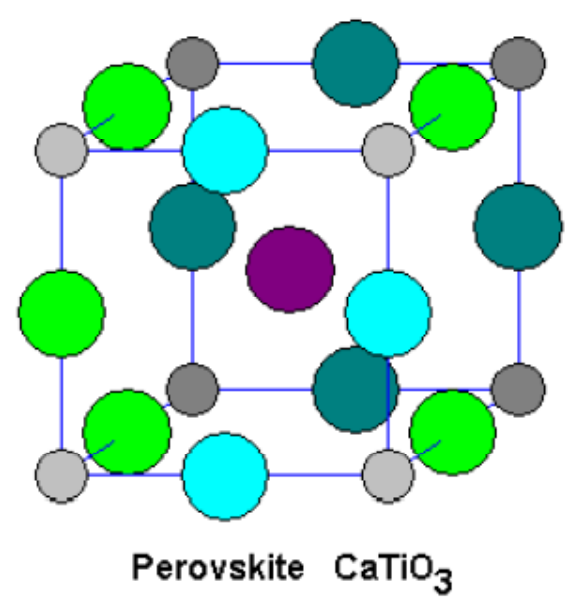

Figure 7: Perovskite cubic unit cell with titanium atoms at the corners (gray), oxygen atoms at the midpoints of the edges (green and blue), and a calcium atom (purple) in the center. Dark shades are used to indicate layers further back [26]. 


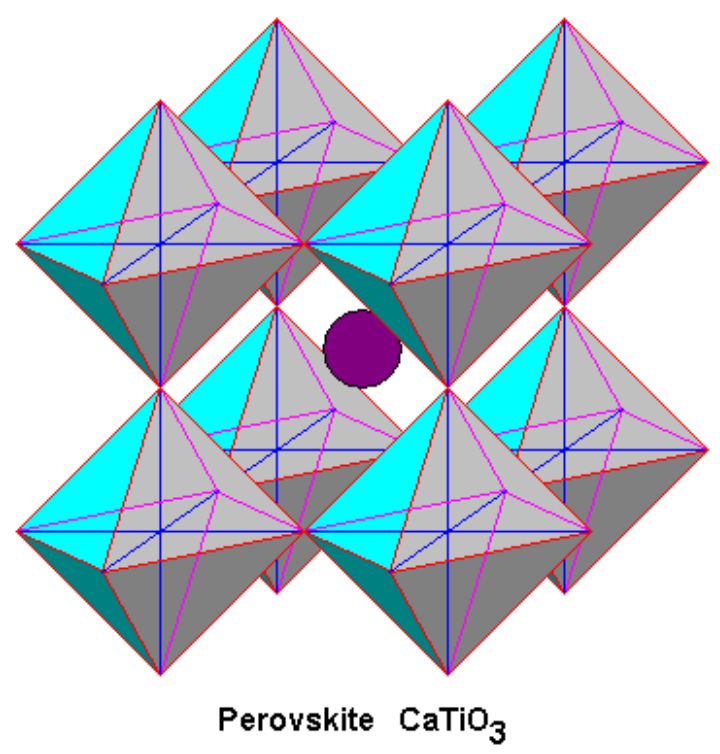

Figure 8: Each titanium atom is octahedrally coordinated with six oxygen atoms, with a calcium atom in the center [26].

Sites A and B in perovskite structure can be occupied by different kinds of cations, thus the crystal lattice is able to show very high oxygen ion conductivity at elevated temperature. The perovskite structure is able to accept a broad spectrum of aliovalent cations within a range identified by a tolerance factor $0.95<\mathrm{t}<1.04$. The tolerance factor, which is shown in equation 4 , estimates the stability of cubic perovskite structure.

$$
t=\frac{r_{A}+r_{0}}{\sqrt{2}\left(r_{B}+r_{O}\right)}
$$

Eq. 4

where $r_{A}$ and $r_{B}$ are ionic radii of A-site and B-site cations and $r_{O}$ is ionic radii of oxygen [27]. 
Since many different types of ions can be added into the structure, it allows forming a broad array of non-stoichiometric compositions with designed defect chemistries. In other words, oxygen vacancy concentration and electronic contributions (electrons and holes) can be

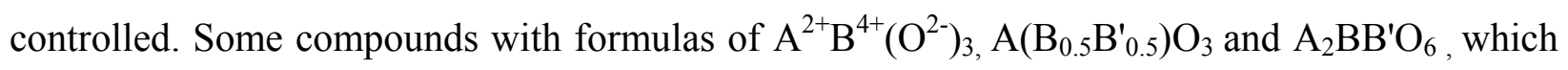
are originated from perovskite structure, exhibit some anisotropy properties such as high ionic conductivity along their crystal structure [26]. Lanthanum gallate $\left(\mathrm{LaGaO}_{3}\right)$ is an example of a perovskite electrolyte (Figure 9), which shows higher ionic conductivity compared to the one resulted from YSZ electrolyte in the intermediate temperature rang $497-827^{\circ} \mathrm{C}$. Obtained compositions from lanthanum gallate show relatively low thermal expansion, similar to YSZ [2]. Substitution of trivalent lanthanum and gallium with divalent cations, such as $\mathrm{Mg}^{+2}$, in lanthanum gallate $\left(\mathrm{LaGaO}_{3}\right)$, will increase the oxygen vacancy concentrations, and will contribute to ionic conductivity. In the case of $\mathrm{La}_{1-\mathrm{x}} \mathrm{Sr}_{\mathrm{x}} \mathrm{Ga}_{1-\mathrm{y}} \mathrm{Mg}_{\mathrm{y}} \mathrm{O}_{3-(\mathrm{x} / 2)-(\mathrm{y} / 2)}$ ( $\mathrm{LSGM}$ ), Sr provides the minimum lattice distortion for the crystal structure, and will result in maximum oxygen ion mobility, increasing the ionic conductivity [2]. 
a)

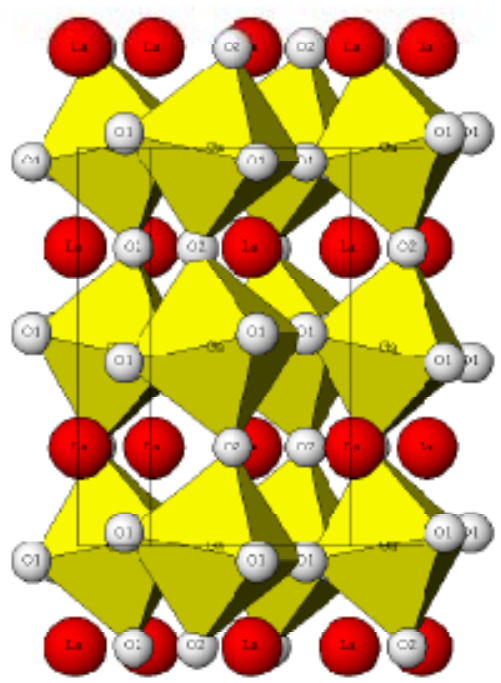

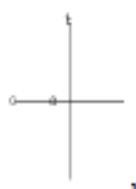

b)

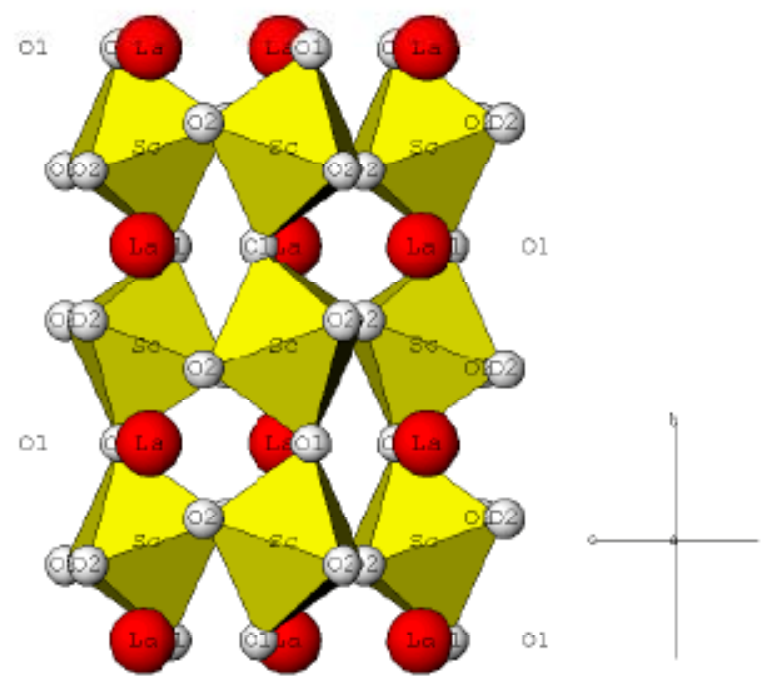

Figure 9: Perovskite type structure of a) $\mathrm{LaGaO}_{3}$.b) lanthanum scandate [23].

\subsubsection{Oxygen Ionic Conductivity in Oxide Brownmillerite $\left(\mathrm{A}_{2} \mathrm{~B}_{2} \mathrm{O}_{5}\right)$ based Solid Electrolytes}

Alternating perovskite layers of $\mathrm{BO}_{6}$ octahedral, which are corner shared, and layers of $\mathrm{BO}_{4}$ tedrahedra forms the Brownmillerite $\left(\mathrm{A}_{2} \mathrm{~B}_{2} \mathrm{O}_{5}\right)$ structure. Oxygen vacancies are lined up along the (010) planes. This might be considered as a diffusion pathway in the tetrahedral for oxygen ions migration through the crystal structure of Brownmillerite. 
One example of an ionic Brownmillerite is the $\mathrm{Ba}_{2} \mathrm{In}_{2} \mathrm{O}_{5}$ composition. At moderate temperatures, doped $\mathrm{Ba}_{2} \mathrm{In}_{2} \mathrm{O}_{5}$ shows higher conductivity compared to YSZ. However, $\mathrm{Ba}_{2} \mathrm{In}_{2} \mathrm{O}_{5^{-}}$ based ceramics show high reactivity with $\mathrm{CO}_{2}$, instability in humid atmosphere, and they reduce easily, which limits their practical applications [2]. At moderate temperature, doped $\mathrm{Ba}_{2} \operatorname{In}_{2} \mathrm{O}_{5}$ shows higher conductivity compared to YSZ. However, $\mathrm{Ba}_{2} \mathrm{In}_{2} \mathrm{O}_{5}$-based ceramics show high reactivity with $\mathrm{CO}_{2}$, instability in humid atmosphere, they reduce easily, and they show less ionic conductivity compared to LSGM , which limits their practical applications [2].

A second example is perovskite $\mathrm{SrFeO}_{3}$ composition. Figure 10 shows perovskite structure of $\mathrm{SrFeO}_{3}$. Fe ions at the center of octahedrons are surrounded by six oxygen ions and $\mathrm{Sr}$ atoms occupy a cube array around the oxygen. $\mathrm{SrFeO}_{3}$ with perovskite structure will change to Brownmillerite $\mathrm{SrFeO}_{2.5}$ if the unit cell loses two oxygens from alternative octahedrons (Fig. 11) [17].

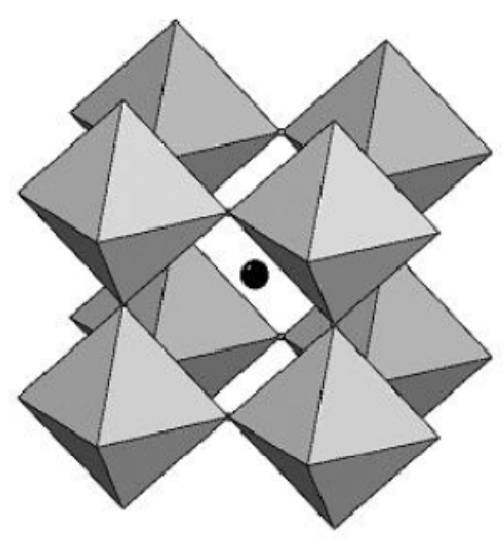

Figure 10: Perovskite has oxygen on the corners of each octahedral, an iron is in the center of each octahedral, and the dark circle is strontium. The strontiums together form cubes around the octahedral [17]. 


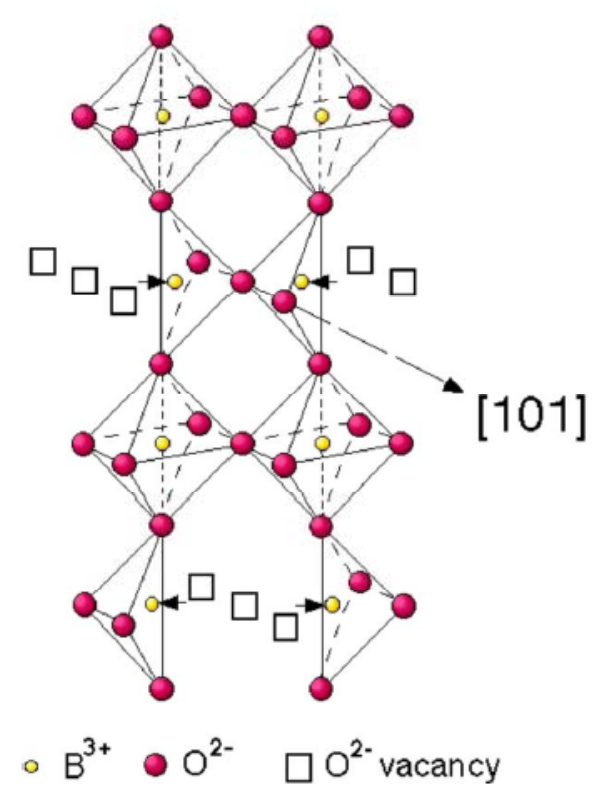

Figure 11: Brownmillerite is $\mathrm{SrFeO}_{2.5}$. The yellow circles represent iron $\left(\mathrm{B}^{3+}\right)$, the red circles represent oxygen, and the boxes represent vacancies. Strontium is not shown [17].

\subsubsection{Oxide Ion Conductivity in $\mathrm{Bi}_{2} \mathrm{O}_{3}$ based Solid Electrolytes}

Among all oxide conductors, $\mathrm{Bi}_{2} \mathrm{O}_{3}$, which has Fluorite structure, is stabilized by the substitution of aliovalent metal ion to $\delta-\mathrm{Bi}_{2} \mathrm{O}_{3}$ phase and exhibits the highest oxide ion conductivity among the fluorite structures (one or two orders of magnitude higher than that of stabilized zirconia). $\delta$ - $\mathrm{Bi}_{2} \mathrm{O}_{3}$ will show a defect fluorite structure with two vacant oxide ions per unit cell at the temperature range of $730-824^{\circ} \mathrm{C}$. Yittrium or rare earth oxide can be used to stabilize the $\delta$-phase down to room temperature. The monoclinic $\propto$ - phase, the tetragonal $\beta$ phase and the $\mathrm{BCC} \gamma$-phase exist at $650-729^{\circ} \mathrm{C}, 650^{\circ} \mathrm{C}$ and $639^{\circ} \mathrm{C}$ respectively. The $\beta$ - phase and the $\gamma$-phase (two intermediate metastable phases) transform to the monoclinic $\delta$-phase at the temperature range of $773-923{ }^{\circ} \mathrm{C}$ (Figure 12) [18]. 


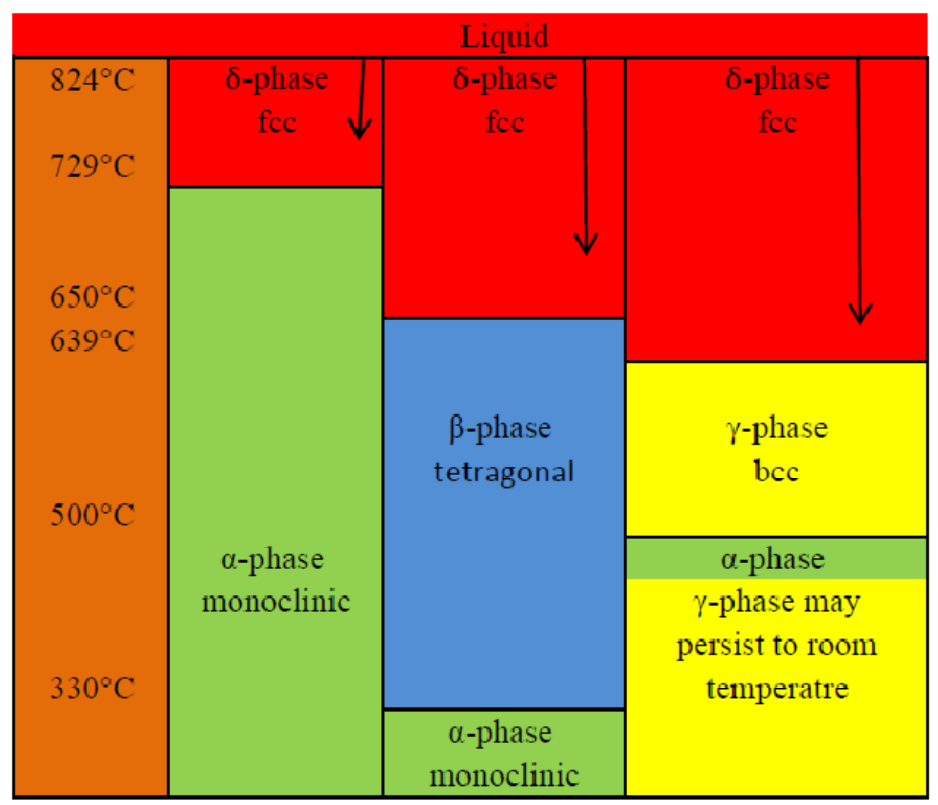

Figure 12: Transformation temperatures for the different phases of $\mathrm{Bi}_{2} \mathrm{O}_{3}[18]$.

Following are listed the reasons which cause high ionic conductivity in $\delta$ - $\mathrm{Bi}_{2} \mathrm{O}_{3}$ :

1- Existence of a vacant oxygen site out of four oxygen sites in fluorite-type structure of $\delta$ $\mathrm{Bi}_{2} \mathrm{O}_{3}$.

2- Cation network shows high polarizability due to the electronic structure of $\mathrm{Bi}^{3+}$ originated from $6 s^{2}$ one pair electrons. This will benefit oxygen ions mobility within the crystal structure.

3- $\mathrm{Bi}^{3+}$ ability to accommodate highly disordered oxygen around itself [18].

Phase domains and related conductivity are shown in table 1 for bismuth oxide. 
Table 1: $\mathrm{Bi}_{2} \mathrm{O}_{3}$ phases and related conductivity at different temperature [28].

\begin{tabular}{c|c|c|c}
\hline Phase & $\begin{array}{c}\text { Existence domain } \mathbf{(}^{\mathbf{0}} \\
\mathbf{C})\end{array}$ & $\begin{array}{c}\text { Conductivity at } \\
\mathbf{6 0 0} \mathbf{C}\left(\mathbf{S c m}^{-\mathbf{1}}\right)\end{array}$ & $\begin{array}{c}\text { Conductivity at } \\
\mathbf{6 5 0} \mathbf{C}\left(\mathbf{S c m}^{\mathbf{- 1}}\right)\end{array}$ \\
\hline$\alpha-\mathrm{Bi}_{2} \mathrm{O}_{3}$ & $0-730$ & $10^{-4}$ & $3 \times 10^{-4}$ \\
\hline$\beta-\mathrm{Bi}_{2} \mathrm{O}_{3}$ & 648 down to 500 & $10^{-3}$ & $2 \times 10^{-3}$ \\
& 500 down to 663 & & $5 \times 10^{-3}$ \\
\hline$\gamma-\mathrm{Bi}_{2} \mathrm{O}_{3}$ & 650 down to 600 & $3 \times 10^{-3}$ & 1 \\
\hline$\delta-\mathrm{Bi}_{2} \mathrm{O}_{3}$ & $>730$ & $\mathrm{~N} / \mathrm{a}$ & \\
\hline
\end{tabular}

Although the $\delta$-phase of $\mathrm{Bi}_{2} \mathrm{O}_{3}$ shows high oxygen conductivity compared to other oxide ion conductors, its application has been limited due to the stability issue, which has a narrow temperature range of $729-824{ }^{\circ} \mathrm{C}$. Figure 13 shows ionic conductivity for each phase of $\mathrm{Bi}_{2} \mathrm{O}_{3}$ [18]. 


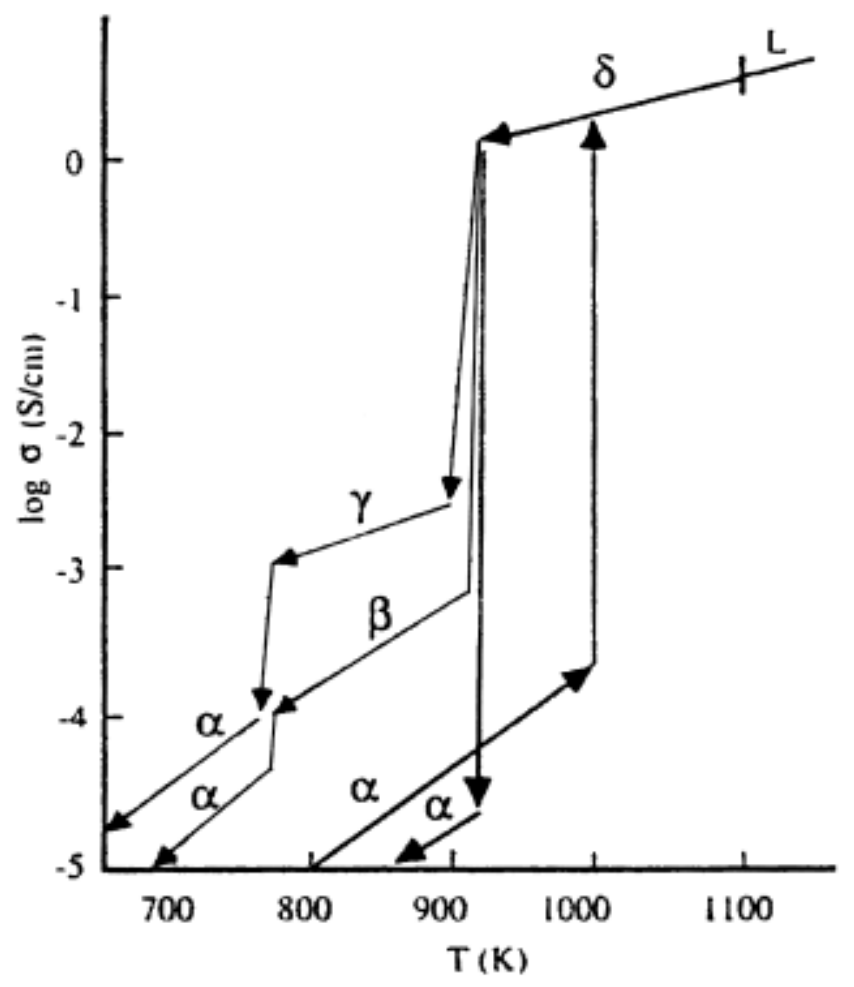

Figure 13: Conductivity of different phases of $\mathrm{Bi}_{2} \mathrm{O}_{3}$ versus temperature [18].

\subsubsection{Oxide Ion Conductivity in Bi-Layered Solid Electrolytes}

$A_{(n-1)} B_{(n)} O_{(3 n+1)}$ denotes the general formula for the Bi-layered structure, which resemble that of the perovskite phase. Usually a motif acts as a separator between perovskite-like layers. The number of $\mathrm{BO}_{6}$ octahedron is indicated by $\mathrm{n}$. For example, by setting $\mathrm{n}=1$ and $\mathrm{n}=2$ the slab thickness will be one and two $\mathrm{BO}_{6}$ octahedron, respectively. 
The Aurivillius phase has a layered perovskite-like structure (Figure 14). For example, the general formula for $\mathrm{Bi}_{3} \mathrm{TiNbO}_{9}$, which has Aurivillius structure $(\mathrm{n}=2)$, is considered to be $\left\{\mathrm{Bi}_{2} \mathrm{O}_{2}\right\}-\left\{\mathrm{A}_{(\mathrm{n}-1)} \mathrm{B}_{2} \mathrm{O}_{7}\right.$. Ti and $\mathrm{Nb}$ can occupy the $\mathrm{B}$ sites in the structure. The the formula can be written as: $\left\{\mathrm{Bi}_{2} \mathrm{O}_{2}\right\}-\mathrm{Bi}(\mathrm{Ti}, \mathrm{Nb})_{2} \mathrm{O}_{7}\left\{\mathrm{Bi}_{2} \mathrm{O}_{2}\right\}-\mathrm{Bi}(\mathrm{Ti}, \mathrm{Nb})_{2} \mathrm{O}_{7}$. The $\mathrm{Bi}_{2} \mathrm{O}_{2}$ layer is considered as an interlayer separator for all of the Aurivillius phases [29].

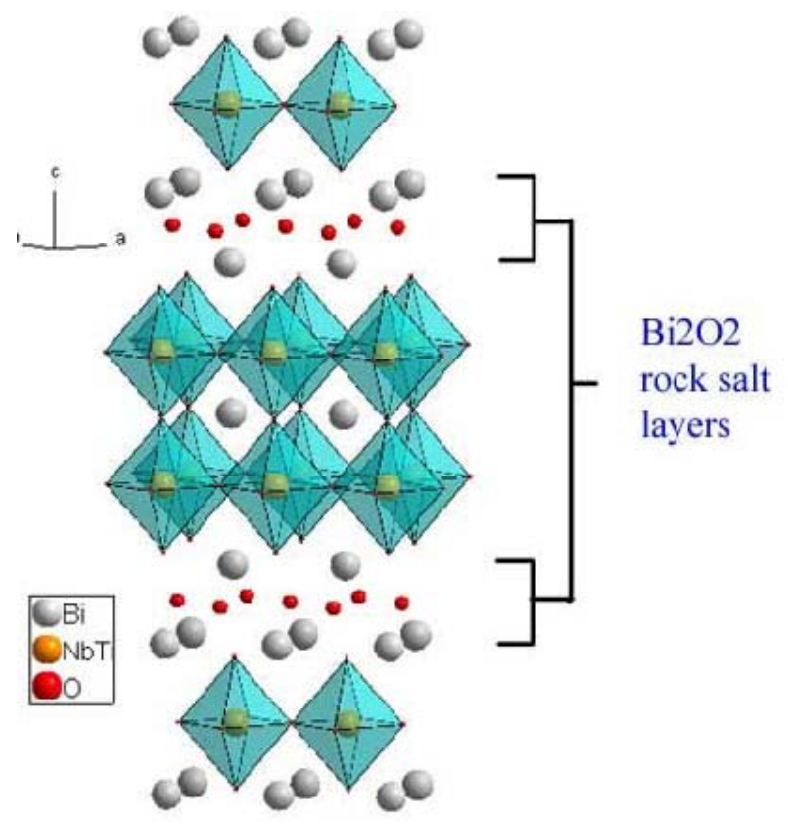

Figure 14: Aurivillius phases of $\mathrm{Bi}_{3} \mathrm{TiNbO}_{9}$ [29].

Some materials with the Aurivillius structure are able to show high anion conductivity. Layered bismuth mixed oxides $\mathrm{Bi}_{2} \mathrm{~A}_{n-1} \mathrm{~B}_{n} \mathrm{O}_{3 \mathrm{n}+3}$ have constituted $n$ perovskite-like layers $\left(\mathrm{A}_{n-}\right.$ $\left.{ }_{1} \mathrm{~B}_{\mathrm{n}} \mathrm{O}_{3 \mathrm{~m}-1}\right)^{-2}$ alternating with fluorite-like bismuth oxide layers $\left(\mathrm{Bi}_{2} \mathrm{O}_{2}\right)^{+2}[30]$. 
In order to represent an Aurivillius structure, $\mathrm{A}_{\mathrm{m}-1} \mathrm{Bi}_{2} \mathrm{~B}_{\mathrm{m}} \mathrm{O}_{3 \mathrm{~m}+3}$ can be used as a general formula. Elements with larger ionic radius and bigger charge, such as $\mathrm{Ba}, \mathrm{Sr}, \mathrm{Bi}, \mathrm{Pb}$, can occupy the A site. Other ions such as $\mathrm{Ti}, \mathrm{Nb}, \mathrm{Ta}, \mathrm{Mo}, \mathrm{W}, \mathrm{Fe}, \mathrm{Mn}$, which have smaller ionic radius and lower charge, will occupy the B site. $\mathrm{N}$ represents the number of perovskite layers along the $\mathrm{C}$ axis [20].

More discussion related to the mechanism of ionic conductivity in Aurivillius structure has been provided in the following sections.

\subsubsection{Oxygen Ionic Conductivity in BIMEVOX based Solid Electrolytes}

$\mathrm{Bi}_{2} \mathrm{VO}_{5.5}$ is a solid solution of $\mathrm{Bi}_{2} \mathrm{O}_{3}$ and $\mathrm{V}_{2} \mathrm{O}_{5}$ and it belongs to the BIMEVOX family (BIbismuth, ME-dopant metal, V-vanadium, OX-oxygen). This phase can be obtained at the range $\sim 66.7$ to $70.4 \% \mathrm{Bi}_{2} \mathrm{O}_{3} .\left(\mathrm{Bi}_{2} \mathrm{VO}_{5.5}\right.$ is obtained by choosing $0.86<\mathrm{x}>1$ at the solid solution of $\mathrm{Bi}_{2} \mathrm{O}_{3} . \mathrm{XVO}_{2.5 .}$.). $\mathrm{Bi}_{2} \mathrm{VO}_{5.5}$ shows high oxide ionic conductivity. The Aurivillius structure $(\mathrm{n}=1)$ of this composition includes alternating $\left[\mathrm{Bi}_{2} \mathrm{O}_{2}\right]^{+2}$ layers and defective perovskite-like slabs $\left.\left[\mathrm{VO}_{3.5}\left(\mathrm{~V}_{0}\right)_{0.5}\right)\right]^{-2}$, which contain the oxygen vacancies $V_{o}^{*}[31]$.

$\mathrm{Bi}_{2} \mathrm{VO}_{5.5}$ shows three different phases at different temperatures. which are $\alpha, \beta$ and $\gamma$ exist at room temperature, $447-567^{\circ} \mathrm{C}$, and $612^{\circ} \mathrm{C}$ respectively. Figure 15 represents the crystal systems and lattice parameters of $\alpha, \beta$ and $\gamma-\mathrm{Bi}_{2} \mathrm{VO}_{5.5}$. 

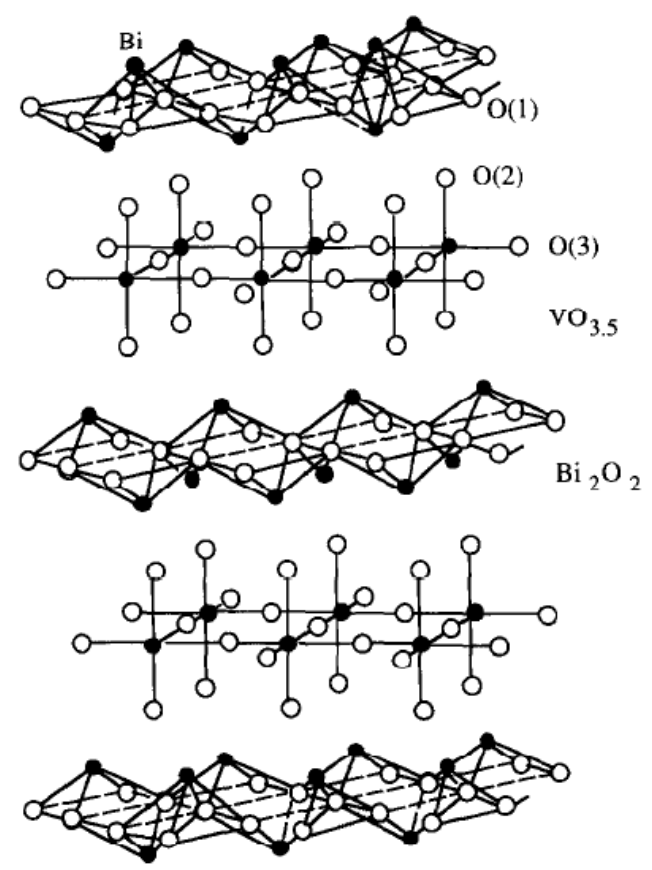

Figure 15: The ideal structure of $\gamma$-type $\mathrm{Bi}_{2} \mathrm{VO}_{5.5}[20]$.

At the temperature range of $567^{\circ} \mathrm{C}$ to $777^{\circ} \mathrm{C} \gamma$-phase of $\mathrm{Bi}_{2} \mathrm{VO}_{5.5}$ shows high oxygen ion conductivity. Considering the substitution formula $\left(\mathrm{Bi}_{2} \mathrm{~V}_{1-\mathrm{x}} \mathrm{M}_{\mathrm{x}} \mathrm{O}_{5.5-1.5 \mathrm{x}}\right)$ for vanadium, the best result for ionic conductivity will be obtained if some cation dopants like $\mathrm{Cu}, \mathrm{Ni}, \mathrm{Zn}, \mathrm{Pb}, \mathrm{Mo}, \mathrm{W}$, $\mathrm{Co}, \mathrm{Ti}, \mathrm{Zr}$, Sn will partially be substituted by an x value close to 0.10 . Figure 16 shows ionic conductivity achieved by substitution of different cations in the BIMEVOX crystal structure, which is about $0.1 \mathrm{Scm}^{-1}$ at relatively low temperature $\left(600^{\circ} \mathrm{C}\right)$ [32]. 


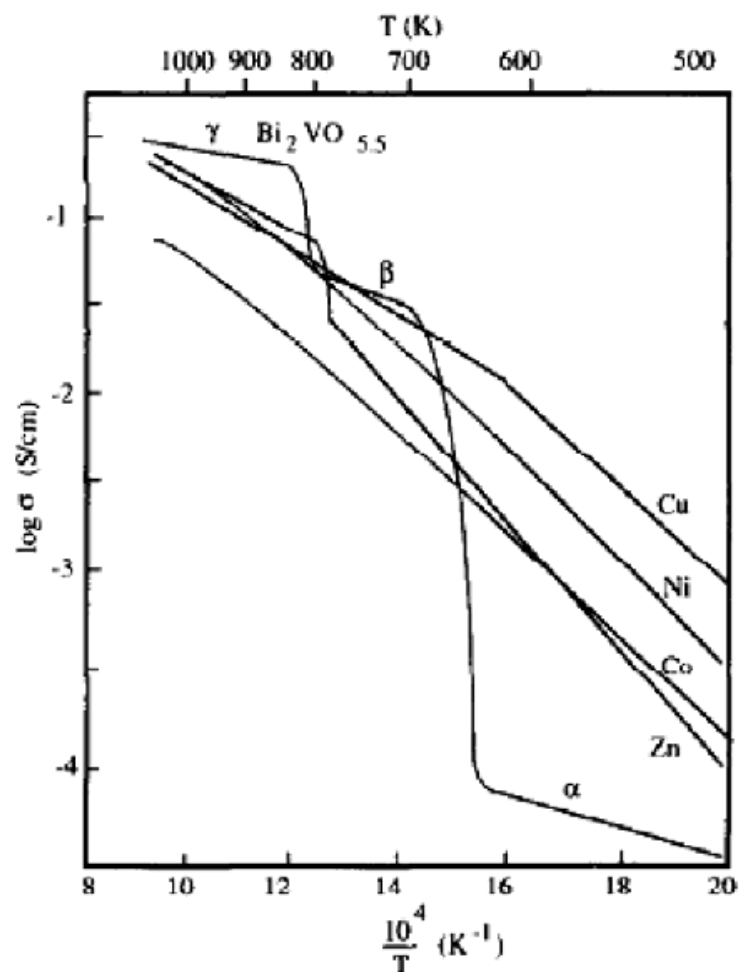

Figure 16: Oxide ion conductivity of selected $\mathrm{Bi}_{2} \mathrm{~V}_{1-\mathrm{x}} \mathrm{M}_{\mathrm{x}} \mathrm{O}_{5.5-1.5 \mathrm{x}}$ with $\mathrm{M}=\mathrm{Cu}, \mathrm{Co}, \mathrm{Ni}, \mathrm{Zn}$ [20].

As mentioned, the $\left(\mathrm{A}_{\mathrm{m}-1} \mathrm{~B}_{\mathrm{m}} \mathrm{O}_{3 \mathrm{~m}-1}\right)^{-2}$ perovskite layers alternate with the $\left(\mathrm{Bi}_{2} \mathrm{O}_{2}\right)^{+2}$ bismuth oxygen layers. The $\gamma-\mathrm{Bi}_{2} \mathrm{VO}_{5.5}$ phase will be stabilized at room temperature by substitution of some metallic ions for vanadium. By substitution of copper cations in the range of $0.07<\mathrm{x}<0.20$ (using the general formula for substitution of metallic ions $\mathrm{Bi}_{2} \mathrm{~V}_{1-\mathrm{x}} \mathrm{Me}_{\mathrm{x}} \mathrm{O}_{5.5-3 \mathrm{x} / 2}$ ), the result is the stabilization of $\gamma$ - phase of $\left(\mathrm{VO}_{3.5}\right)^{-2}$ at room temperature and improvement of oxygen ion conductivity at lower temperatures. For example, BICUVOX $\left(\mathrm{Bi}_{2} \mathrm{~V}_{0.9} \mathrm{Cu}_{0.1} \mathrm{O}_{5.35}\right)$, which exhibits the highest oxygen conductivity at $300^{\circ} \mathrm{C}(0.001 \mathrm{~s} / \mathrm{cm})$, can be synthesized by the substitution of copper cations at the range of $(0.07<\mathrm{x}<0.12)$ [20]. 
Figure 17 displays the ionic conductivity versus temperature for materials with different crystal structures. The graph includes the following: Aurivillius (BICUVOX), perovskite (LSGM), and fluorite (CGO, YSZ) materials. BICUVOX ceramics, which are able to produce the same ionic conductivity as YSZ at the lower temperature-(about $400^{\circ} \mathrm{C}$ ), are considered a good candidate for reducing the operating temperature of SOFCs below $800^{\circ} \mathrm{C}$ [21].

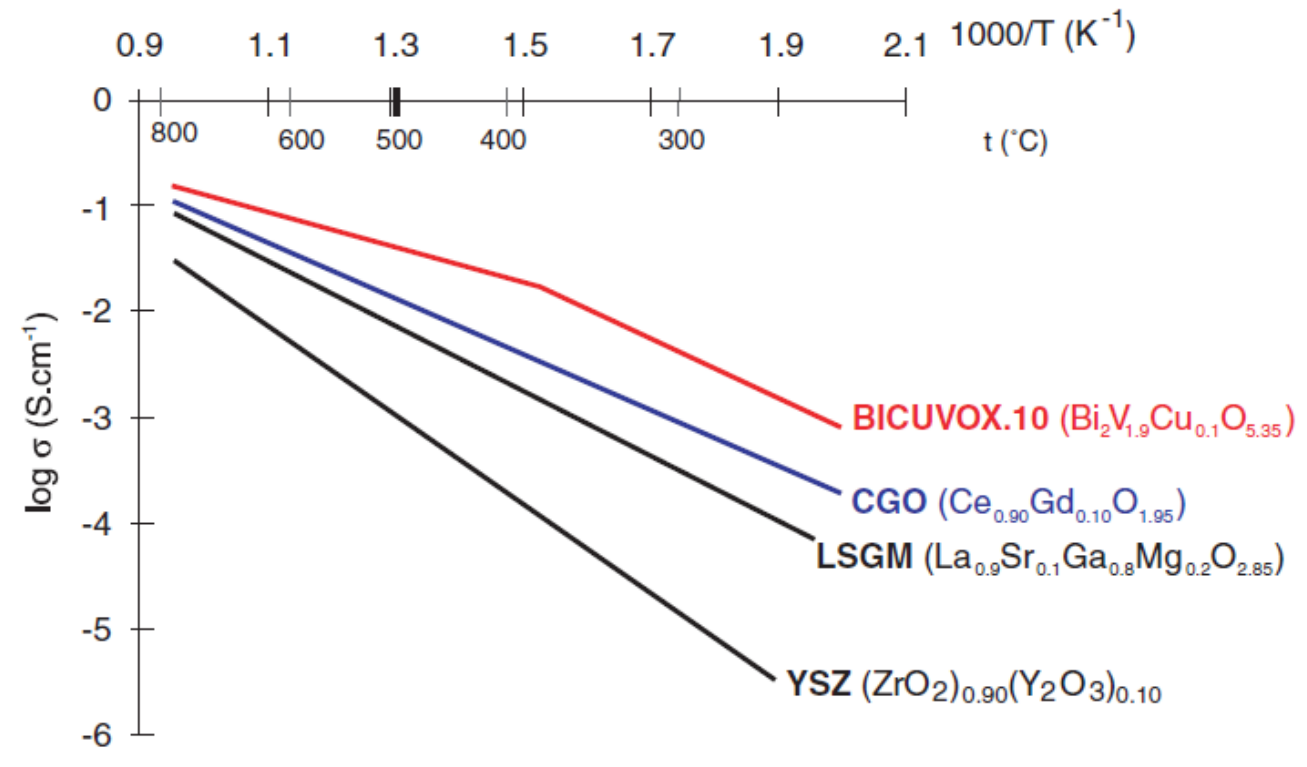

Figure 17: Comparison of ionic conductivity for ionic conductors with different crystal structure [21].

Low mechanical strength due to intrinsic microstructure property, high reactivity with possible electrodes, high thermal expansion coefficient $\left(15 \times 10^{-6} /{ }^{\circ} \mathrm{C}\right)$, and low stability at reduction atmosphere $\left(\mathrm{pO}_{2}<10^{-2} \mathrm{~atm}\right)$ are barriers to the fabrication of the SOFC electrolytes made of BICUVOX; but due to its high conductivity, this material has gotten much attention of researchers in recent years $[1,2,4]$. 


\section{CHAPTER 3: BICUVOX POWDER SYNTHESIS}

\subsection{Objective}

Completion of densification at lower temperatures and shorter times prevents grain growth, which will improve the mechanical strength of most ceramics. Densification and grain growth are occurred simultaneously, and they are competitive. The two processes are both driven by the grain size. Reducing the particle size provides stronger driving force for the sintering mechanism, which increases the densification rate of the green body [6].

The purpose of this chapter is to investigate a new synthesis method for BICUVOX powder, which produces sub-micron powder particles. Results will be compared with the powder obtained from solid-state reaction method (SSR). Also, the synthesis of BICUVOX powder by molten salts method will be discussed for future work.

\subsection{Synthesis of $\mathrm{Bi}_{0.2} \mathrm{~V}_{0.9} \mathrm{Cu}_{0.1} \mathrm{O}_{5.35}$ by Solid-State Reaction}

Solid-state reaction is one of the most common methods for production of powders for complex oxides. In this work, solid reactants, which are in the form of simple oxide or carbonate powders are chemically reacted with each other at high temperature. Based on the formulation, the SSR process will produce the required composition. The duration of milling/mixing process and calcination conditions (time, temperature) are some of the variables that affect size and morphology of the particles [6]. 


\subsubsection{Experimental Procedure}

The stoichiometric mixture of $84.01 \mathrm{wt} \% \mathrm{Bi}_{2} \mathrm{O}_{3}$ (99\%, Alfa-Aesar, Ward Hill,MA), 14.65 wt $\% \mathrm{~V}_{2} \mathrm{O}_{5}(99.6 \%$, Alfa-Aesar, Ward Hill,MA) and $1.31 \mathrm{wt} \% \mathrm{CuO}$ (99.7\%, Alfa-Aesar, Ward Hill,MA) was attrition-milled (1000 rpm) in ethanol using $3 \mathrm{~mm}$ zirconia balls for 4 hours.

The final slurry was dried in air. In order to observe the effects of calcination on powder particle size, the milled powder was calcined at the temperatures ranging between 200 to $500^{\circ} \mathrm{C}$ for 4 hours.

\subsubsection{Results}

Figure 18 compares particle size of raw BICUVOX powder with the one calcined at $200^{\circ} \mathrm{C}$ for 4 hours.
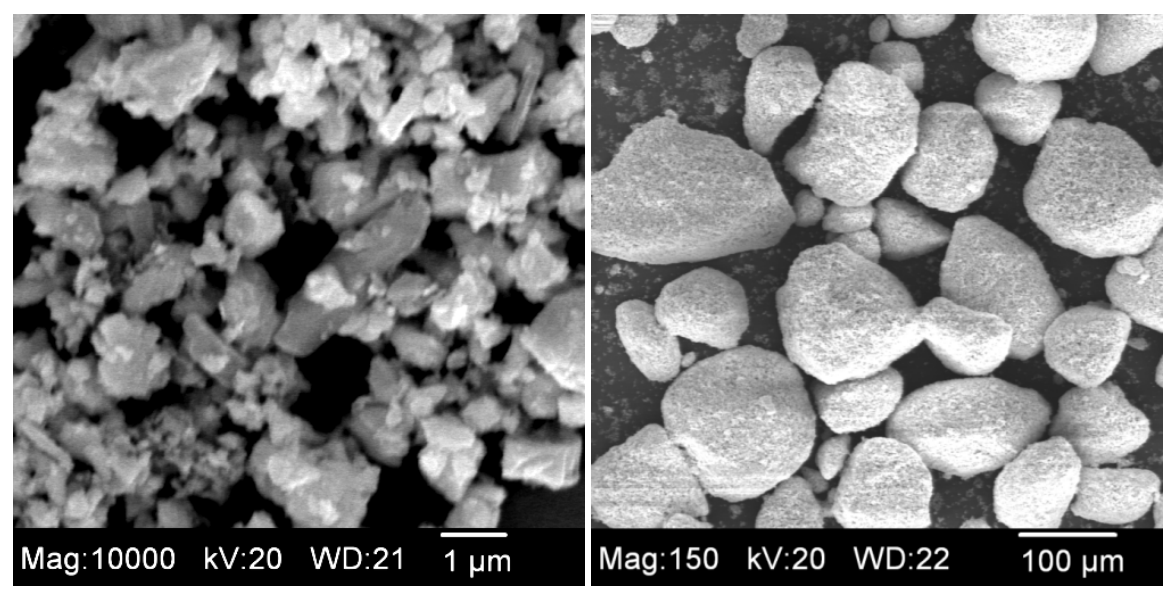

Figure 18: SEM micrograph of raw BICUVOX (SSR) powder (left) and calcined one at $200^{\circ} \mathrm{C}$ for $4 \mathrm{~h}$ (right) 
A comparison of particle size before and after calcination shows the negative effects of thermal treatment on particle size. At the end of the calcination process, micron particle size of raw powder is converted to a hundred micron-hard particle agglomerates, which leads to large grain size and a poor microstructure (Figure 19).

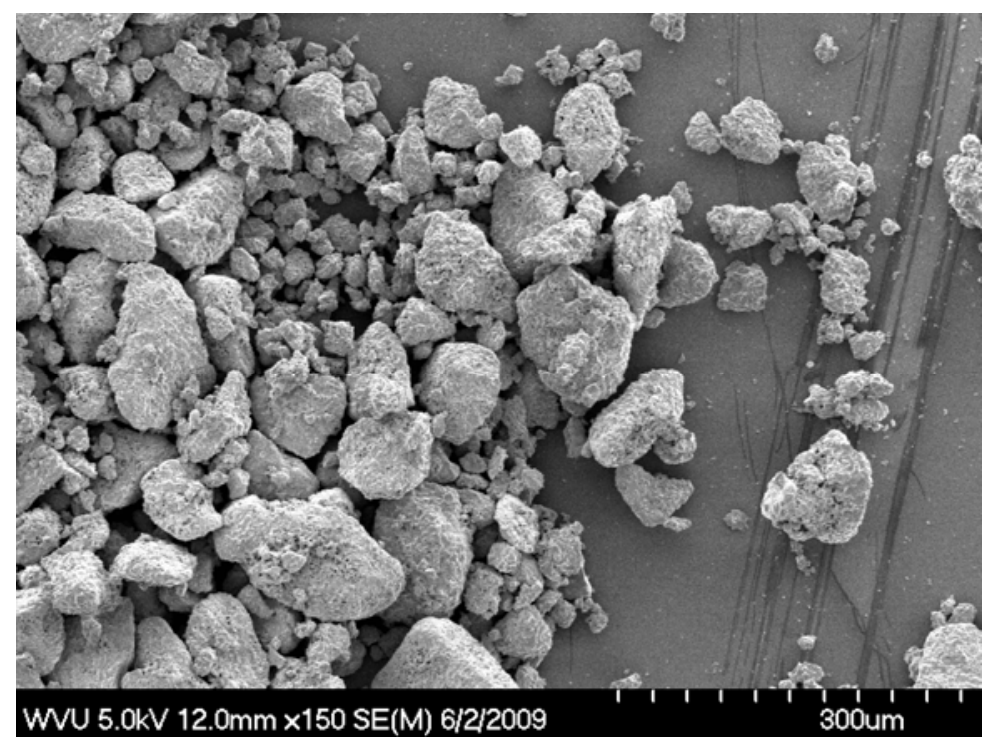

Figure 19: SEM micrograph of calcined BICUVOX powder (SSR) at $700^{\circ} \mathrm{C}$ for $4 \mathrm{~h}$

Calcination study was completed at the temperature range from $200^{\circ} \mathrm{C}$ to $500^{\circ} \mathrm{C}$. The $\mathrm{BET}$ surface area measurement was carried on for the further investigation on surface area (Table 2). 
Table 2: BET surface area data obtained from calcined SSR powder at different temperatures.

\begin{tabular}{c|c|c}
\hline $\begin{array}{c}\text { Milling and Calcination } \\
\text { Conditions }\end{array}$ & $\mathbf{S}_{\text {BET }}\left(\mathbf{m}^{2} / \mathbf{g}\right)$ & Particle Size $(\boldsymbol{\mu m})$ \\
\hline $\begin{array}{c}\text { Raw powder (attrition } \\
\text { milled for } 4 \mathrm{~h})\end{array}$ & 3.66 & 0.9 \\
\hline calcined at $200^{\circ} \mathrm{C} / 4 \mathrm{~h}$ & 3.61 & 1.1 \\
\hline calcined at $400^{\circ} \mathrm{C} / 4 \mathrm{~h}$ & 2.60 & 1.3 \\
\hline calcined at $500^{\circ} \mathrm{C} / 4 \mathrm{~h}$ & 0.71 & 1.5 \\
\hline $\begin{array}{c}\text { calcined at } 500^{\circ} \mathrm{C} / 4 \mathrm{~h}- \\
\text { remilled for } 4 \mathrm{~h}(\text { overall } 8 \\
\mathrm{h} \text { milling) }\end{array}$ & 1.59 & 1 \\
\hline
\end{tabular}

Listed data (Table 2) exhibits reduction in surface area as the calcination temperature increases. These particle sizes are bigger than the ones achieved by co-precipitated method for the same temperatures (table 3). Figure 18 and Figure 19 show the formation of large agglomerates $(>100 \mu \mathrm{m})$ as the calcination process initiates. Agglomerates lead to heterogeneous packing during the consolidation process, resulting in different shrinking rate during the firing stage. Differential sintering creates large pores and cracklike voids in the sintered body. SSR produces hard agglomerates that are bonded chemically and cannot be broken by either pressing or milling.

The XRD study on calcined powder at $700^{\circ} \mathrm{C} / 4 \mathrm{~h}$, still shows the existence of the impurity phases $\mathrm{Bi}_{2} \mathrm{O}_{3}$ and $\mathrm{BiOV}_{4}$ (Figure 20), that is higher temperatures are needed to establish the BICUVOX phase for the powder synthesized by SSR method. This results in bigger particle size. 


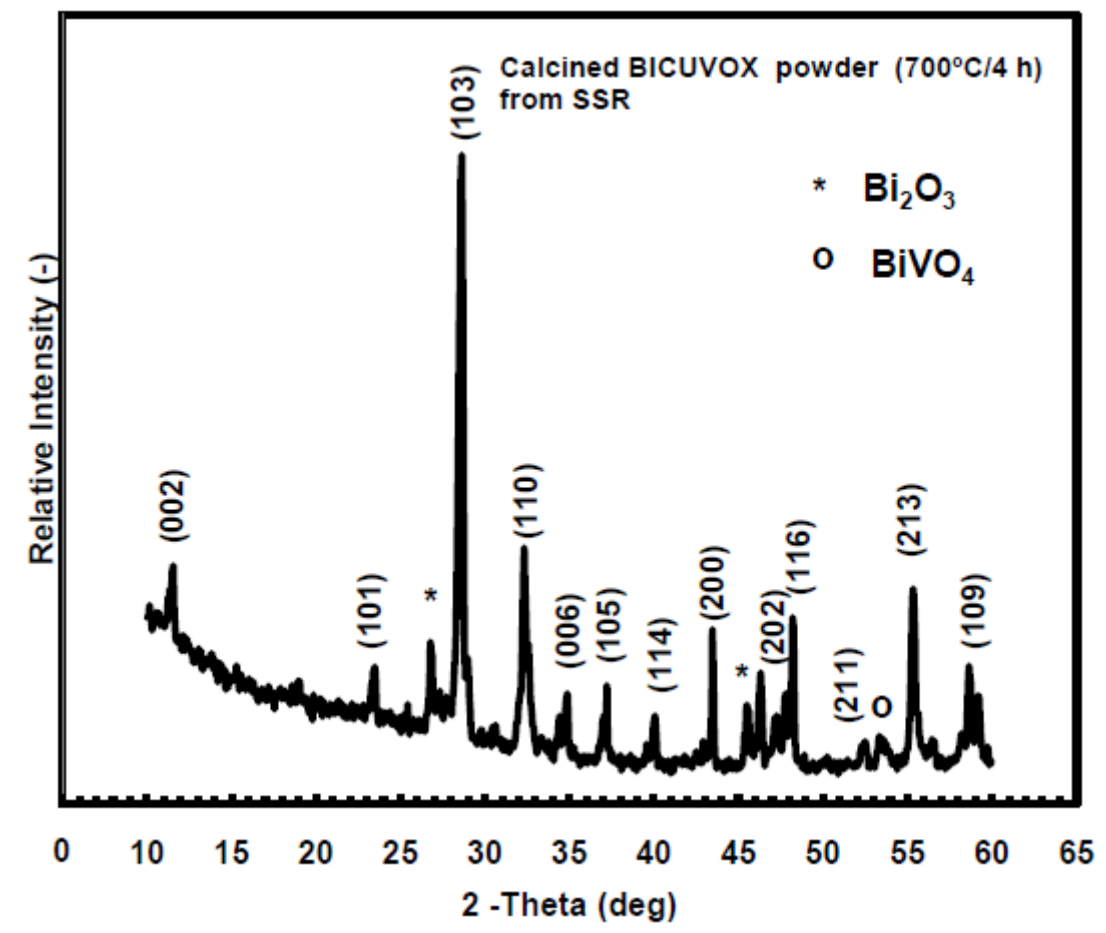

Figure 20: X-ray pattern of BICUVOX pellet made by SSR method and sintered at $700^{\circ} \mathrm{C}$ for $4 \mathrm{~h}$

Reactive sintering process was applied to eliminate negative effects of the calcination process on consolidation and sintering. In this method, calcination process of the milled oxide and sintering process of the compacted powder will be completed in a one heat treatment cycle [6].

The milled/mixed powder (obtained from section 3.2.1) was used for making pellets. Assuming that calcinations and densification processes will be completed simultaneously, BICUVOX phase would be obtained when the sintering process is completed. 
In order to confirm the purity of obtained BICUVOX phase after reactive sintering process, $\mathrm{X}$-ray diffraction pattern (XRD) was run on the pellet sintered at $750^{\circ} \mathrm{C}$ for 4 hours (Figure 21).

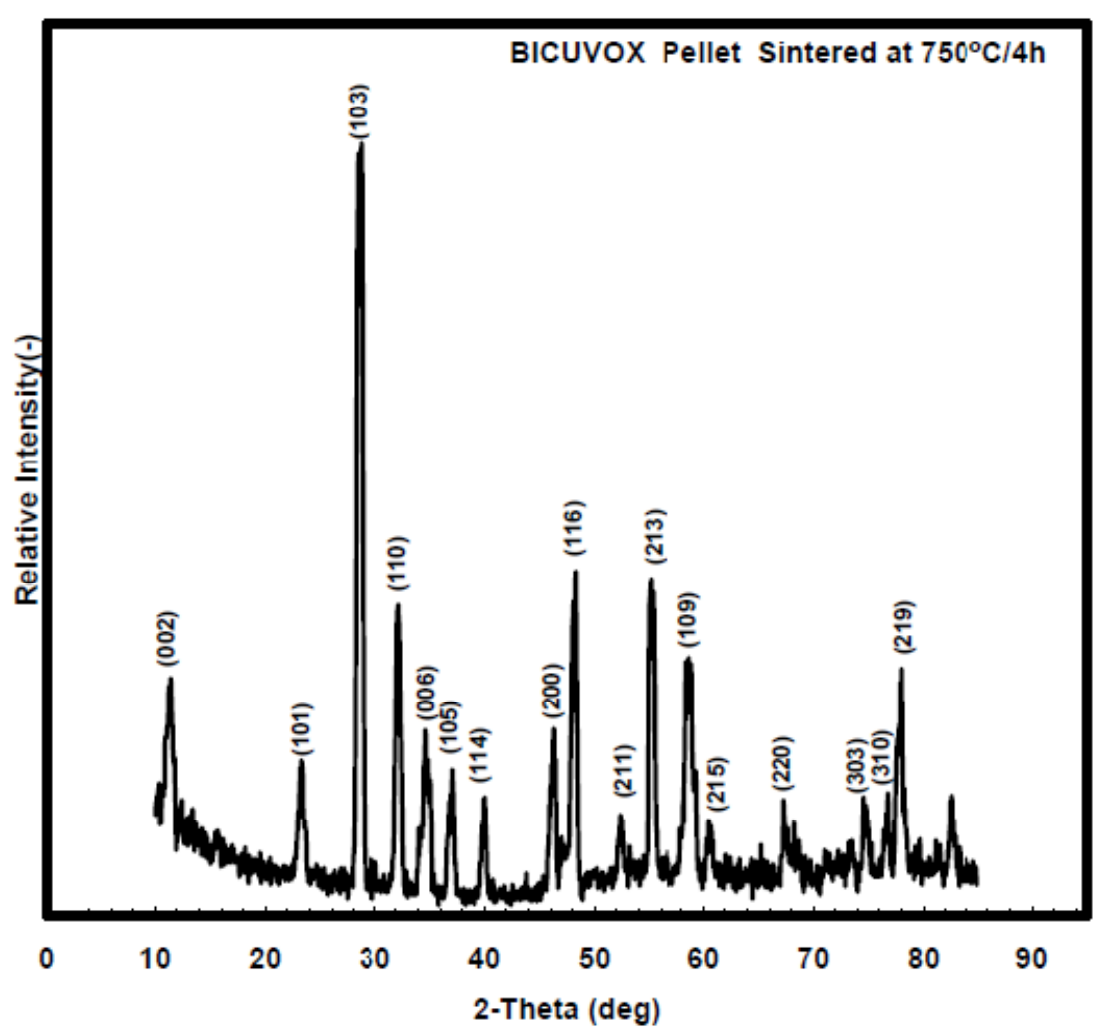

Figure 21: X-ray pattern of BICUVOX pellet made by SSR method and sintered at $750^{\circ} \mathrm{C}$ for $4 \mathrm{~h}$

Comparison of Figure 20 and Figure 21 shows that calcination temperature should be reached at $750^{\circ} \mathrm{C}$ to obtain pure BICUVOX phase.

One of the drawbacks of the calcination process is that raise in calcination temperature will reduce the surface area of the particles and will result in the increase of the particle size. 
Further attrition milling has a negligible effect on reducing the particle size (Table 2). As demonstrated by the XRD data (Figure 21), the powder processed through attrition milling needs to be calcined at a temperature as high a $750^{\circ} \mathrm{C} / 4 \mathrm{~h}$ until pure BICUVOX phase is obtained. This calcination temperature is high and increases the particle size, resulted in large initial grain agglomerates.

\subsection{Synthesis of $\mathrm{Bi}_{0.2} \mathrm{~V}_{0.9} \mathrm{Cu}_{0.1} \mathrm{O}_{5.35}$ by Co-Precipitation}

Co-precipitation method is applied to synthesize fine particle sizes, stoichiometric, and high purity powder. The required powder will precipitate from a solution of reactants by adding a chemical reagent that reacts with the solution. Normally a solution of mixed alkoxides, mixed salts, or a combination of both will be used for this purpose. Acidic solution of mixed nitrates (bismuth nitrate and copper nitrate) reacts with the $\mathrm{OH}^{-}$coming from the basic solution of ammonium vanadium oxide and the required products will precipitate out by $\mathrm{pH}$ adjustment. Pourbaix diagram was employed to determine the $\mathrm{pH}$ range that results in the final required compositions.

Similar to SSR method, during the calcination process, time and temperature are the most important factors that affect the particles size and morphology [6].

In this section, BICUVOX powder will be synthesized by co-precipitation method; and results will be compared with SSR to investigate which method achieves finer BICUVOX powder. 


\subsubsection{Experimental Procedure}

83.84 wt \% bismuth nitride hydrate $\left(\mathrm{Bi}\left(\mathrm{NO}_{3}\right)_{3} .5 \mathrm{H}_{2} \mathrm{O}, 98 \%\right.$ Alfa Aesar) and $1.4 \mathrm{wt} \%$ copper nitrate $\left(\mathrm{Cu}\left(\mathrm{NO}_{3}\right)_{2} .3 \mathrm{H}_{2} \mathrm{O}\right.$, 98-102\% Alfa Aesar) were dissolved in $1 \mathrm{~N} \mathrm{HNO}_{3}$ aqueous solutions. The combined acidic solutions were added to a basic solution of $14.72 \mathrm{wt} \%$ ammonium vanadium oxide $\left(\mathrm{NH}_{4} \mathrm{VO}_{3}, 99 \%\right.$ Alfa Aesar) by titration while the solution was continuously being stirred at $\mathrm{pH}=8$.

Pourbaix diagrams for $\mathrm{Bi}-\mathrm{H}_{2} \mathrm{O}, \mathrm{V}-\mathrm{H}_{2} \mathrm{O}$ and $\mathrm{Cu}-\mathrm{H}_{2} \mathrm{O}$ systems (Figure 22, Figure 23, and Figure 24) show that there is a narrow $\mathrm{pH}$ regime that directly precipitates $\mathrm{Bi}_{2} \mathrm{O}_{3}, \mathrm{Cu}_{2} \mathrm{O}$, and $\mathrm{V}_{2} \mathrm{O}_{5}$ compositions. This means there is a possibility for formation of other cations or anions at higher or lower $\mathrm{pH}$. Separation of precipitated powders from the water will be done by evaporation of water. This prevents the waste of possible unprecipitated materials from the solution. That is some amount of bismuth, vanadium or copper may stay in the solution since the $\mathrm{pH}=8$ is so close to other ion fields. 


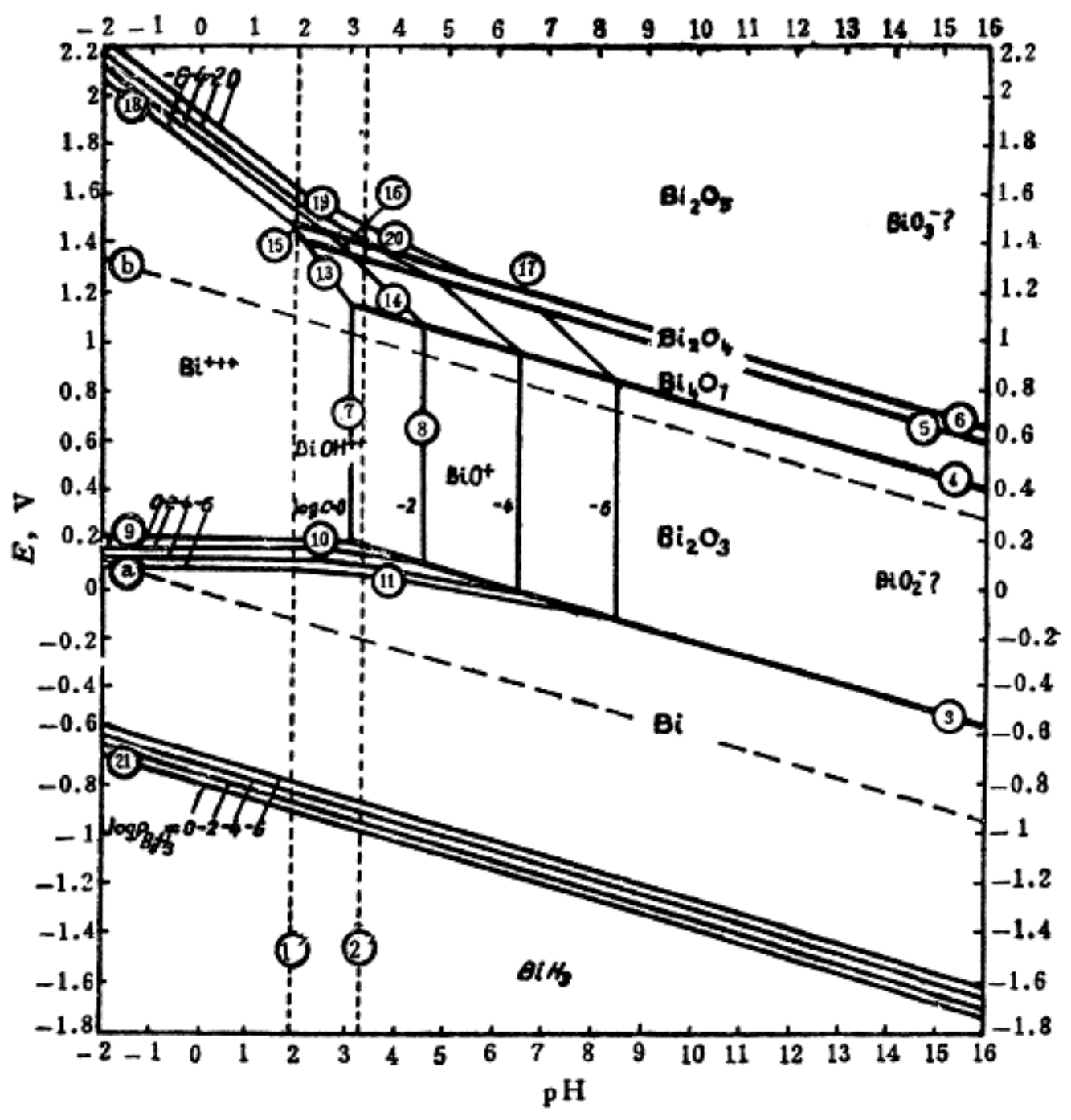

Figure 22: Pourbaix diagram of the $\mathrm{Bi}-\mathrm{H}_{2} \mathrm{O}$ system [33]. 


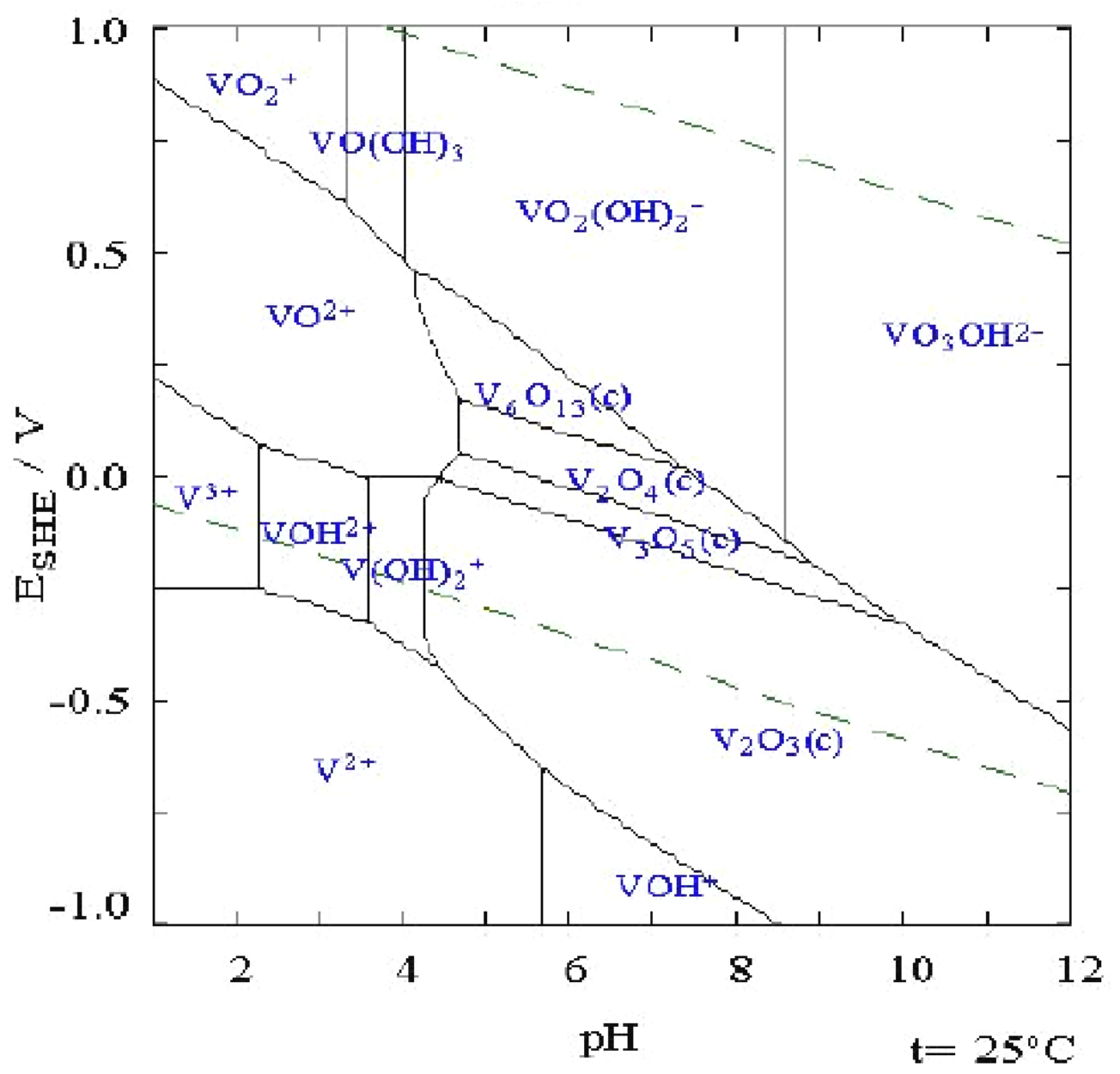

Figure 23: Pourbaix diagram of the $\mathrm{V}-\mathrm{H}_{2} \mathrm{O}$ system [34]. 


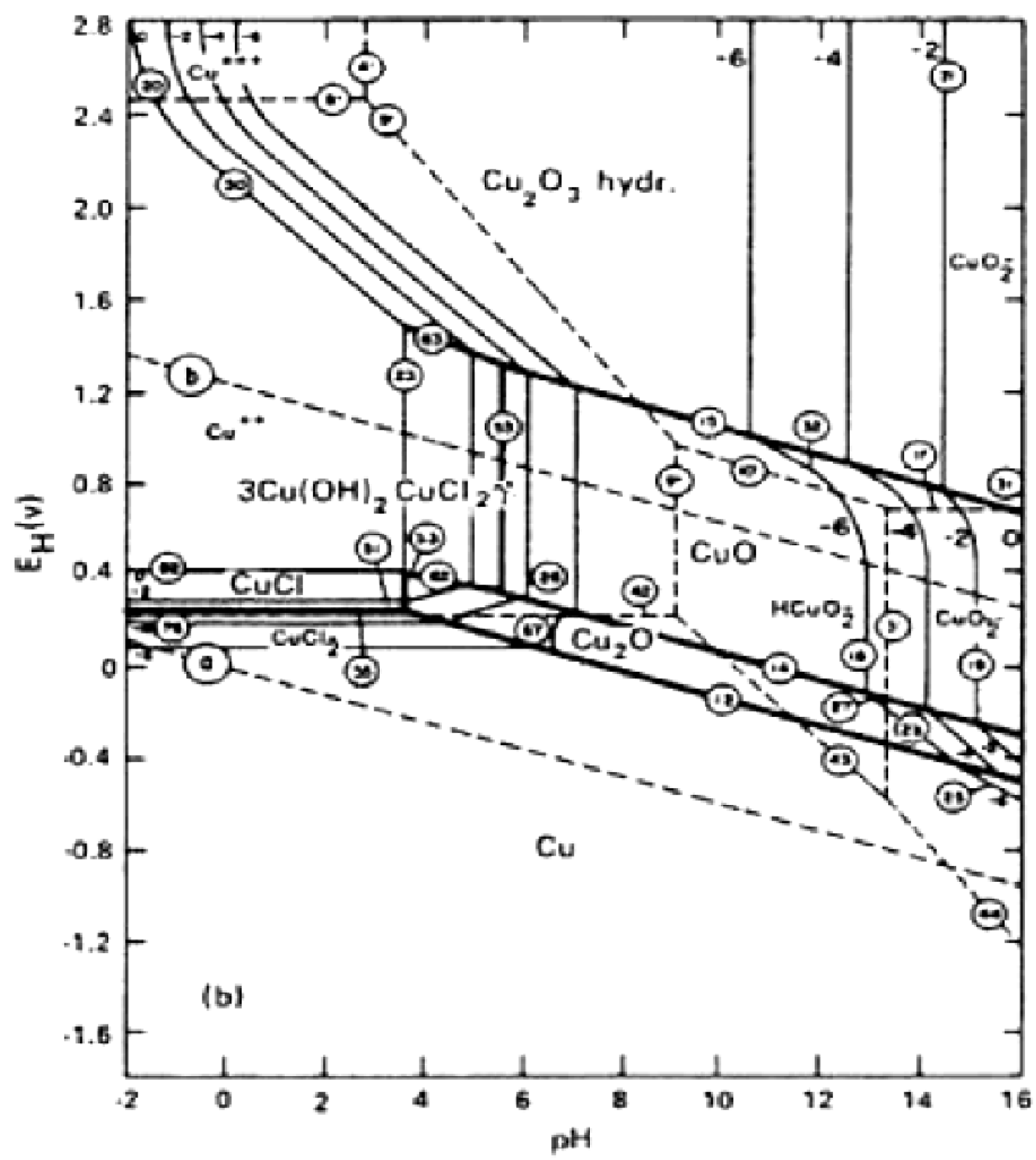

Figure 24: Pourbaix diagram of the $\mathrm{Cu}-\mathrm{H}_{2} \mathrm{O}$ system [35].

Equations 5-10 summarize the reactions for precipitation processing steps. First bismuth nitride hydrate $\left(\mathrm{Bi}\left(\mathrm{NO}_{3}\right)_{3} .5 \mathrm{H}_{2} \mathrm{O}, 98 \%\right.$ Alfa Aesar) and copper nitrate $\left(\mathrm{Cu}\left(\mathrm{NO}_{3}\right)_{2} .3 \mathrm{H}_{2} \mathrm{O}, 98-102 \%\right.$ Alfa Aesar) were dissolved in $1 \mathrm{~N} \mathrm{HNO}_{3}$ aqueous solutions (Eq. 5 and Eq.6), and ammonium vanadium oxide $\left(\mathrm{NH}_{4} \mathrm{VO}_{3}, 99 \%\right.$ Alfa Aesar) was dissolved in ammonium hydroxide (Eq.7) 
$\mathrm{Bi}\left(\mathrm{NO}_{3}\right)_{3} \cdot 5 \mathrm{H}_{2} \mathrm{O} \rightarrow \mathrm{Bi}^{3+}+3 \mathrm{NO}_{3}^{-}+5 \mathrm{H}_{2} \mathrm{O}$

$\mathrm{Cu}\left(\mathrm{NO}_{3}\right)_{2} \cdot 3 \mathrm{H}_{2} \mathrm{O} \rightarrow \mathrm{Cu}^{2+}+2 \mathrm{NO}_{3}^{-}+3 \mathrm{H}_{2} \mathrm{O}$

$\begin{array}{ll}\mathrm{NH}_{4} \mathrm{VO}_{3} \rightarrow \mathrm{NH}_{4}^{+}+\mathrm{VO}_{3}^{-} & \text {Eq. } 7\end{array}$

The mixture of acidic solution of bismuth nitrate hydrate and copper nitrate contains several different anion or cation including $\left(\mathrm{Cu}^{2+}, \mathrm{Bi}^{3+}\right.$ and $\left.\mathrm{NO}_{3}{ }^{-}\right)$. By adding this acidic solution to basic solution of ammonium vanadium oxide and increasing the $\mathrm{pH}$ to 8 (based on Pourbaix diagram), $\mathrm{Bi}_{2} \mathrm{O}_{3}$ and $\mathrm{Cu}_{2} \mathrm{O}$ species are expecting to precipitate out (Eq.8 and Eq.9)

$\mathrm{Bi}^{3+}+2 \mathrm{OH}^{-} \rightarrow \mathrm{Bi}_{2} \mathrm{O}_{3}$

$\mathrm{Cu}^{2+}+2 \mathrm{OH}^{-} \rightarrow \mathrm{Cu}_{2} \mathrm{O}$

Also decreasing the $\mathrm{pH}$ of basic solution of ammonium vanadium oxide from 14 to 8 , results in precipitation of $\mathrm{V}_{2} \mathrm{O}_{5}$ (Eq.10)

$2 \mathrm{VO}_{3}^{-}+2 \mathrm{H}^{+} \rightarrow \mathrm{V}_{2} \mathrm{O}_{5}+\mathrm{H}_{2} \mathrm{O}$

Eq. 10

The suspension of precipitated hydroxide powder was heated at $250^{\circ} \mathrm{C}$ and the final gel was dried in an oven at $85^{\circ} \mathrm{C}$. The final powder was crushed by a mortar and pestle, and sieved by using 60-mesh then calcined at different temperatures in the range of $300^{\circ} \mathrm{C}$ to $700^{\circ} \mathrm{C}$ for 2 hours. Co-precipitation processes have been summarized in Figure 25. 


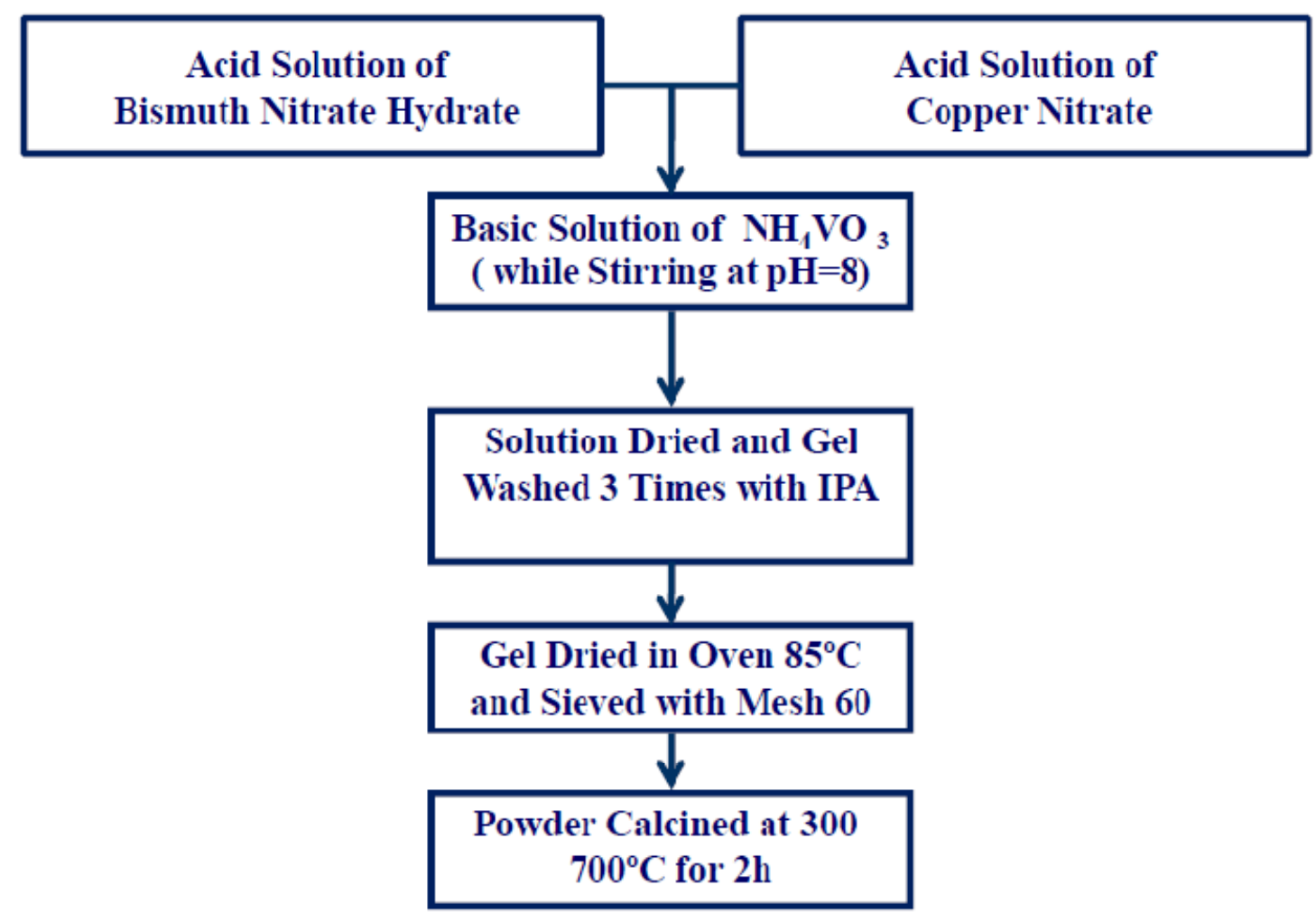

Figure 25: Summary of Co-Precipitation Processes

\subsubsection{Results}

X-ray diffraction patterns (XRD) were used to determine the phase composition of calcined powders at different temperatures Figure 26. 


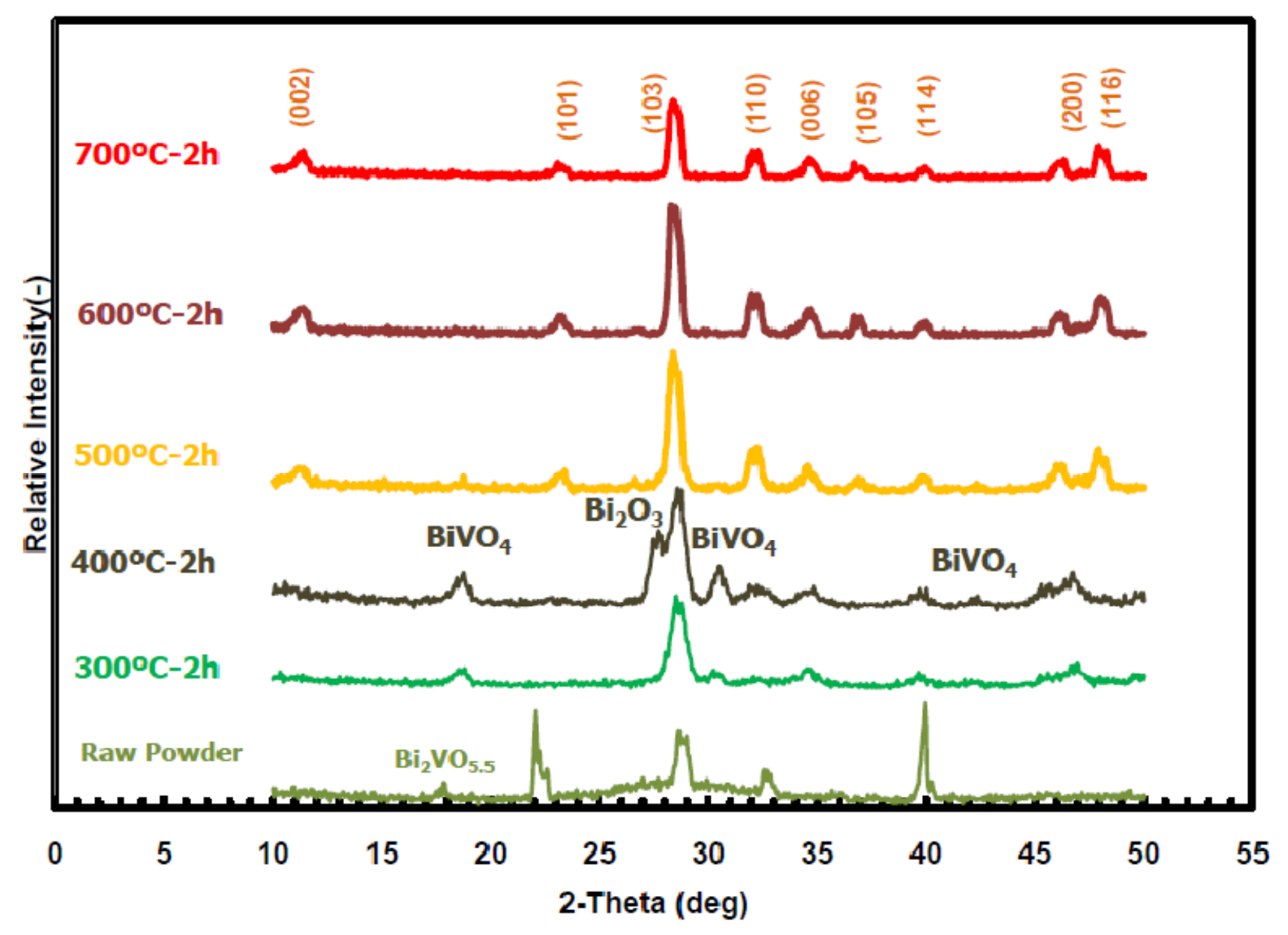

Figure 26: XRD patterns of BICUVOX powder synthesized by co-precipitation method calcined at different temperatures.

Figure 27 compares the particle sizes (calcined at $500^{\circ} \mathrm{C}$ ) obtained by the co-precipitation method versus solid state reaction. 

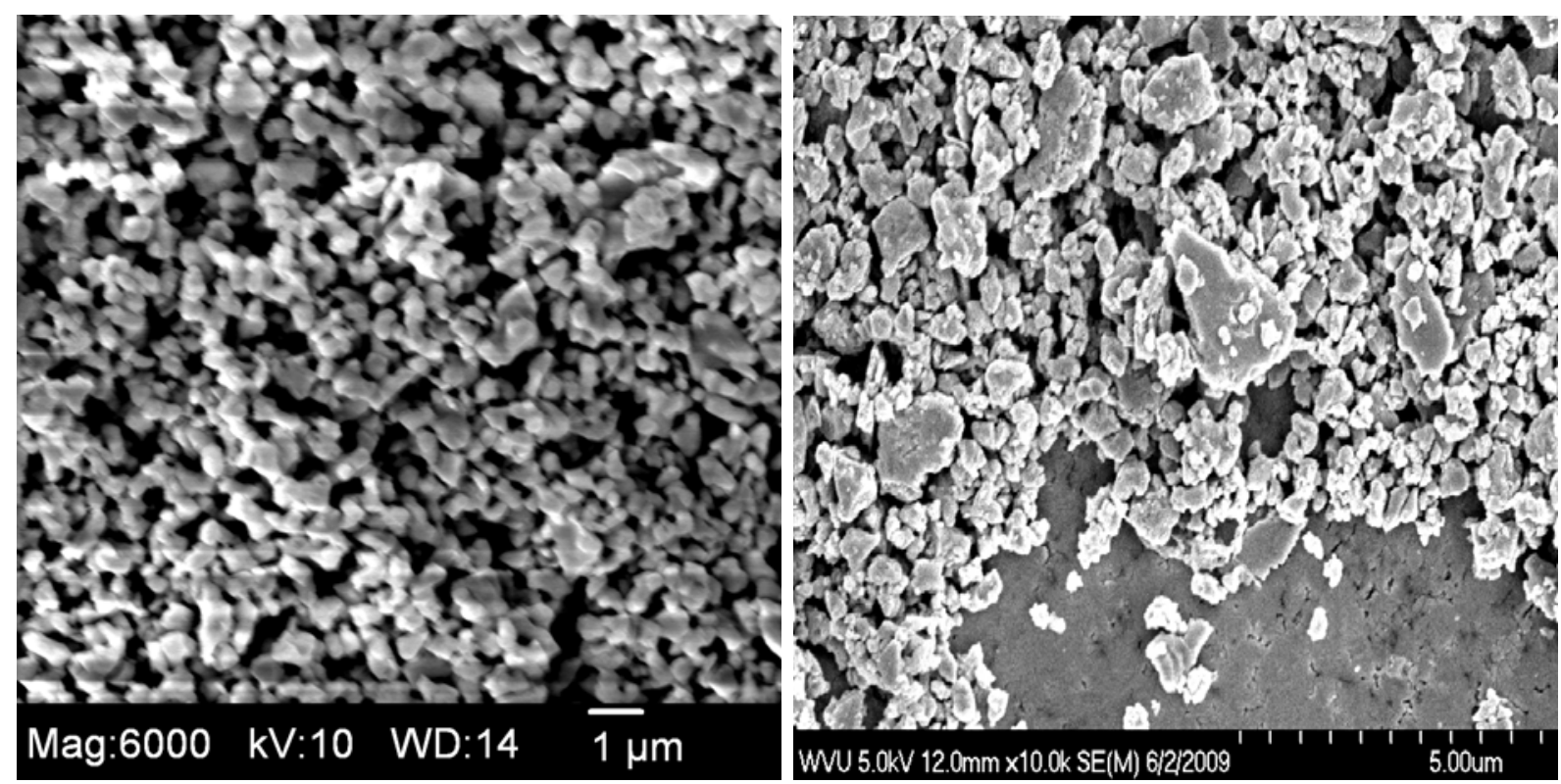

Figure 27: BICUVOX powder obtained by co-precipitation method and calcined at $500^{\circ} \mathrm{C} / 2 \mathrm{~h}$ (left), BICUVOX powder obtain from SSR method; calcined at $500^{\circ} \mathrm{C} / 4 \mathrm{~h}$ and remilled for $4 \mathrm{~h}$ (right).

XRD patterns of synthesized BICUVOX powder from co-precipitation method (Figure 26) shows that the desired crystallography BICUVOX phase is synthesized at $500^{\circ} \mathrm{C}$, and traces of impurities such as $\mathrm{Bi}_{2} \mathrm{VO}_{5.5}$ and $\alpha-\mathrm{BiVO}_{4}$ have fully disappeared by $500^{\circ} \mathrm{C}$. This temperature is $150^{\circ} \mathrm{C}$ below the calcination temperature that is needed for the powder obtained by SSR method. Jibo et al. [73] have investigated synthesis of BICUVOX by a complex EDTA-citric acid (EC) method. Using Pechini method, BICUVOX phase was established at $650^{\circ} \mathrm{C}$. There is no report of obtained average of particle size in their work. 
The synthesis of BICUVOX phase at such a low temperature and short time (this work) can be attributed to the co-precipitation method used for powder preparation. Reduction in particle size (co-precipitation technique) will increase the reaction rate during the calcination process, which is due to closer diffusion distance and relative number of contacts between the reactant particles.

Comparison of particle size between the powder obtained from the co-precipitation method and SSR shows, even though another 4 hours remilling (after calcination process), was applied to the powder obtained by SSR method (Figure 27 right), negligible change in reducing the particle size is observed. Synthesized powder from the co-precipitation method shows submicron particle sized after thermal treatment at $500^{\circ} \mathrm{C}$ for 4 hours (Figure 27 left). Table 3 compares particle sizes obtained from different synthesis methods of other researches. 
Table 3: The influence of different powder synthesis methods on particle size

\begin{tabular}{c|c|c|c|c}
\hline $\begin{array}{c}\text { (BICUVOX.1) } \\
\text { Synthesis } \\
\text { Method }\end{array}$ & $\begin{array}{c}\text { Calcination } \\
\text { Conditions }\end{array}$ & $\begin{array}{c}\text { Particle } \\
\text { Size } \\
\mathbf{\mu m})\end{array}$ & $\mathbf{S}_{\text {BET }}\left(\mathbf{m}^{2} / \mathbf{g}\right)$ & Ref. \\
\hline Attrition Milled 4 h & Raw Powder & 0.9 & 3.66 & This Work \\
\hline Attrition Milled 4 h & $200^{\circ} \mathrm{C} / 4 \mathrm{~h}$ & 1.1 & 3.61 & This Work \\
\hline Attrition Milled 4 h & $400^{\circ} \mathrm{C} / 4 \mathrm{~h}$ & 1.3 & 2.60 & This Work \\
\hline Attrition Milled 4 h & $500^{\circ} \mathrm{C} / 4 \mathrm{~h}$ & 1.5 & 0.71 & This Work \\
\hline Attrition Milled 8 h & $500^{\circ} \mathrm{C} / 4 \mathrm{~h}$ & 1 & 1.59 & This Work \\
\hline Ball-milled & $800^{\circ} \mathrm{C}$ & 15 & 0.24 & {$[36]$} \\
\hline Attrition Milled 4 h & $800^{\circ} \mathrm{C}$ & 0.7 & 4.6 & {$[36]$} \\
\hline Ball-milled 20 h & $800^{\circ} \mathrm{C} / 12 \mathrm{~h}$ & 5 & 0.15 & {$[37]$} \\
\hline Attrition Milled 25 h & $650^{\circ} \mathrm{C} / 15 \mathrm{~h}$ & 1 & 0.76 & This Work \\
\hline Co-precipitation & Raw Powder & 0.5 & 50 & This Work \\
\hline Co-precipitation & $500^{\circ} \mathrm{C} / 2 \mathrm{~h}$ & 0.230 & 3.30 & \\
\hline
\end{tabular}

The raw and calcined BICUVOX powders obtained from co-precipitation method show the highest surface area compared with other works. 


\subsection{Synthesis of $\mathrm{Bi}_{0.2} \mathrm{~V}_{0.9} \mathrm{Cu}_{0.1} \mathrm{O}_{5.35}$ Templates by Molten Salt Synthesis (MSS)}

Molten Salt Synthesis is a synthesis method that normally is used to grow anisotropic particles of oxide ceramic compounds. Particle shape and size of powder can be controlled by applying different thermal conditions (time and temperature). Generally eutectic points of salt compositions are chosen to obtain the maximum reactivity at the minimum temperature [39]. This method is based on dissolution and dissociation of participant reagent $\left(\mathrm{CuO}, \mathrm{Bi}_{2} \mathrm{O}_{3}, \mathrm{~V}_{2} \mathrm{O}_{5}\right)$, using fused salts as reaction medium ( $\mathrm{KCl}: \mathrm{NaCl}=1: 1$ mole ratio), and increasing the diffusivity of $\mathrm{Bi}^{3+}, \mathrm{V}^{5+}$, and $\mathrm{Cu}^{2+}, \mathrm{O}^{2-}$ ions to form the complex ionic compounds. This method allows greater mobility of atomic species and stable formation of required phase. Temperature, time and amount of fused salt are variables that affect the particle size.

This work discusses the synthesis of BICUVOX template particles using molten salt synthesis. The effect of time and temperature on template particle morphology and size will be investigated. 


\subsubsection{Experimental Procedure}

Molten salt synthesis (MSS) was used to fabricate large anisotropic platelet particle BICUVOX. The stoichiometric mixture of $84.01 w t \% \mathrm{Bi}_{2} \mathrm{O}_{3}(99 \%$, Alfa-Aesar, Ward Hill, MA), $14.65 \mathrm{wt} \% \mathrm{~V}_{2} \mathrm{O}_{5}(99.6 \%$, Alfa-Aesar, Ward Hill, MA) and $1.31 \mathrm{wt} \% \mathrm{CuO}(99.7 \%$, Alfa-Aesar, Ward Hill,MA) was added to 1:1 mole ratio (eutectic composition) of the $\mathrm{NaCl}(>99 \%$, AlfaAesar, Ward Hill,MA) and $\mathrm{KCl}(>90 \%$, Alfa-Aesar, Ward Hill,MA) at various volume fractions, and were ball-milled in ethanol for 24 hours. The slurry was dried in an oven at $85^{\circ} \mathrm{C}$, and sieved by using different mesh $(60,200)$.

The mixture was reacted at times and temperatures between $2-4$ hours and $650-700^{\circ} \mathrm{C}$, respectively. The final powder was washed in de-ionized water until a conductivity of $<0.4$ $\mu \mathrm{S} / \mathrm{cm}(\sim 10$ times $)$ was obtained with the wash water.

\subsubsection{Results}

X-ray diffraction patterns (XRD), scanning electron microscopy (SEM), and energydispersive X-ray (EDX) were used to determine the phase content and effects of time, temperature, and solids loading \% on particle morphology.

Figure 28 lists the SEM pictures of the obtained particles from MSS method. Regardless of the reaction time, temperature and percentage of solid volume, most particles show platelet morphology. Increasing solid loading from $20 \%$ to $30 \%$ and $50 \%$ do not make any significant changes in the particle size of the platelet particles. 
Figure 28 (e) also shows the effect of sieving before the firing process. The condition of $700^{\circ} \mathrm{C} / 4 \mathrm{~h}$ (Fig. e, f, g, h) indicates the least amount of needle-shaped particles and sieving the raw powder using mesh 60 improved the unity distribution of the round-shaped platelet particles. Sieving provides more uniform distribution of powder before thermal treatment.

As temperature and time increase from $680^{\circ} \mathrm{C}$ to $700^{\circ} \mathrm{C}$ and 2 hours to 8 hours, respectively, particle sizes increase and larger particles appear. At the higher temperatures mobility increases and the rate of crystal growth also increases (Figure 28). 


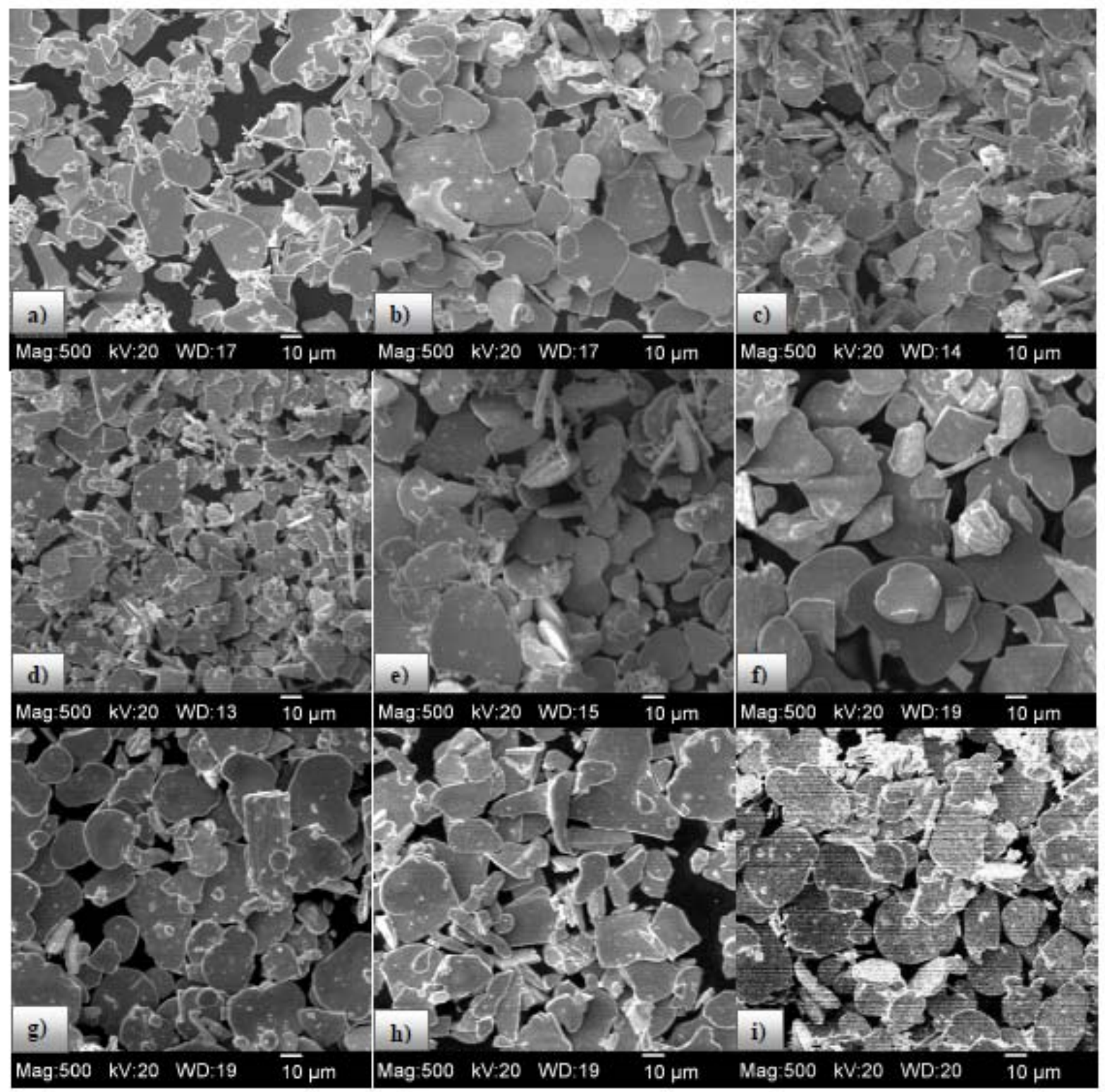

Figure 28: SEM images of MSS powders fired at (a) $680^{\circ} \mathrm{C} / 3 \mathrm{~h}$ contains $30 \%$ solid volume, (b) $700^{\circ} \mathrm{C} / 1 \mathrm{~h}$ contains $20 \%$ solid volume, (c) $700^{\circ} \mathrm{C} / 2 \mathrm{~h}$ contains $20 \%$ solid volume, (d) $700^{\circ} \mathrm{C} / 2 \mathrm{~h}$ contains $30 \%$ solid volume, (e) powder sieved by mesh 60 and fired at $700^{\circ} \mathrm{C} / 4 \mathrm{~h}$ contains $20 \%$ solid volume, (f) $700^{\circ} \mathrm{C} / 4$ h contains $20 \%$ solid volume, $(\mathrm{g}) 700^{\circ} \mathrm{C} / 4 \mathrm{~h}$ contains $30 \%$ solid volume, (h) $700^{\circ} \mathrm{C} / 4 \mathrm{~h}$ contains $50 \%$ solid volume, (i) $700^{\circ} \mathrm{C} / 8 \mathrm{~h}$ contains $20 \%$ solid volume. 
Phase monitoring of synthesized particles was carried on by X-ray diffraction (XRD) for the different conditions containing of $20 \%$ solid volume (Figure 29and Figure 30). Figure 29 shows the XRD pattern for the powder fired at $700^{\circ} \mathrm{C}$ for 2 hours. As it is shown, some trace of $\mathrm{BiVO}_{4}$ impurity exists in the XRD pattern. Increasing the treatment time from 2 hours to 4 hours removed the trace of $\mathrm{BiVO}_{4}$ and a pure BICUVOX phase was synthesized at the $700^{\circ} \mathrm{C} / 4 \mathrm{~h}$ condition (Figure 30).

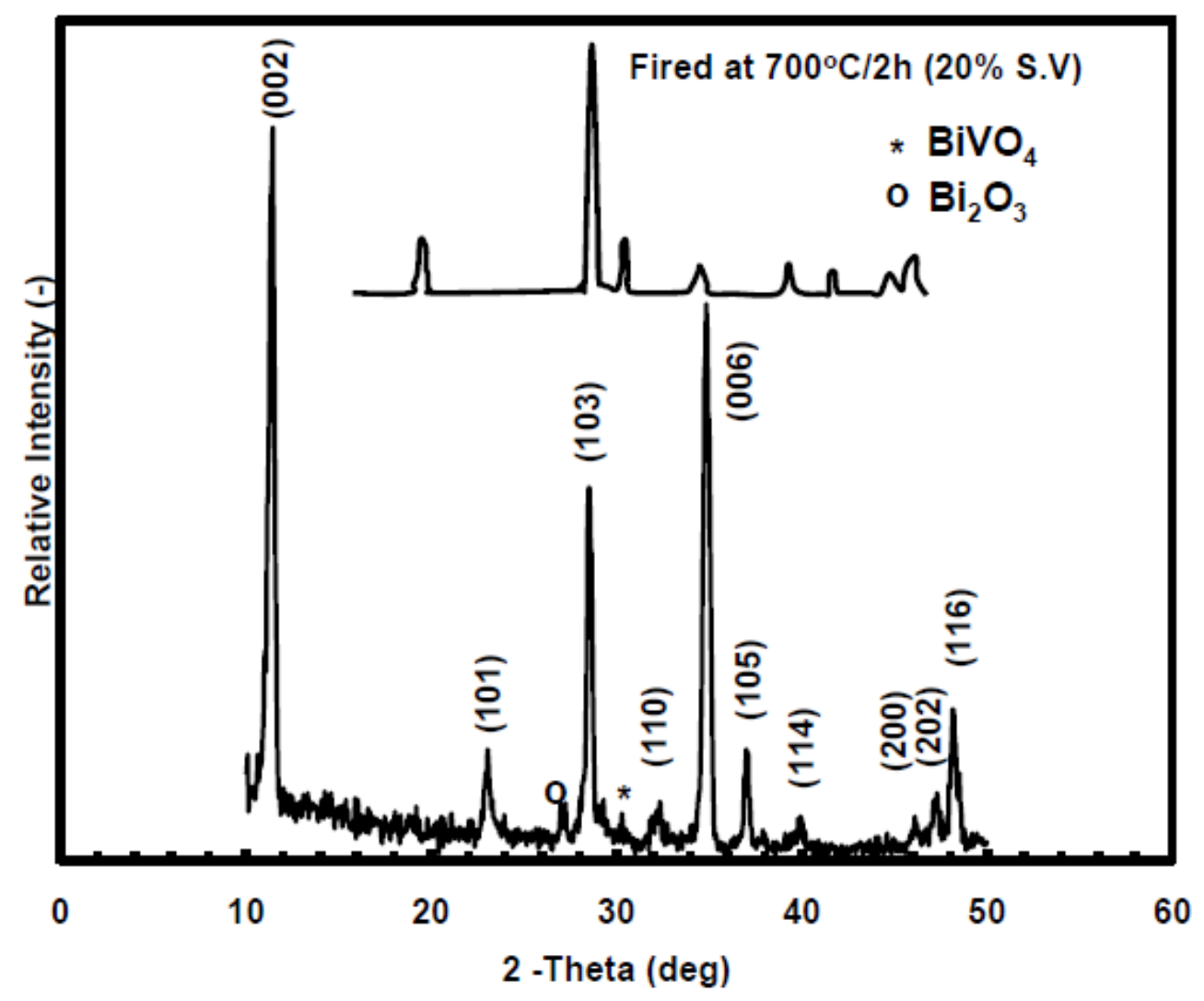

Figure 29: XRD pattern of the MSS BICUVOX powder treated at $700^{\circ} \mathrm{C} / 2 \mathrm{~h}(20 \% \mathrm{~S} . \mathrm{V})$. 


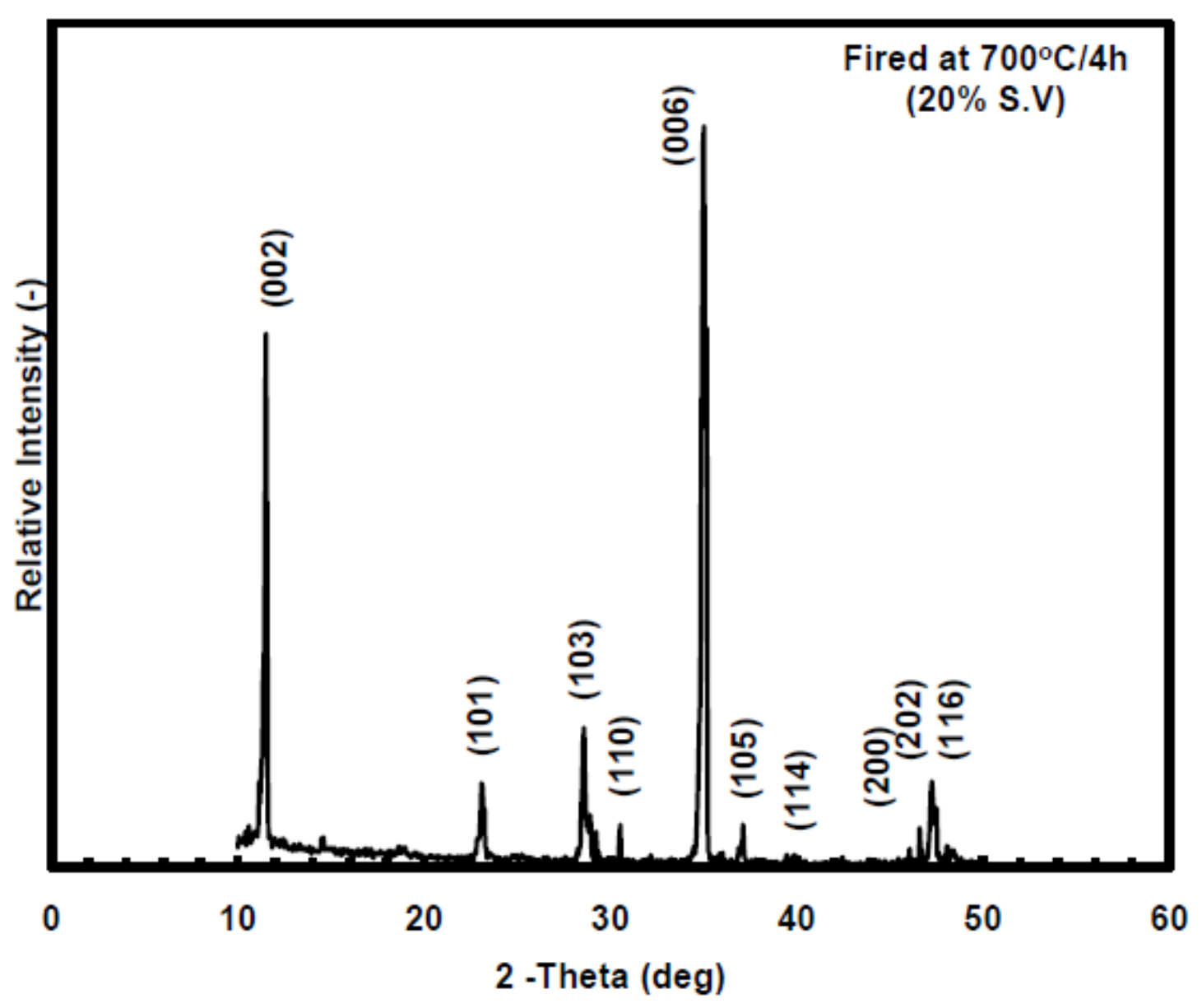

Figure 30: XRD pattern of the MSS BICUVOX powder treated at $700^{\circ} \mathrm{C} / 4 \mathrm{~h}(20 \% \mathrm{~S} . \mathrm{V})$

Ostwald ripening is the dominant mechanism in molten salt synthesis. Precipitation of dissolved oxide from molten salt will result in growth of particles. The $\{001\}$ crystallography plane in BICUVOX structure has a lower level of solid-liquid interfacial energy and this causes the growth of platelet particles in $<001>$ direction. Molten salt environment and increasing temperature have strong effects on increasing the solubility of oxide and diffusivity of components which directly speed up the particle growth [2]. 
Considering $700^{\circ} \mathrm{C} / 4 \mathrm{~h}$ treatment, increasing percentage of solid volume will decrease the size of particles while maintaining the morphology (comparison Fig. 27 (f) and (g)), but at the same temperature $\left(700^{\circ} \mathrm{C}\right)$, increasing time of treatment caused further growth of particles (Fig. 27, i).Needle-shaped particles appear for some conditions. Analysis of the needle-shaped particles was carried on by using energy dispersive X-ray (EDX) and samples were free of any trace of K, $\mathrm{Na}$ or $\mathrm{Cl}$. These could be referred to $\mathrm{Na}-\mathrm{V}$ or $\mathrm{K}-\mathrm{V}$, but washing process continued to $\mathrm{pH}<7$, which might washed $\mathrm{Na}$ and $\mathrm{K}$ out. They may have leached $\mathrm{Na}$, $\mathrm{K}$ out a left $\mathrm{VO}_{\mathrm{X}}$ skeleton.

\subsection{Conclusions}

Solid-state reaction (SSR), co-precipitation, and molten salt synthesis (MSS) methods were employed to synthesize BICUVOX powder. Co-precipitated powder showed finer particle size $(<1 \mu \mathrm{m})$ compared with SSR, and the BICUVOX phase was established at $500^{\circ} \mathrm{C} / 2 \mathrm{~h}$.The SSR powder needed calcination up to $750^{\circ} \mathrm{C} / 4 \mathrm{~h}$ in order to develop the BICUVOX phase. This increases the particle sizes to several hundred microns.

Molten Salt synthesis study was carried out by applying different solids loadings (20-30\%), and thermal treatments $\left(680-700^{\circ} \mathrm{C}\right)$. Development of BICUVOX phase was completed for the conditions $700^{\circ} \mathrm{C} / 4 \mathrm{~h}(20$ and $50 \%$ solids loadings). Increasing the solid loading up to $50 \%$ did not decrease the size of platelet particles. Also, sieving the powder using mesh 60 will improve the unity distribution of the round-shaped platelet particles, which can be used in tape casting to obtain high degree of texture. 


\section{CHAPTER 4: CONSOLIDATION AND DENSIFICATION}

\subsection{Objectives}

Consolidation and thermal processing are two of the most important factors which directly affect the microstructure and physical properties of a ceramics. Many aspects of the microstructure are controlled by these two factors.

Any nonuniformity during the consolidation processes will cause microstructural flaws such as cracklike voids, large pores, and nonuniform grain size at the end of firing process. Achievement of high density, small grain size and uniform microstructure are desired goals for the densification process, which needs sufficient attention for controlling of sintering time, temperature, atmosphere and heating rate [6].

The following will be discussed during this section:

Optimization of applied pressure for green body and its relationship with achieved density after firing process

$>$ Investigation of achieved density by controlling sintering time and temperature.

$>$ Effect of particle characteristics and thermal processing on grain growth kinetics.

Method of prevention of grain coarsening using Zener-pinning principle. 


\subsection{Powder Consolidation}

In order to determine the optimum pressure for pressing pellets, the relationship between green density and sintered density was studied using precipitated BICUVOX. This powder was precipitated, washed 3 times with IPA, dried at $85^{\circ} \mathrm{C}$, sieved using 60 -mesh, calcined at $500^{\circ} \mathrm{C} / 2 \mathrm{~h}$, and ball milled for 24 hours in Ethanol. $13 \mathrm{~mm}\left(1 / 2^{\prime \prime}\right)$ diameter (ID) hardened steel dry pressing die was used for pellet presses in cylinder-shape. 0.72 gram of precipitated BICUVOX was used to prepare circular pellets by using uniaxial pressing at the pressure between 35-275 MPa. All pellets were loaded into an alumina crucible and sintering was carried out in air at $625^{\circ} \mathrm{C}$ for 8 hours with a heating rate of $3^{\circ} \mathrm{C} / \mathrm{min}$ and then the temperature (heating rate of $26^{\circ} \mathrm{C} / \mathrm{min}$ ) was increased to $650^{\circ} \mathrm{C}$ (without holding) and cooled down immediately. Two steps sintering process was applied in order to prevent the grain growth and de-densification that might happen at higher sintering temperatures and longer dwelling times.

\subsubsection{Results}

Figure 31 shows the relationship between applied pressure versus obtained bulk density after completion of sintering process. (Archimedes's method was used to measure the density after sintering). 


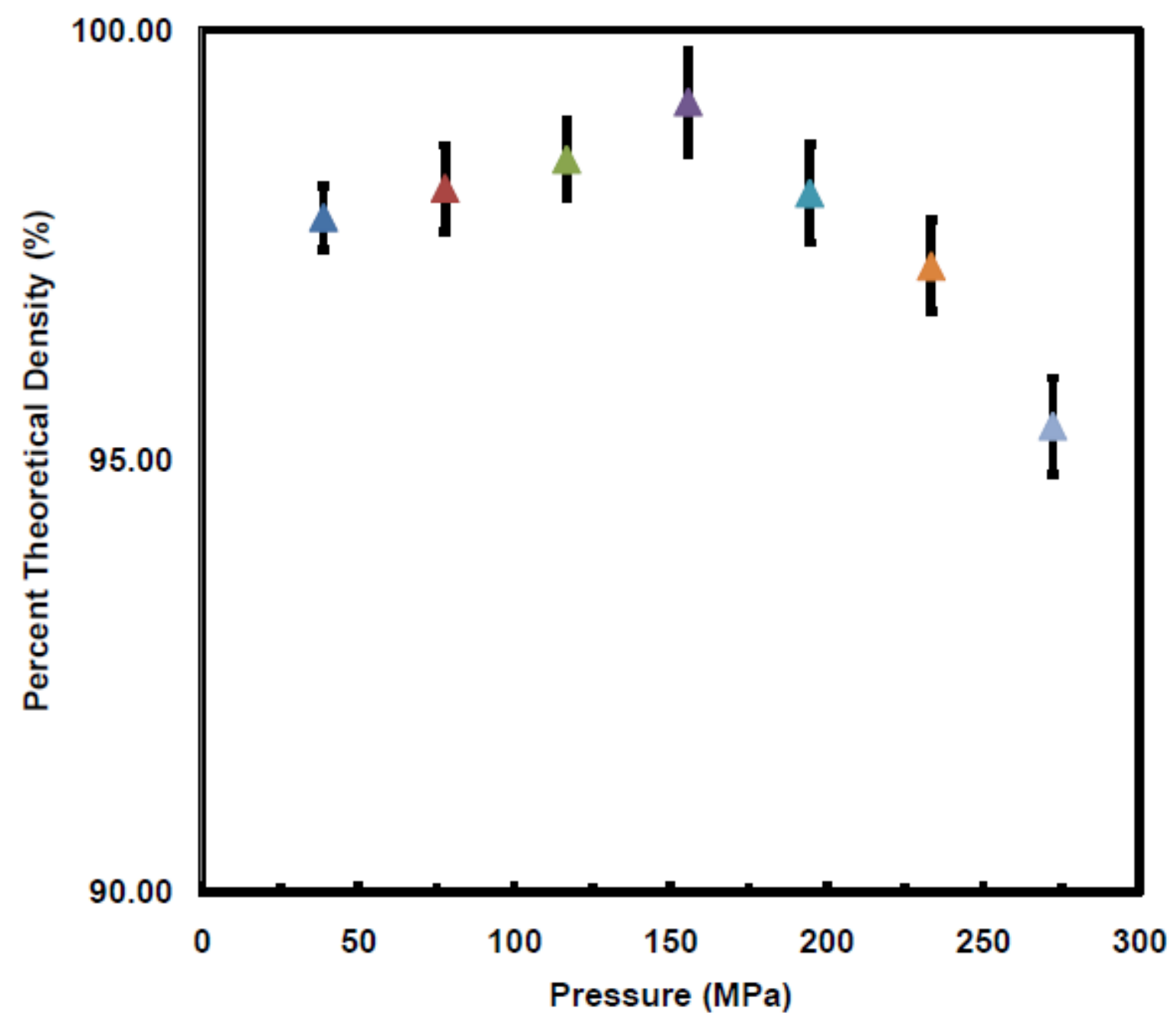

Figure 31: Effect of employed pressure during consolidation process on density of BICUVOX after sintering.

As is shown in Figure 31, the highest density was obtained for the samples pressed at 138 MPa. This pressure (138 MPa) will be used as the optimum pressing condition pellets during the entire sintering study. 
Reduction in density for those green pellets pressed at the pressures higher than $138 \mathrm{MPa}$ can be attributed to pressure and density gradient caused by uniaxial press. Uniaxial pressure $P_{z}$ causes varying radial and sheer stresses $\left(\mathrm{P}_{\mathrm{r}}\right.$ and $\left.\tau\right)$ at the die walls, which will be lead to a nonuniform resultant stress within the green body [6].

\subsection{Sintering}

In order to determine the optimum sintering condition, green samples were pressed at the obtained optimum pressure $(155 \mathrm{MPa})$ and were sintered at temperature and time ranging between of 625 to $800^{\circ} \mathrm{C}$ and $0 \mathrm{~min}$ to $8 \mathrm{~h}$, in air (Table 4).

\subsubsection{Results}

As it is shown in Table 4, those pellets sintered at the temperatures range from $675^{\circ} \mathrm{C}$ to $800^{\circ} \mathrm{C}$ for 30 minutes to 1 hour represent densities as high as 96 to $98 \%$ of theoretical density $(7.84 \mathrm{~g} /$

$\mathrm{cm}^{3}$ ). Therefore, the mentioned sintering conditions can be considered to be the optimum for fabricating pellets with high density. 
Table 4: Density data and standard deviation of all sintering conditions

\begin{tabular}{c|c|c|c|c|c|c}
\hline $\begin{array}{c}\text { Time (h) / } \\
\begin{array}{c}\text { Temperature } \\
\left({ }^{\circ} \mathbf{C}\right)\end{array}\end{array}$ & $\mathbf{0}$ & $\mathbf{0 . 5}$ & $\mathbf{1}$ & $\mathbf{2}$ & $\mathbf{4}$ & $\mathbf{8}$ \\
\hline $\mathbf{6 2 5}$ & 79.87 & 91.10 & 94.66 & 92.95 & 92.4 & 95.55 \\
\hline STDEV & 1.32 & 0.87 & 0.34 & 0.37 & 1.64 & 1.00 \\
\hline $\mathbf{6 5 0}$ & 85.02 & 95.32 & 95.64 & 94.85 & 96.6 & 96.11 \\
\hline STDEV & 0.28 & 0.11 & 0.66 & 0.57 & 0.81 & 1.04 \\
\hline $\mathbf{6 7 5}$ & 90.73 & 97.77 & 96.85 & 95.66 & 95.75 & 95.78 \\
\hline STDEV & 0.95 & 1.08 & 0.31 & 0.16 & 0.21 & 0.25 \\
\hline $\mathbf{7 0 0}$ & 94.61 & 96.48 & 98.5 & 97.75 & 96.51 & 94.62 \\
\hline STDEV & 0.20 & 0.25 & 0.72 & 0.14 & 0.32 & 0.33 \\
\hline $\mathbf{7 5 0}$ & 96.98 & 98.21 & 95.96 & 95.51 & 96.55 & 96.5 \\
\hline STDEV & 0.98 & 0.30 & 0.94 & 1.42 & 0.23 & 0.16 \\
\hline $\mathbf{8 0 0}$ & 96.09 & 96.75 & 97.09 & 95.84 & 96.1 & 93.28 \\
\hline STDEV & 0.57 & 1.36 & 0.41 & 0.74 & 0.60 & 0.51 \\
\hline
\end{tabular}

Conditions $650^{\circ} \mathrm{C} / 30$ min and $620^{\circ} \mathrm{C} / 4 \mathrm{~h}$ show the lowest and highest standard deviation, respectively. No specific trend in changing standard deviation was observed at sintering conditions were changed. Densification appears to be complete at $675-800^{\circ} \mathrm{C}$ for dwell $<2 \mathrm{~h}$. Increasing sintering dwell time $(>1 \mathrm{~h})$ resulted in de-densification Figure 32. 


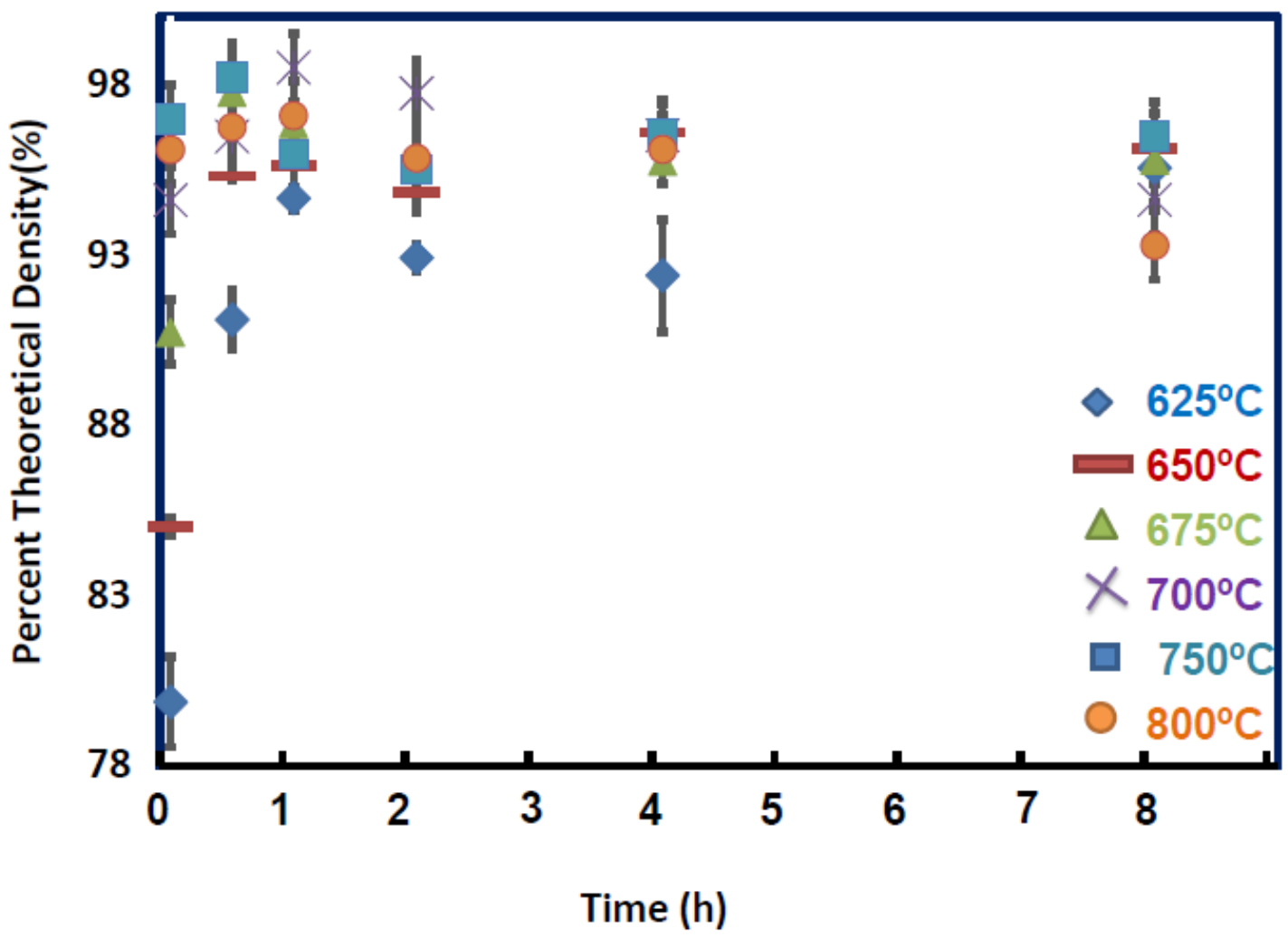

Figure 32: Densification characterization of BICUVOX related to time and temperature

No paper has reported achieving such high densities at these short dwelling times. This is attributed to applied powder synthesis method (co-precipitation), which resulted in synthesis of submicron particle sizes. Smaller particle sizes have a higher surface area, which can provide a strong thermodynamic driving force for sintering.

Table 5 compares the obtained density data with other works. As it is shown, at the same sintering condition, some work has reported similar density. However, these samples have larger grain size $(>5-10 \mu \mathrm{m})$ and have lower mechanical strength (This will be discussed in the next section). 
Table 5: Comparison of sintering conditions and achieved density data with repeated works

\begin{tabular}{c|c|c}
\hline Sintering Condition & \multicolumn{1}{c}{$\begin{array}{c}\text { Density } \\
\left(\mathbf{g} / \mathbf{c m}^{3}\right)\end{array}$} & Ref \\
\hline $675^{\circ} \mathrm{C} / 1 \mathrm{~h}$ & 96.85 & This work \\
\hline $750^{\circ} \mathrm{C} / 1 \mathrm{~h}$ & 96 & This work \\
\hline $750^{\circ} \mathrm{C} / 1 \mathrm{~h}$ & 97 & {$[36]$} \\
\hline $750^{\circ} \mathrm{C} / 4 \mathrm{~h}$ & 96.55 & This work \\
\hline $750^{\circ} \mathrm{C} / 4 \mathrm{~h}$ & 95 & {$[40]$} \\
\hline $730-750^{\circ} \mathrm{C} / 5-10 \mathrm{~h}$ & 95 & {$[1]$} \\
\hline $770^{\circ} \mathrm{C} / 5 \mathrm{~h}$ & 95 & {$[41]$} \\
\hline $793^{\circ} \mathrm{C} / 5 \mathrm{~h}$ & 90 & {$[42]$} \\
\hline $800^{\circ} \mathrm{C} / 0 \mathrm{~min}$ & 96.09 & This work \\
\hline $813^{\circ} \mathrm{C} / 15 \mathrm{~min}$ & 90 & {$[42]$} \\
\hline $800^{\circ} \mathrm{C} / 0 \mathrm{~min}-10 \mathrm{~h}$ & 95 & {$[37]$} \\
\hline
\end{tabular}

Obtained cross section SEM pictures from pellets sintered at $625^{\circ} \mathrm{C}$ and $650^{\circ} \mathrm{C}$, show the completion of the sintering process and removal of intergranular porosities (Figure 33). Grain growth also can be observed as the sintering time increases from 2 hours to 8 hours. All sintered samples were polished with $\mathrm{SiC}$ sand paper (started from 320 grit up to grade 1200) followed by fine diamond paste (diamond grain of 7 down to $1 \mu \mathrm{m}$ in diameter). In order to expose grain boundaries, different etching conditions were applied for each sintering temperature. 

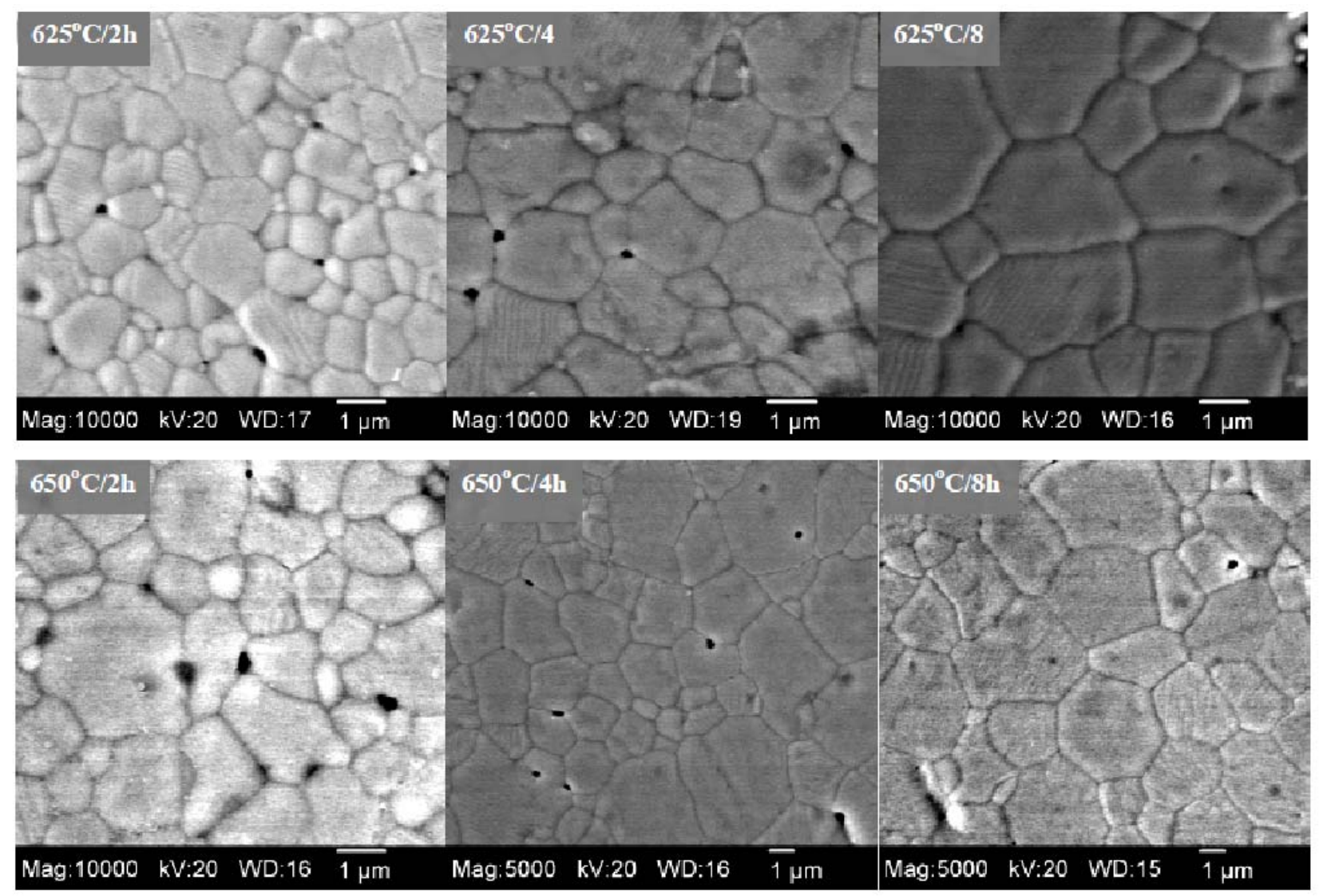

Figure 33: SEM pictures of sintered samples at $625^{\circ} \mathrm{C}$ and $650^{\circ} \mathrm{C}$ for $2 \mathrm{~h}, 4 \mathrm{~h}$, and $8 \mathrm{~h}$.

As the sintering condition shifts to higher temperatures, time for removing porosities within the microstructure reduces, which makes them intragranular porosity (Figure 34 ). This represents high mobility of grain boundary that entraps the intergranular pores located on grain boundaries. 

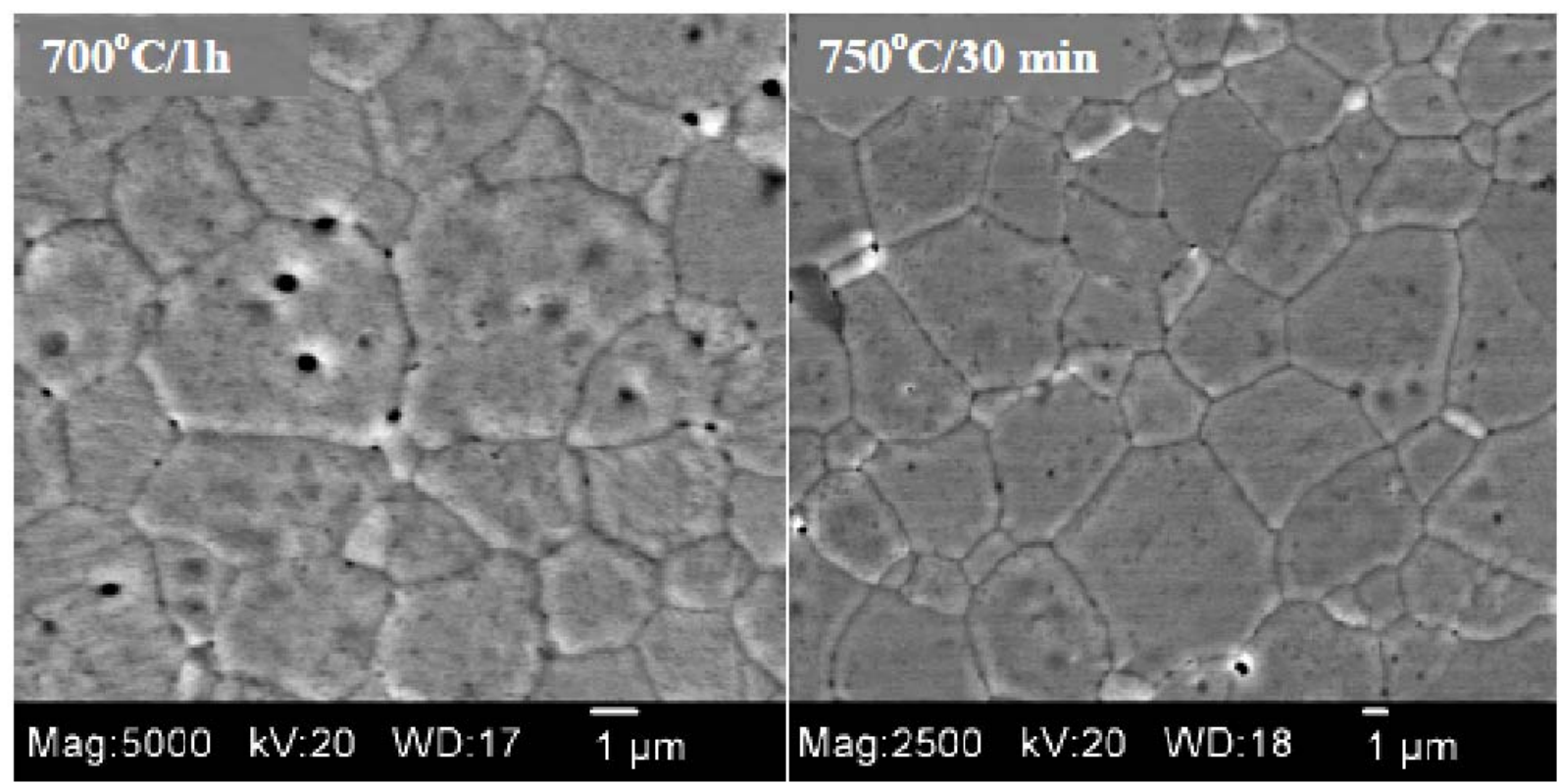

Figure 34: SEM pictures of sintered samples at $700^{\circ} \mathrm{C} / 1 \mathrm{~h}$ and $750^{\circ} \mathrm{C} / 30 \mathrm{~min}$

The circle-shape black holes that are shown in Figure 34 represent the trapped porosities within the microstructure of samples. This usually happens at higher temperatures when the rate of grain growth is much higher than the rate of porosity removal.

Sub-micron BICUVOX particles, synthesized by co-precipitation method, shows higher surface area compared to solid state reaction one, therefore it increases the rate of reagent conversion and sintering will be completed at lower temperature and shorter times [43]. Submicron BICUVOX particles provide huge driving force and kinetic for the densification process, which allow densification to be complete up to $80-96 \%$ of theoretical density only during the heating process (Table 4,conditions $625-800^{\circ} \mathrm{C} / 0 \mathrm{~h}$ ). 


\subsection{Grain Growth study of BICUVOX Samples}

Investigation of microstructure properties was carried out by polishing and thermal etching. All sintered samples were polished with SiC sand paper (started from 320 grit up to grade 1200) followed by fine diamond paste (diamond grain of 7 down to $1 \mu \mathrm{m}$ in diameter). In order to expose grain boundaries, different etching conditions were applied for each sintering temperature.

\subsubsection{Results}

Table 6 displays thermal etching conditions for all sintering conditions. SEM pictures of all the sintering condition were obtained after etching process was completed. 
Table 6: Etching profile for different sintering conditions

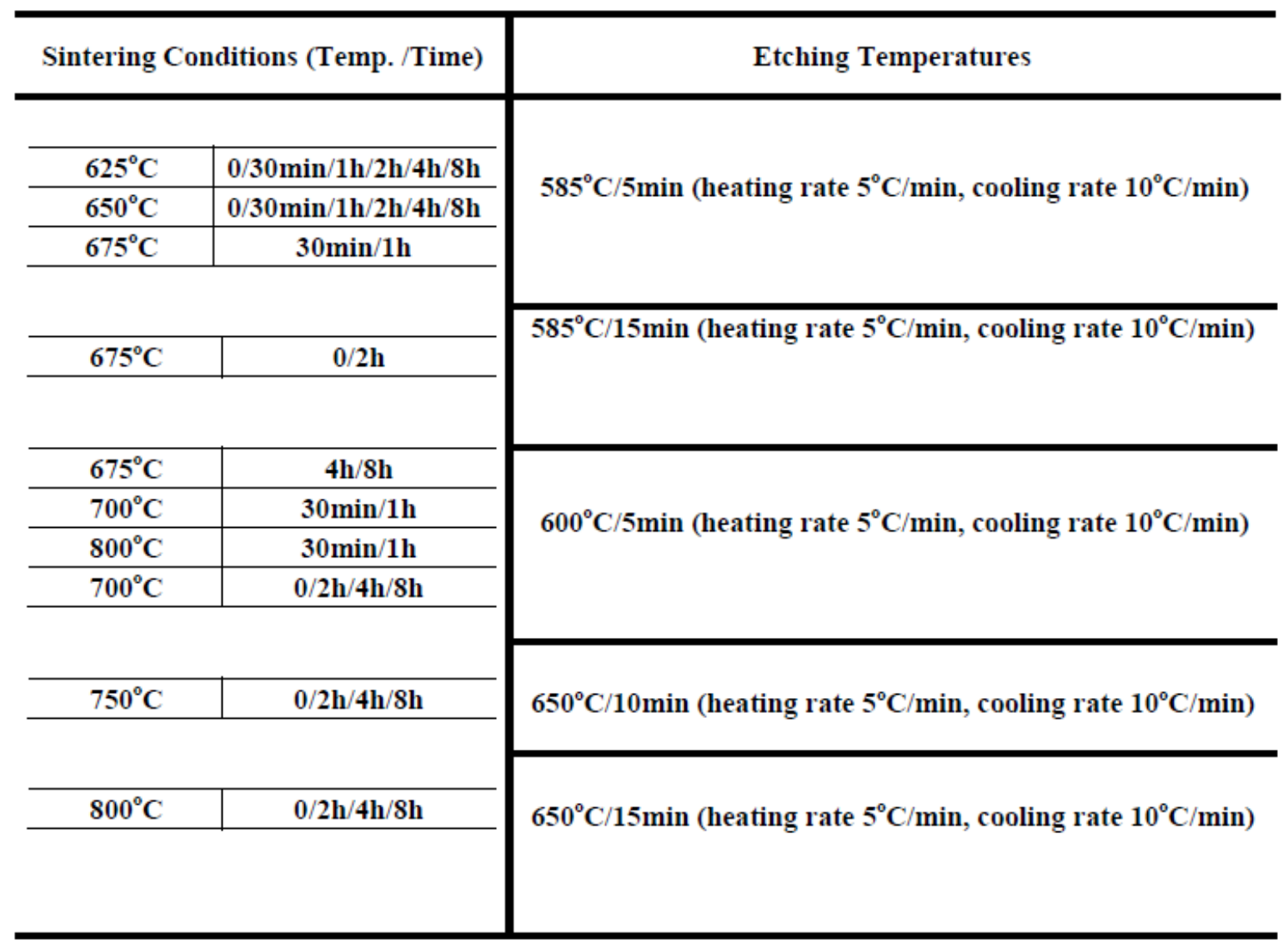

Surface analysis software tool (ImageJ) was used to calculate the average of grain size for micrograph SEM pictures obtained from each of the sintering condition (Figure 35, the error bars are not shown). In image analysis, numerical data is extracted from an image. In order to obtain more accurate data, grains that are not shown completely at the edges of the images, have been excluded from final calculation, otherwise the program detects a very large grain instead of several small ones in a certain area [44]. This was done using " exclude on edges option" in ImageJ software. Before using the software, it is necessary to circle grains by hand for the program to function and recongnise grains. 


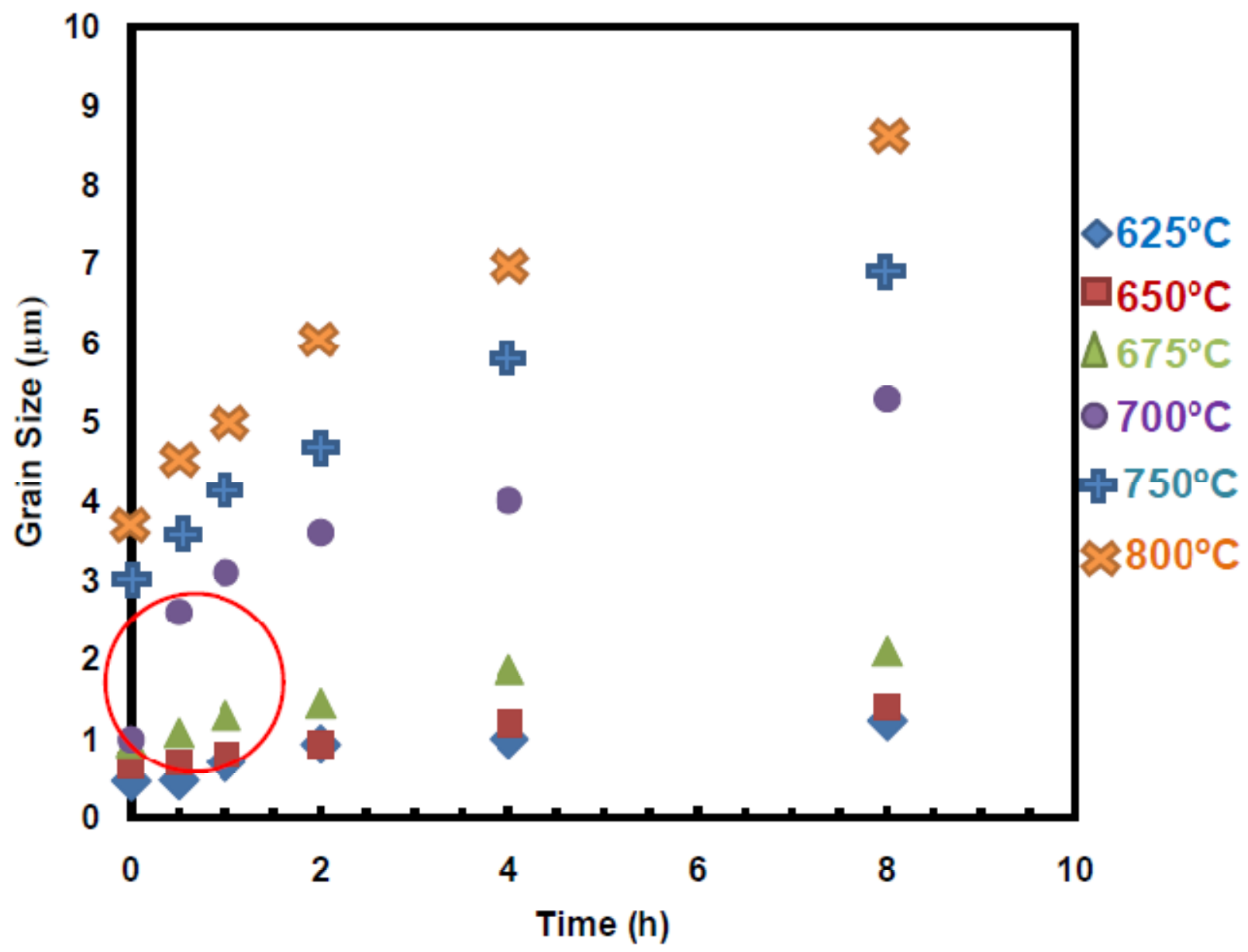

Figure 35: Effects of sintering time and temperature on BICUVOX grain size

The circled data points in Figure 35 represent the area that has shown some of the highest density during the sintering process $(94-98.21 \%)$. This area is suggested for fabrication of the high efficient BICUVOX electrolyte (high density) that presents a high mechanical property (small grain size).

Effects of time and temperature on grain size and density were studied by taking the microstructure pictures of etched samples using scanning electron microscope (SEM). Figure 36 and Figure 37 compare obtained densities and grain sizes from different sintering conditions. 


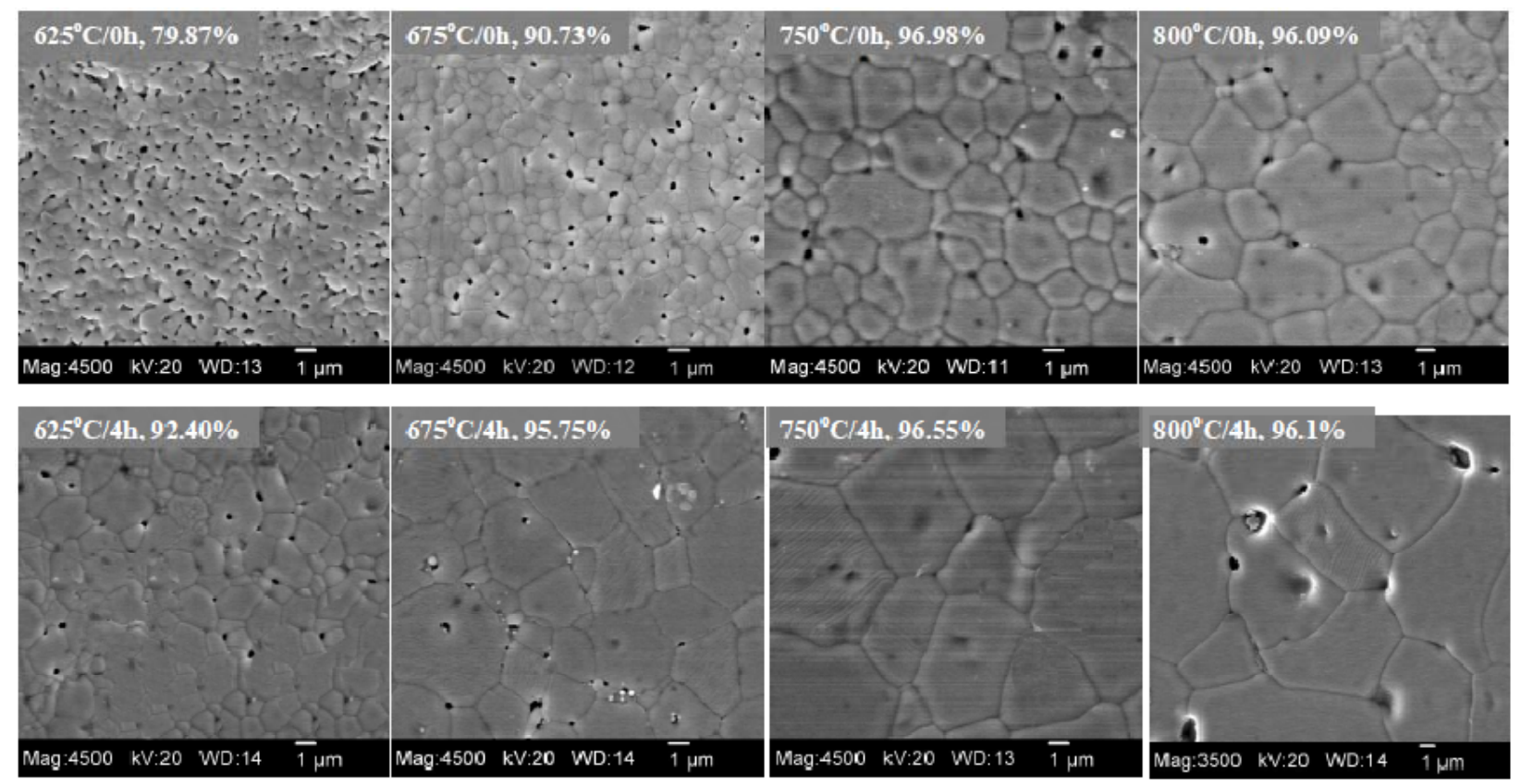

Figure 36: SEM pictures of sintered sample at $625^{\circ} \mathrm{C}, 675^{\circ} \mathrm{C}, 750^{\circ} \mathrm{C}$ and $800^{\circ} \mathrm{C}$ for $0 \mathrm{~h}$ and $4 \mathrm{~h}$.

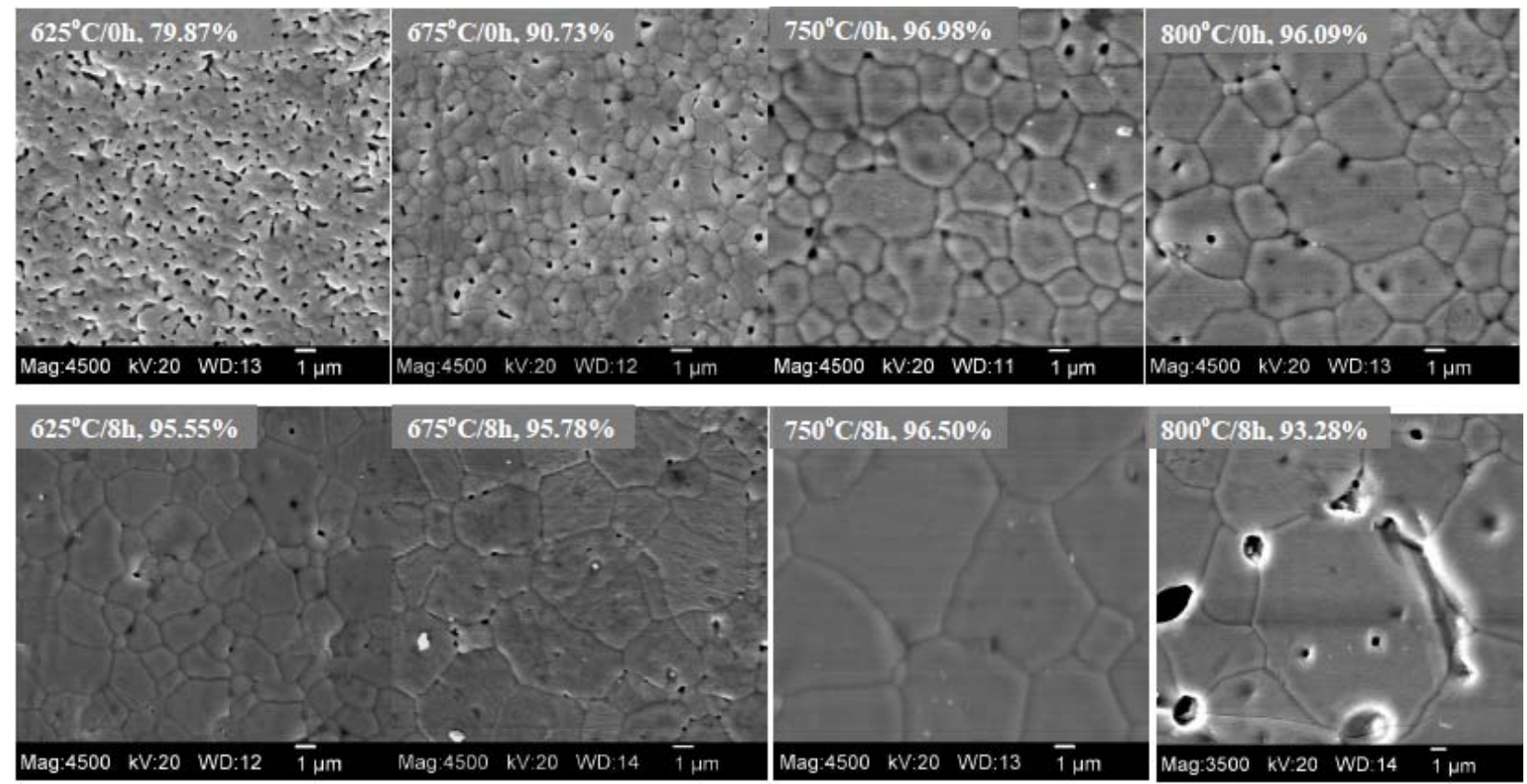

Figure 37: SEM pictures of sintered sample at $625^{\circ} \mathrm{C}, 675^{\circ} \mathrm{C}, 750^{\circ} \mathrm{C}$ and $800^{\circ} \mathrm{C}$ for $0 \mathrm{~h}$ and $8 \mathrm{~h}$. 
The trend of densification and grain growth processes can be seen in Figure 36 and Figure 37. Increasing time and temperature to 2 hours and $700^{\circ} \mathrm{C}$ will improve the density of the samples. Increasing sintering time and temperature causes grain growth for all the conditions, but grain growth and grain size distribution accelerate at $\left(>675^{\circ} \mathrm{C}\right)$. This is due to the phase transformation for the sintering conditions above $660^{\circ} \mathrm{C}$ (Figure 38). Kinetic of grain growth accelerates above eutectic point due to liquid phase sintering, which provides a nice diffusion for materials. Therefore, grain boundary diffusion is the dominant mechanism at temperature above $675^{\circ} \mathrm{C}$.

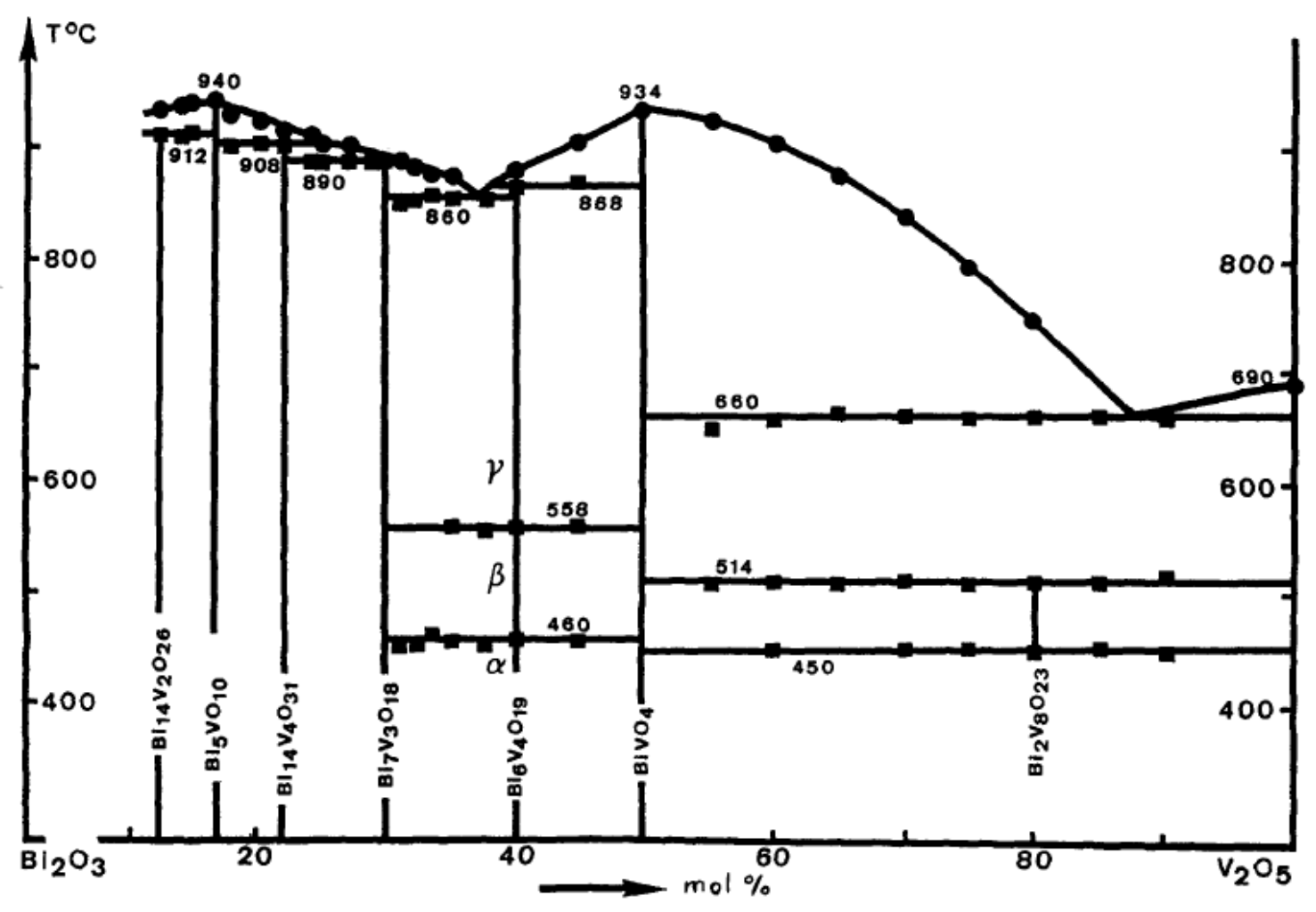

Figure 38 : Phase diagram of the system $\mathrm{Bi}_{2} \mathrm{O}_{3}-\mathrm{V}_{2} \mathrm{O}_{5}[45]$. 
Equation 6 was employed to investigate the change in grain growth mechanism above eutectic point $\left(>660^{\circ}\right)[6]$ :

$$
\mathrm{G}^{\mathrm{n}}-\mathrm{G}_{0}^{\mathrm{n}}=\mathrm{kt}
$$

where $\mathrm{G}$ is the grain size, $\mathrm{k}$ is the temperature dependent growth factor, $\mathrm{t}$ is the sintering time, and $\mathrm{n}$ is the exponent that depends on the mechanism of the sintering. The $\mathrm{n}$ value can be calculated from the slope of $\log$ (grain size) versus $\log$ (time) plot and is equal to $(1 / \mathrm{n})$. The grain size data obtained from isothermal sintering conditions (Figure 35) were used to calculate the $n$ values using linear regression method.

Fitting model for sintering conditions displays the $\mathrm{n}$ coefficient changes $\left(>675^{\circ} \mathrm{C}\right)$ as temperature goes above eutectic point, which means the sintering mechanism changes above eutectic point. This proves that grain boundary diffusion $(n=4)$ is the dominating mechanism transport above eutectic point for grain growth (Figure 39). 


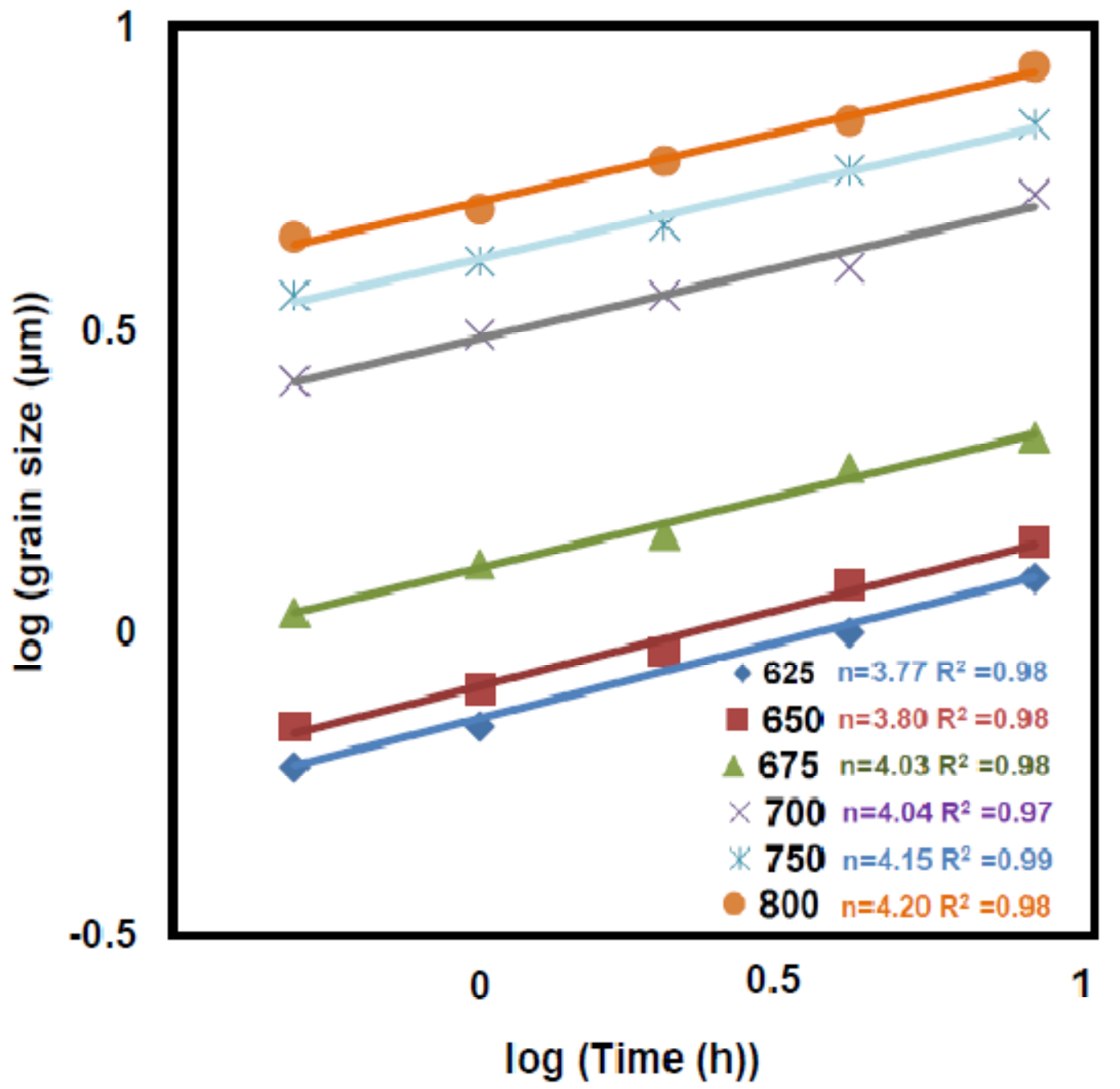

Figure 39: Determination of sintering mechanism at different temperatures

The activation energy can be calculated from the linear relationship of $\mathrm{T}^{-1}$ versus $\ln \left(\mathrm{d}_{\mathrm{g}}{ }^{4} \cdot \mathrm{t}^{-1}\right)$ Figure 40 [46], where $\left(\mathrm{d}_{\mathrm{g}}\right)$ is the grain size and the exponent $(\mathrm{n}=4)$ depends on the sintering mechanism. 


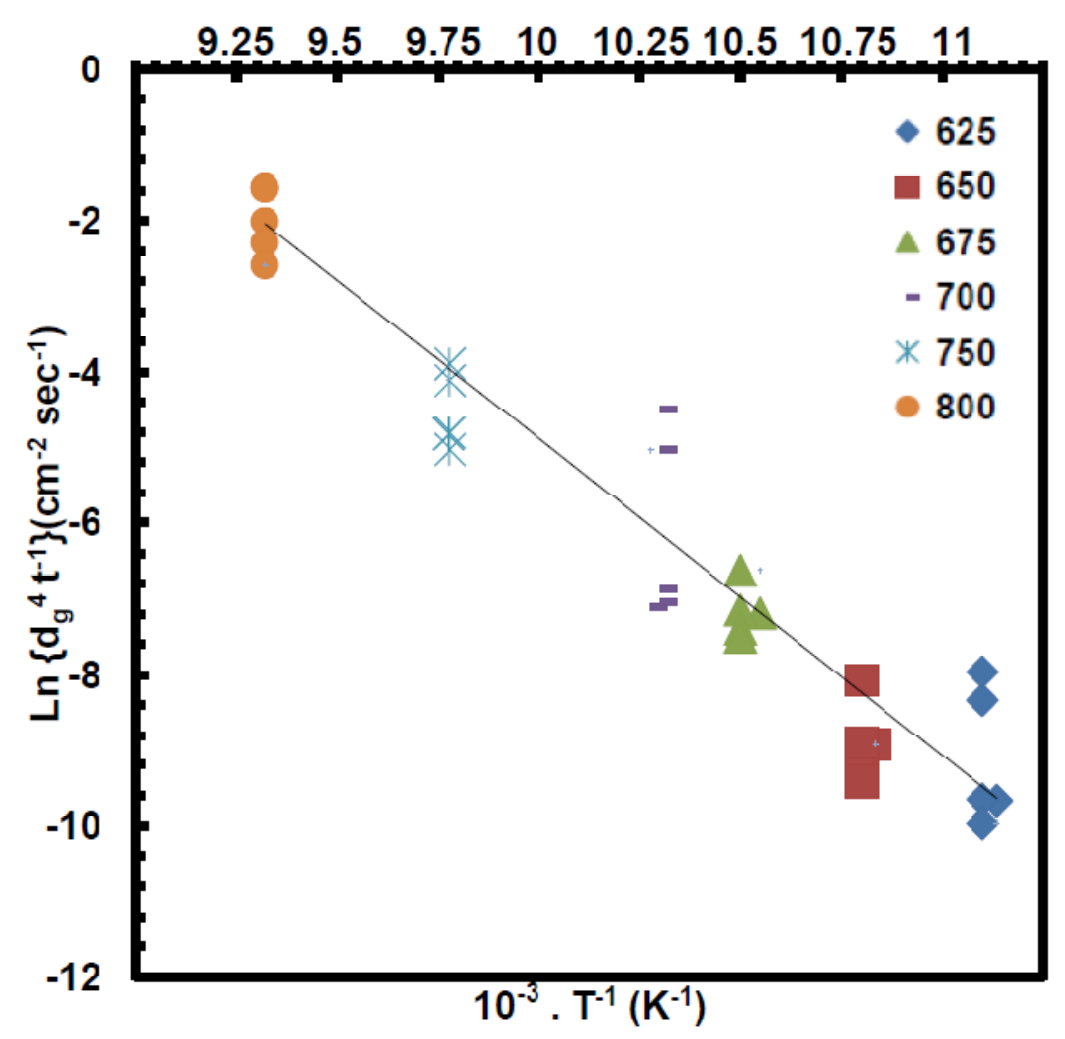

Figure 40: A linear fit to the curve in the plot of $10 \times \mathrm{T}^{-1}$ vs. $\ln \left(\mathrm{d}_{\mathrm{g}}^{-1} \times \mathrm{t}^{-1}\right)$

The activation energy is determined from the slope of the linear relationship of $\mathrm{T}^{-1}$ versus $\ln$ $\left(\mathrm{dg}^{4} \cdot \mathrm{t}^{-1}\right)$, which equals $\left\{-\mathrm{Q} \times R^{-1}\right\}$, and it is calculated using Eq. 7.

$$
Q=-R \times \partial\left[\ln \left(d_{g}^{4} \times t^{-1}\right) \times \partial\left[T^{-1}\right]^{-1}\right.
$$

where $\mathrm{Q}$ is the activation energy, and $\mathrm{R}$ the molar gas constant $\left(8.314 \mathrm{~J} \mathrm{~mol}^{-1} \mathrm{~K}^{-1}\right)$. The obtained activation energy equals $0.36 \mathrm{eV}$ atom $^{-1}\left(34.82 \mathrm{~kJ} \mathrm{~mol}^{-1}\right)$. 
No activation energy for grain growth of BICUVOX has been reported in literatures. Won et al [47] have shown the activation energy for grain growth of nanocrystals Aurivillius phase $\mathrm{Bi}_{5} \mathrm{Ti}_{3} \mathrm{FeO}_{15}\left(2.61 \mathrm{~kJ} \cdot \mathrm{mol}^{-1}\right)$ is much lower than that formed by the SSR method $\left(10.9 \mathrm{~kJ} \cdot \mathrm{mol}^{-1}\right)$.

Table 7 compares the obtained density and grain size achieved by this work and other researchers.

Table 7: Comparison of obtained density and grain size with other sintering work

\begin{tabular}{|c|c|c|c|}
\hline Sintering Condition & $\begin{array}{l}\text { Avg. } \\
\text { density } \\
\left(\mathrm{g} / \mathrm{cm}^{3}\right)\end{array}$ & $\begin{array}{c}\text { Avg. } \\
\text { Grain } \\
\text { Size } \\
(\mu \mathrm{m}) \\
\end{array}$ & Ref \\
\hline $675^{\circ} \mathrm{C} / 1 \mathrm{~h}$ & 96.85 & 1.29 & This work \\
\hline $750^{\circ} \mathrm{C} / 1 \mathrm{~h}$ & 96 & 2.32 & This work \\
\hline $750^{\circ} \mathrm{C} / 1 \mathrm{~h}$ & 97 & 10 & {$[36]$} \\
\hline $750^{\circ} \mathrm{C} / 4 \mathrm{~h}$ & 96.55 & 4.14 & This work \\
\hline $\begin{array}{c}750^{\circ} \mathrm{C} / 4 \mathrm{~h}(0.6 \% \\
\text { GDC }\end{array}$ & 98.27 & 2.51 & This work \\
\hline $750^{\circ} \mathrm{C} / 4 \mathrm{~h}$ & 95 & $7-10$ & [48] \\
\hline $770^{\circ} \mathrm{C} / 5 \mathrm{~h}$ & 95 & 4.3 & [49] \\
\hline $730-750^{\circ} \mathrm{C} / 5-10 \mathrm{~h}$ & 95 & 10 & {$[1]$} \\
\hline $800^{\circ} \mathrm{C} / 0 \mathrm{~min}$ & 96.09 & 3.72 & This work \\
\hline $\begin{array}{c}800^{\circ} \mathrm{C} / 4 \mathrm{~h}(0.6 \% \\
\text { GDC }\end{array}$ & 97.12 & 1.88 & This work \\
\hline $813^{\circ} \mathrm{C} / 15 \mathrm{~min}$ & 90 & 7 & [50] \\
\hline $800^{\circ} \mathrm{C} / 0 \mathrm{~min}-10 \mathrm{~h}$ & 95 & $5-8$ & [37] \\
\hline
\end{tabular}




\subsection{Control of Grain Growth through Boundary Pinning (Zenner Pinning)}

Nano-sized GDC $\left(\mathrm{Ce}_{0.90} \mathrm{Gd}_{0.10} \mathrm{O}_{1.95)}\right.$, obtained from a hydrothermal synthesis process (HT), was added in different $(0.2$ to $8 \mathrm{wt} \%)$ to weighed amount of BICUVOX powder. Solvent (basic $\mathrm{H}_{2} \mathrm{O}, \mathrm{pH}=1$ ) of the hydrothermal (HT) product has to be exchanged to isopropanol (IPA) before BICUVOX and GDC are mixed. It is assumed that the hydrothermal product remains in a solvent to maintain dispersion. HT GDC in IPA solvent is added to BICUVOX powder which are then ball milled in IPA for 12 hours. GDC/BICUVOX suspension was dried in an oven at $85^{\circ} \mathrm{C}$ and sieved through $60-$ mesh. For each of the sintering conditions, 0.2070 gram of GDC/BICUVOX powder was used to prepare circular pellets $(6.35 \mathrm{~mm}$ in diameter) by using uniaxial pressing at the pressure $155 \mathrm{MPa}$ (53-55 \% theoretical density). Prepared pellets were loaded in an alumina crucible and sintering was carried on in air at $675,700,750$ and $800^{\circ} \mathrm{C}$ for 4 hours with a heating and cooling rate of 3 and $5^{\circ} \mathrm{C} / \mathrm{min}$, respectively.

\subsubsection{Synthesis of Gadolinium Doped Ceria (GDC, $\mathrm{Ce}_{0.90} \mathbf{G d}_{\mathbf{0 . 1 0}} \mathbf{O}_{1.95}$ ) by Hydrothermal Method}

The precursor for the hydrothermal process was synthesized by co-precipitation.Cerium (IV) Ammonium nitrate $\left(\left(\mathrm{NH}_{4}\right)_{2} \mathrm{Ce}\left(\mathrm{NO}_{3}\right)_{6}, 98 \%\right.$ Alfa Aesar) was dissolved into $79.12 \mathrm{ml} \mathrm{H}_{2} \mathrm{O}$; and $10 \mathrm{wt} \%$ gadolinium (III) carbonate hydrate $\left(\mathrm{Gd}_{2}\left(\mathrm{CO}_{3}\right)_{3} \cdot \mathrm{xH}_{2} \mathrm{O}, 99.99 \%\right.$ Alfa Aesar) was dissolved into aqueous solutions of $120 \mathrm{ml} \mathrm{H} \mathrm{H}_{2} \mathrm{O}$ and 95 gram of $\mathrm{HNO}_{3}$. Aqueous solution of cerium nitrate was added to acidic solution of gadolinium. 
The final mixture was titrated to a basic solution of 198 gram $\mathrm{H}_{2} \mathrm{O}$ and 726 gram of tetramethylammonium hydroxide $\left(\left(\mathrm{CH}_{3}\right)_{4} \mathrm{NOH}, 25 \% \mathrm{wt} / \mathrm{w}\right.$ aqueous solution Alfa Aesar) (while the solution was continuously being stirred and $\mathrm{pH}$ kept above 6). The final product was washed with isopropanol until the conductivity of the solution reduced to $8 \mathrm{mS} / \mathrm{cm}$. The final gel was dried in an oven at $85^{\circ} \mathrm{C}$. The final powder was crushed by a mortar and pestle and sieved by using 60-mesh then calcined at $800^{\circ} \mathrm{C}$ for $4 \mathrm{~h}$.

The hydrothermal process using an Autoclave Engineers $300 \mathrm{ml}$. EZE-Seal Stirred Reactor was used to synthesize the GDC nano particles. Aqueous slurry prepared by dispersing 200 grams of co-precipitated GDC powder into $\mathrm{H}_{2} \mathrm{O}$ (deionized water) and $\mathrm{pH}$ was adjusted above 10 by using ammonium hydroxide $(\mathrm{NH} 4 \mathrm{OH})$. Nitrogen was purged through reactor to remove air $(2$ minutes at $5 \mathrm{psi}$ ). The prepared solution was heated up at the rate of $3^{\circ} \mathrm{C} / \mathrm{min}$ to $240^{\circ} \mathrm{C} / 1 \mathrm{~h}$ and cooled down at the rate of $5^{\circ} \mathrm{C} / \mathrm{min}$.

X-ray diffraction (XRD) analysis was used to confirm the phase purity of obtained GDC powder after further calcination at $800^{\circ} \mathrm{C} / 4 \mathrm{~h}$ (Figure 41). The BET surface area test and a Transmission Electron Microscope (TEM) were used to confirm synthesis of nano GDC powder by hydrothermal method (Figure 42). The X-ray diffraction pattern is consistent with the one reported by Chourashiya et al. [51], and it confirms the calcination condition $\left(800^{\circ} \mathrm{C} / 4\right)$ for synthesis of GDC (Figure 41). Surface area measurement data (BET), shows a very high surface area for the hydrothermal GDC $\left(180 \mathrm{~m}^{2} / \mathrm{g}\right)$.TEM image (Figure 42$)$ of the powder particles confirms the synthesis of nano size GDC powder by hydrothermal method. 


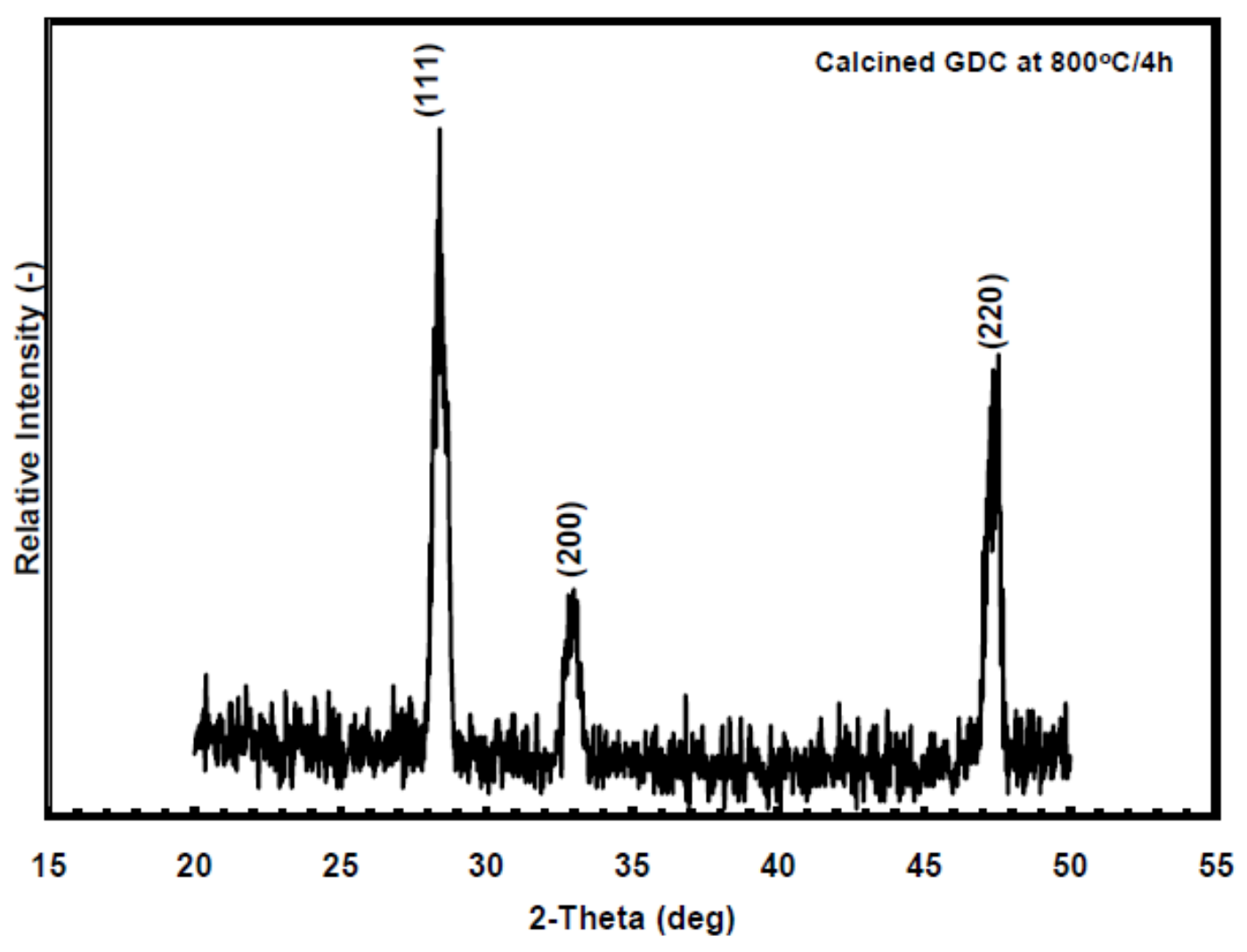

Figure 41: XRD pattern of the calcined GDC at $800^{\circ} \mathrm{C}$ for $4 \mathrm{~h}$

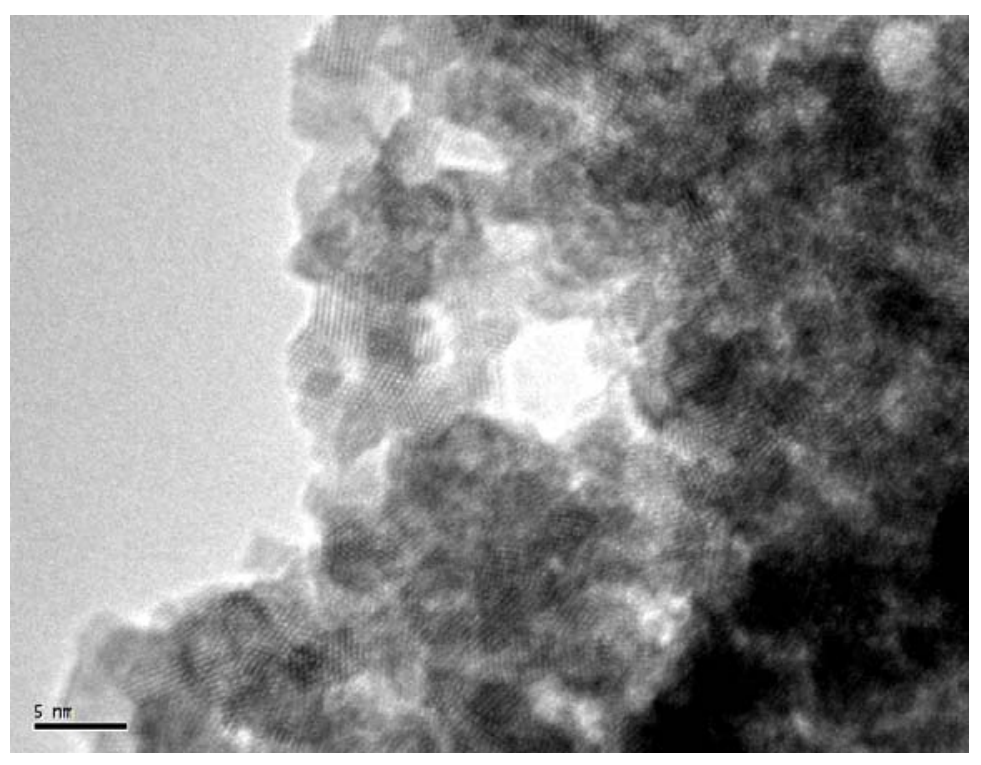

Figure 42: TEM image of the GDC powder prepared by hydrothermal method 
Figure 43 exhibits density dependence on temperature and the effects of nano GDC addition on density improvement. As is shown, at the temperature range from $675^{\circ} \mathrm{C}$ to $750^{\circ} \mathrm{C}$, increasing the weight percent of GDC to BICUVOX matrix (up to $0.6 \mathrm{wt} \%$ ) improves the density. Further GDC addition (more than $0.6 \mathrm{wt} \%$ ) will cause de-densification and reduces the density. As the temperature increases and reaches $800^{\circ} \mathrm{C}$, a higher concentration of GDC $(2 \%)$ is needed to improve the density to about $99 \%$ theoretical density $\left(\rho_{\mathrm{GDC}}=7.25 \mathrm{~g} \cdot \mathrm{cm}^{-3}\right)$.

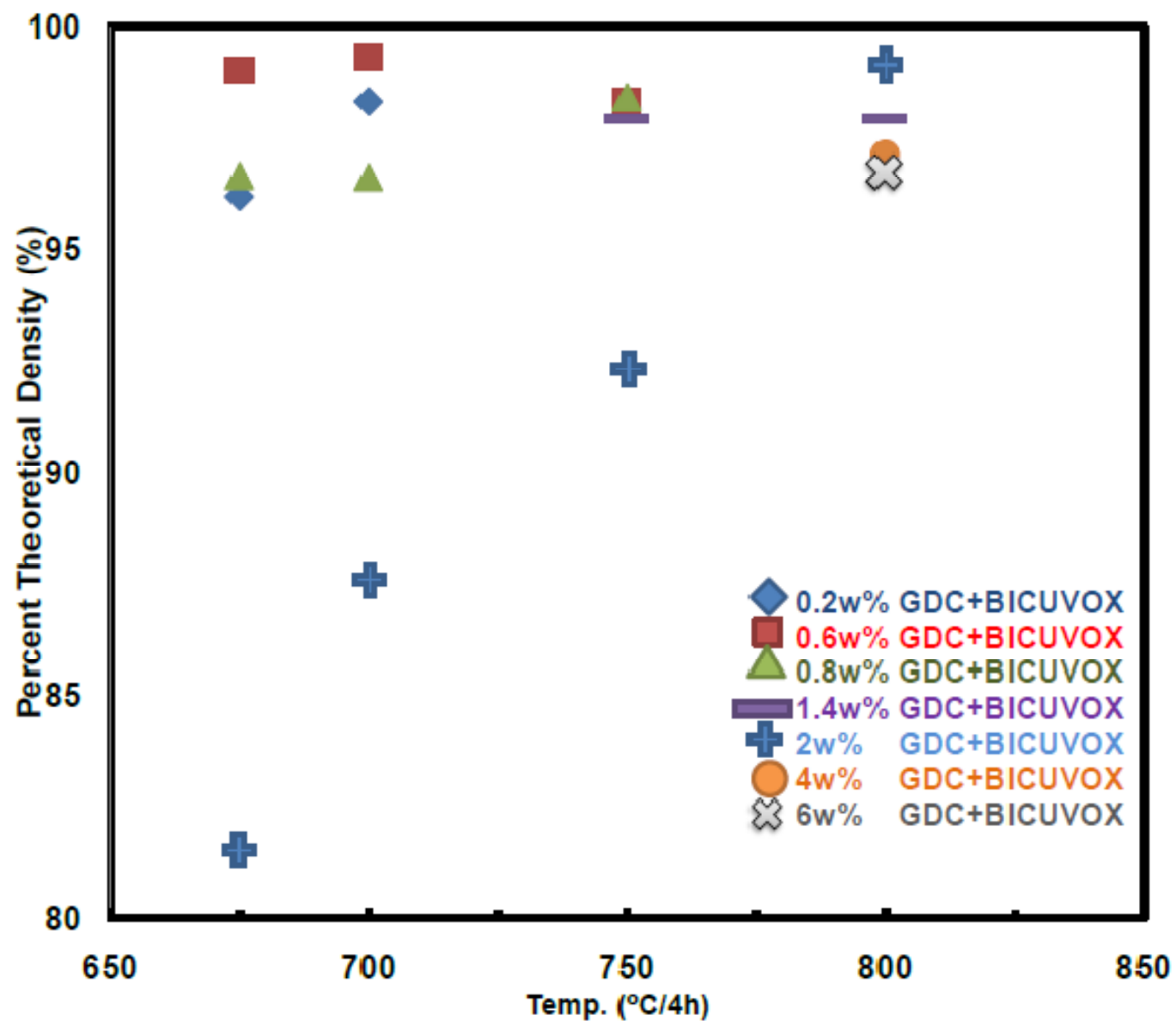

Figure 43: Density dependences of temperature at different $\mathrm{wt} \%$ addition of nano powder GDC 
For the temperature range between $675-750^{\circ} \mathrm{C}$, the highest density was achieved with $0.6 \mathrm{w}$ $\%$ GDC. As the GDC addition increases, higher sintering temperatures required to achieve density. 0.6-0.8 wt\% GDC produces $>99 \%$ dense sample, highest reported in literature (1$1.5 \mu \mathrm{m}$ grain size).

The comparison between BICUVOX density before and after adding GDC (Figure 44) shows that density can be improved up to 3 or 4 percent of theoretical density by 0.6 and $2 \mathrm{wt} \%$ of GDC addition for different sintering conditions.

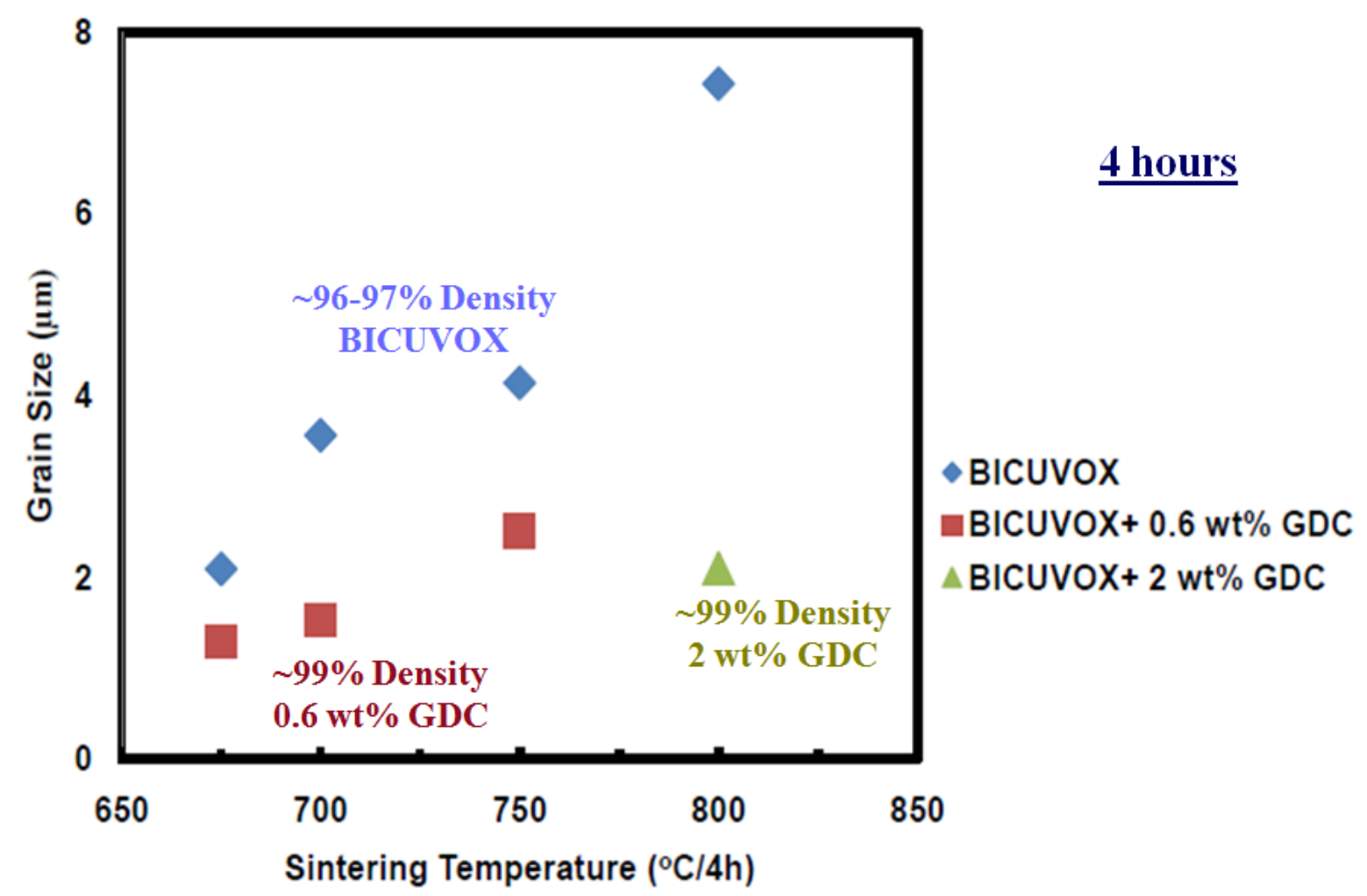

Figure 44: Comparison of the effects of nano powder GDC addition on density of BICUVOX ceramics 
The average grain size for each condition was calculated by using ImageJ software. Figure 43 shows comparison of achieved grain size at different sintering conditions.

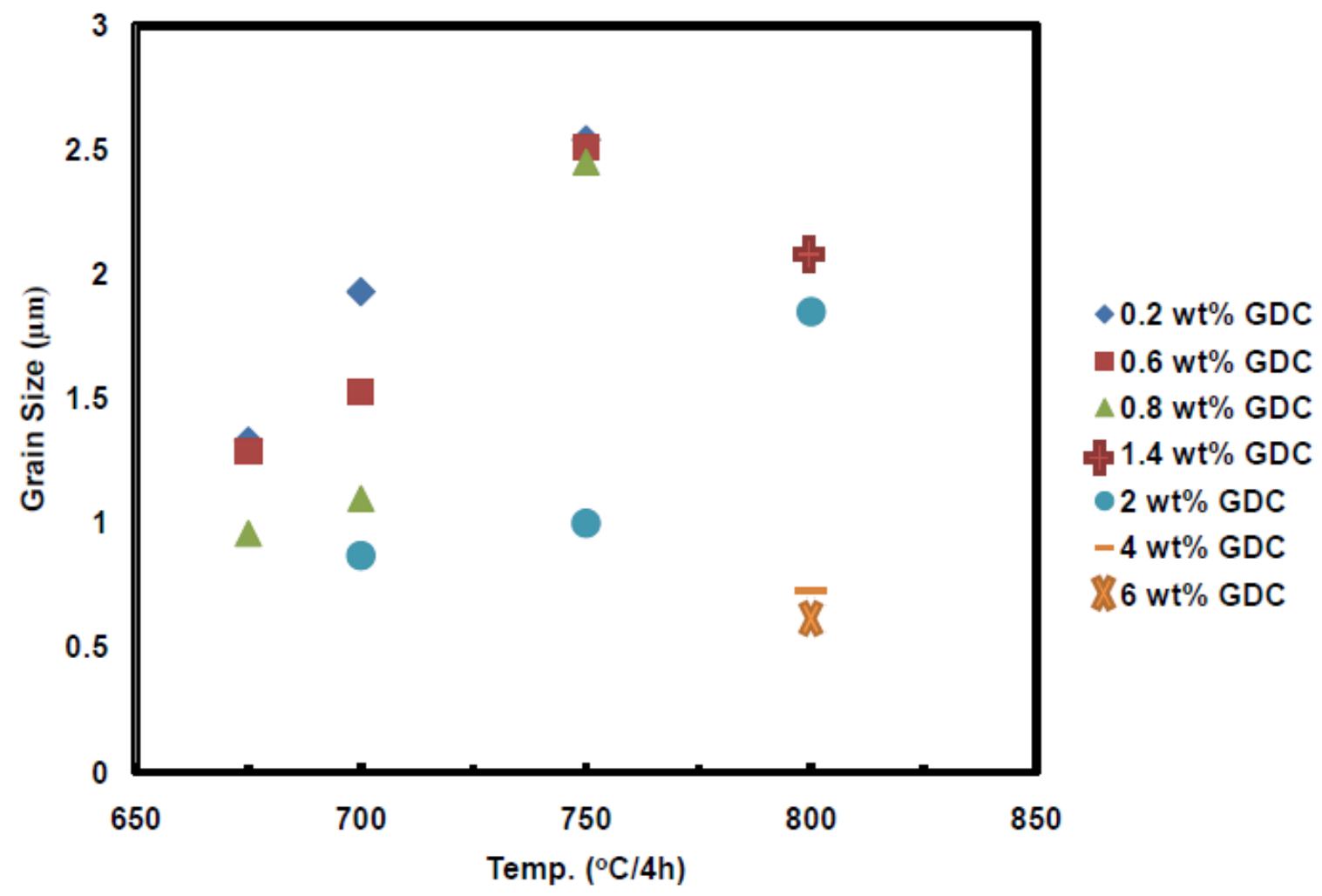

Figure 45: Grain size dependences temperature at different wt \% addition of nano GDC powder

As is shown in Figure 43, increasing the percentage of GDC addition within the BICUVOX matrix decreased the average of grain size. At the higher temperature $\left(750^{\circ} \mathrm{C}\right.$ and $\left.800^{\circ} \mathrm{C}\right)$, a higher amount of GDC addition is needed to reduce the average of grain size to less than $1.5 \mu \mathrm{m}$.

Figure 46 represents a reduction in grain size as a different percentage of nano GDC is added to the BICUVOX matrix. The comparison between BICUVOX grain size before and after adding GDC (Figure 46) shows that 0.6 and $2 \mathrm{wt} \%$ of GDC addition causes a 1 to 5 micron reduction in grain size for different sintering conditions. 


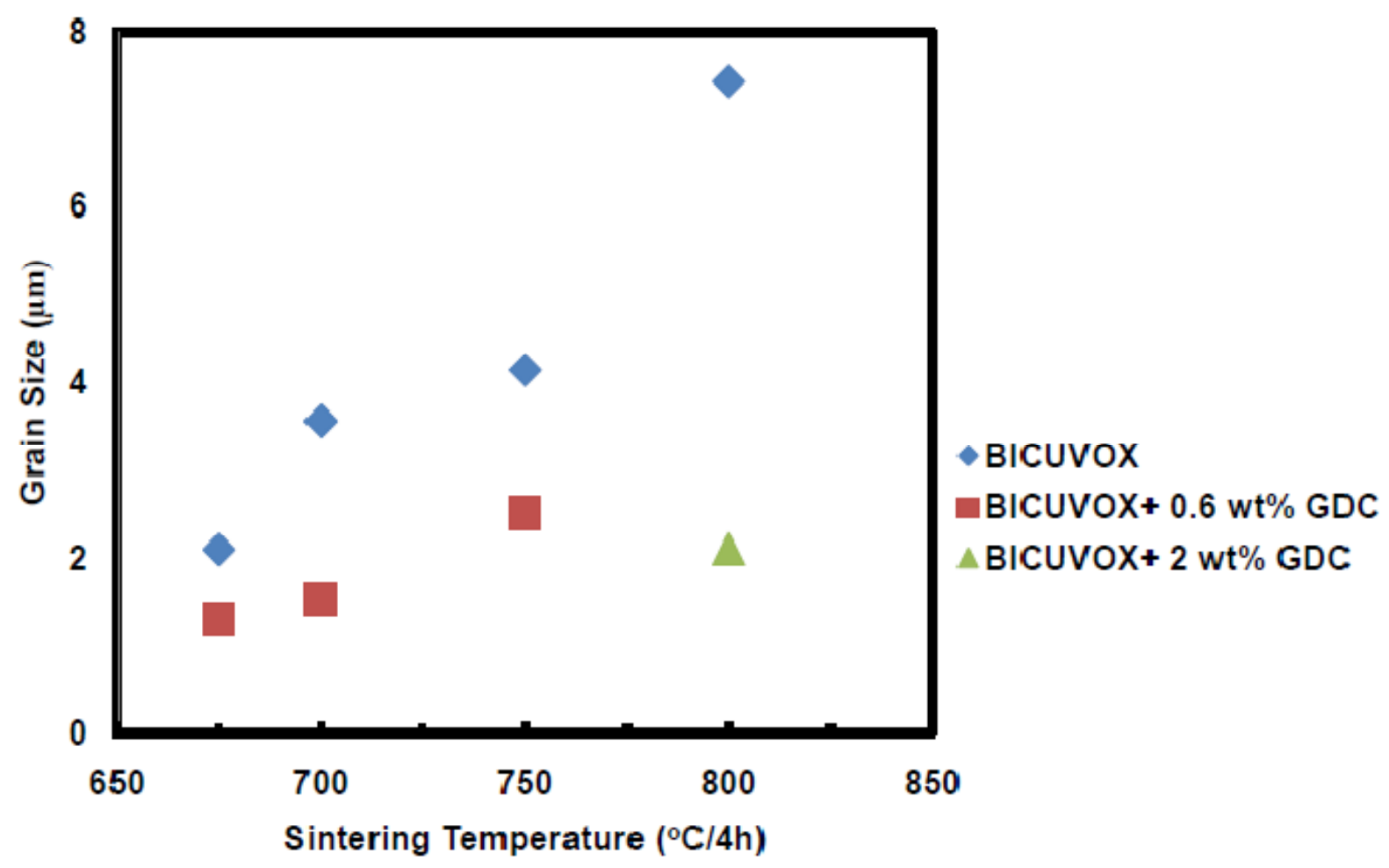

Figure 46: Comparison of addition of different $w \mathrm{t} \%$ nano powder GDC on grain size of BICUVOX ceramics

In order to obtain microstructure pictures of sintered GDC/BICUVOX samples, the same etching conditions and polishing methods used for the pure BICUVOX samples were used for GDC/BICUVOX composition.

Effects of nano GDC on controlling grain size were completed by taking the microstructure pictures of etched samples using scanning electron microscope (SEM). Figures 45-48 show the reduction in grain size (for different sintering conditions) after a different percentage of nano GDC was added to BICUVOX matrix. 


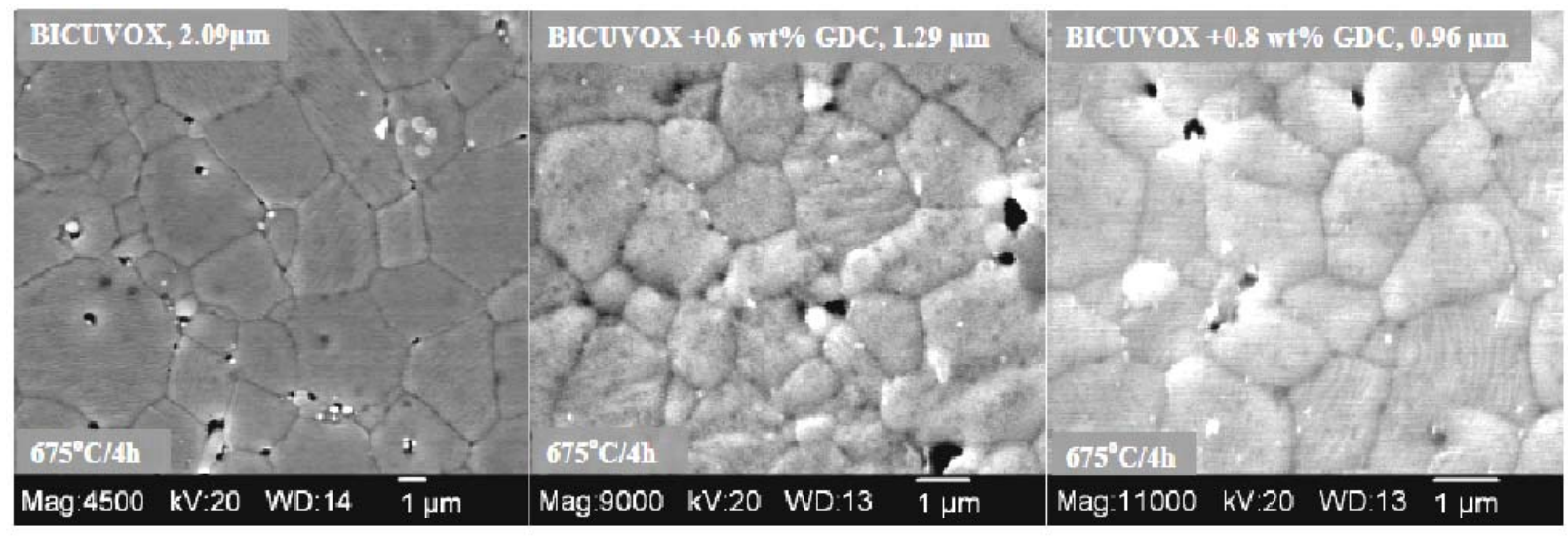

Figure 47: SEM image of effects of nano GDC addition on BICUVOX grain size for the sintered samples at $675^{\circ} \mathrm{C} / 4 \mathrm{~h}$

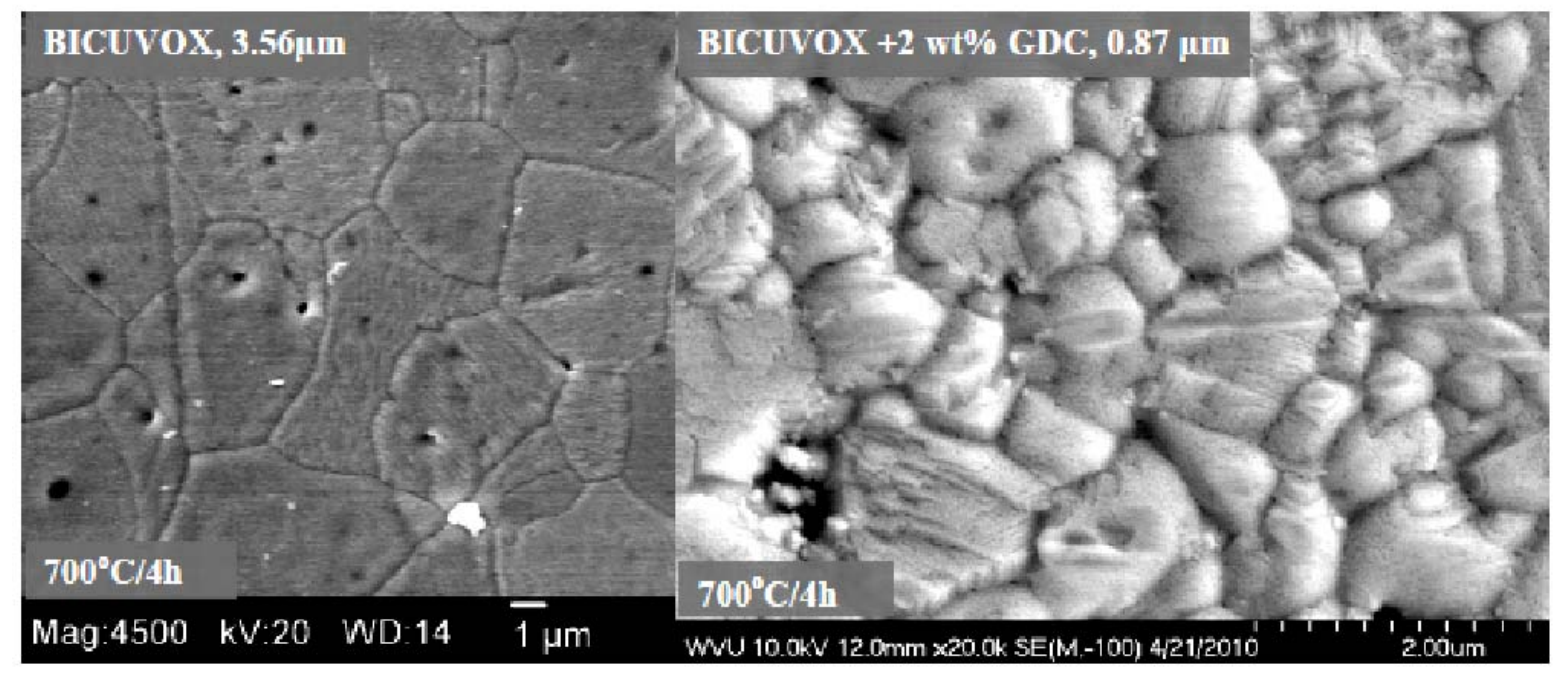

Figure 48: SEM image of effects of nano GDC addition on BICUVOX grain size for the sintered samples at $700^{\circ} \mathrm{C} / 4 \mathrm{~h}$ 


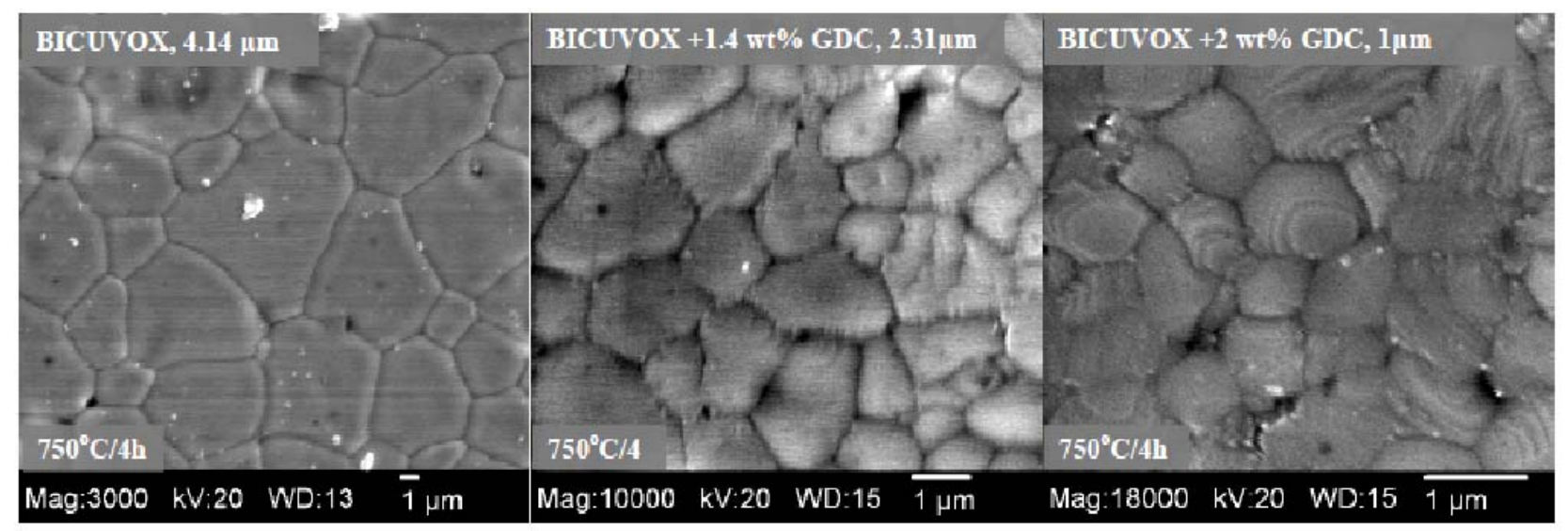

Figure 49: SEM image of effects of nano GDC addition on BICUVOX grain size for the sintered samples at $750^{\circ} \mathrm{C} / 4 \mathrm{~h}$

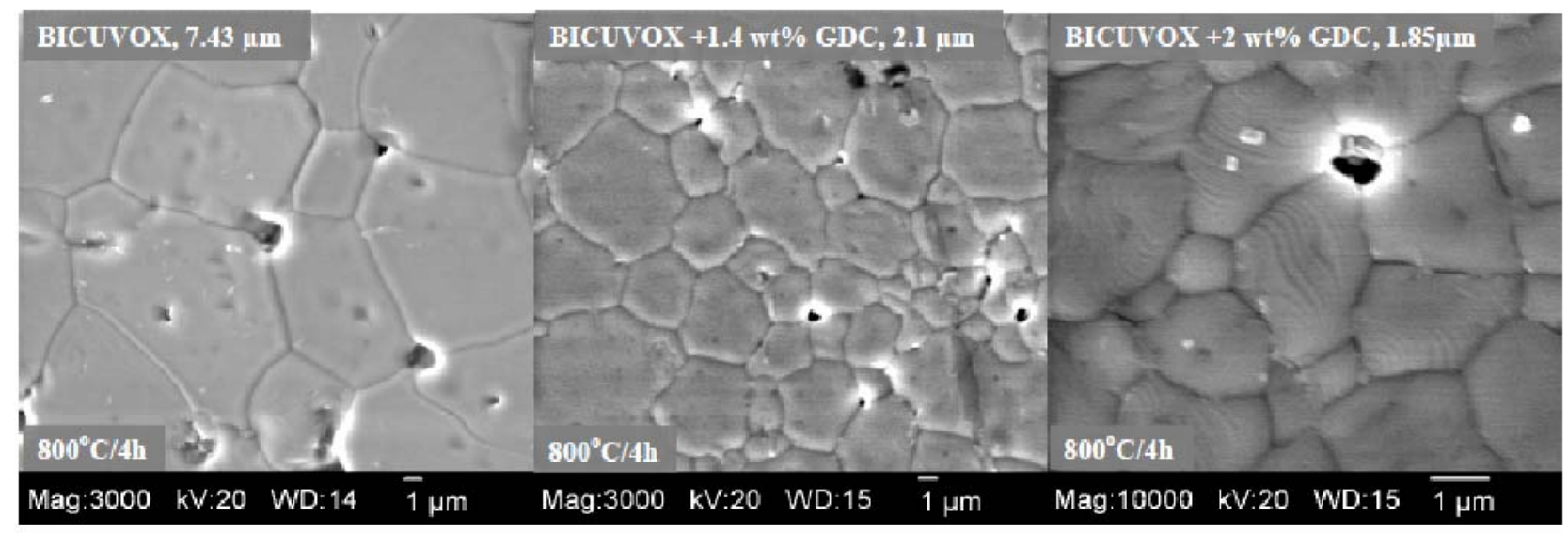

Figure 50: SEM image of effects of nano GDC addition on BICUVOX grain size and density for the sintered samples at $800^{\circ} \mathrm{C} / 4 \mathrm{~h}$

As it is shown, regardless of sintering conditions, the addition of nano GDC to BICUVOX matrix will result in grain size reduction. 
Doping of different concentrations of hydrothermally synthesized GDC nano-sized (10\%Gddoped Ceria) powder into BICUVOX matrix controlled the grain size through boundary pinning (Zener pinning mechanism). GDC nano-sized particles are placed at grain boundaries, which prevents the motion of grain boundaries and grain growth. Zener pinning mechanism also reduces the rate of grain growth and gives enough time for sintering. In this way, porosities will not be trapped inside of the grains. Consequently, the mechanical strength and ionic conductivity of the electrolyte will improve.

As the temperature increases, a higher amount of GDC is needed for completion of the sintering process; which means the addition of nano size GDC, prevents the inhomogeneous grain growth process [39].

\subsection{Conclusion}

Obtained optimum pressure (138 $\mathrm{MPa}$ ) from consolidation process was used to prepare pellets for sintering study. Sintered pellets at the temperatures range from $675^{\circ} \mathrm{C}$ to $800^{\circ} \mathrm{C}$ for 30 minutes to 1 hour represent density as high as 96 to $98 \%$ of theoretical density. Etching profile for all the sintering conditions was investigated. Densification appears to be complete $<4$ hours dwell time at $675^{\circ} \mathrm{C}$ sintering temperature. Grain boundary diffusion is the dominant grain growth mechanism and activation energy for grain growth equals $0.36 \mathrm{eV}$ atom ${ }^{-1}\left(34.82 \mathrm{~kJ} \mathrm{~mol}^{-1}\right)$. 
At the temperature range from $675^{\circ} \mathrm{C}$ to $750^{\circ} \mathrm{C}$, increasing the weight percent of GDC to BICUVOX matrix (up to $0.6 \mathrm{wt} \%$ ) improves the density. Further GDC addition (more than 0.6 wt \%) will cause de-densification and reduces the density. As the temperature increases and reaches $800^{\circ} \mathrm{C}$, more weight percent of GDC (2\%) is needed to improve the density to about 99\%. Increasing the percentage of GDC addition to BICUVOX matrix will decrease the average of grain size. At the higher temperature $\left(750^{\circ} \mathrm{C}\right.$ and $\left.800^{\circ} \mathrm{C}\right)$ higher amount of GDC addition is needed to reduce the average of grain size to less than $1.5 \mu \mathrm{m}$. The comparison between BICUVOX grain size before and after adding GDC (Figure 46) shows that 0.6 and $2 \mathrm{wt} \%$ of GDC addition causes a 1 to 5 micron reduction in grain size for different sintering conditions. 


\section{CHAPTER 5: ELECTRICAL AND MECHANICAL TESTING}

\subsection{Objectives}

The effects of changes in the microstructure due to processing may result in altered electrical and mechanical properties. Grain structure, defect concentration, defect ordering, stoichiometriy, and secondary phases of BICUVOX ceramics can be changed due to powder synthesis, consolidation and/or thermal treatment. This chapter investigates the effects of processing method used in this work has affected the mentioned factors, and their contribution to electrical and mechanical properties. In this investigation, the effects powder synthesis, consolidation, densification and Zener pinning, on electrical and mechanical properties were all addressed. Four-point probe resistivity and flexural strength measurements were completed on BICUVOX membranes. The measured properties were then correlated to the processing conditions and the resultant density and grain size. 


\subsection{Random BICUVOX Conductivity Test}

\subsubsection{Experimental Procedure}

Conductivity characterization of BICUVOX samples (fabricated from precipitated powder method and calcined at $500^{\circ} \mathrm{C}$ ) was carried out using high aspect ratio of conductivity bars fabricated by tape casting. The slurry was made of $88.4 \mathrm{wt} \%$ of BICUVOX powder, $1.8 \mathrm{wt} \%$ diluted fish oil (TCW, Brown Menhaden Fish oil dispersant, Richard E. Mistler, Inc. , Z-3 3053), $5 \mathrm{wt} \%$ of poly vinyl butyral binder (Richard E. Mistler, Inc. , B-98 T44243), $2.4 \mathrm{wt} \%$ butyle benzyle phthalate plasticizer ( Sancticizer, Richard E. Mistler, Inc. , 160 D1093046), 2.4 wt\% polyalkylene glycol plasticizer (Richard E. Mistler, Inc. UCON 50-HB-2000 VE2355S3D3), and $80 \mathrm{wt} \%$ xylene Fisher chemical (Richard E. Mistler, Inc. C8H10 082607) as a solvent of weighted BICUVOX powder.

The slurry was ball-milled 12 hours and tape- casted using a blade height of $150 \mu \mathrm{m}$. The cast tape was cut and laminated using PHI press into samples of about $0.3 \mathrm{~mm}$ thickness. The lamination pressure and temperature were set at $310 \mathrm{MPa}$ and $93^{\circ} \mathrm{C}$, respectively. By using a laser cutter (Universal laser systems OC82189), conductivity bars were cut in dimensions 21 x 5 $\mathrm{mm}$. 
All conductivity bars were binder-burned out at a rate of $1^{\circ} \mathrm{C} / \mathrm{min}$ and fired using the best sintering condition previously described. Total conductivity (which includes ionic and electronic contributors) of sintered bars was measured by means of four point probe resistivity measurements. Silver leads were used to wire the conductivity bars and painted with silver paint to obtain maximum contact. Resistivity measurements were completed in air at temperatures from $300-600^{\circ} \mathrm{C}$ using Keithly digital multimeter (DMM 2100).

\subsubsection{Results}

In order to confirm BICUVOX phase purity for those samples sintered at lower temperature $\left(675^{\circ} \mathrm{C} / 30 \mathrm{~min}\right), \mathrm{X}$-ray diffraction technique using Bruker D8 Discovery $(\mathrm{Cu}-\mathrm{ka} 18047.2 \mathrm{eV}$ source) was employed to analyze the top surface of fabricated conductivity bar (Figure 51). 


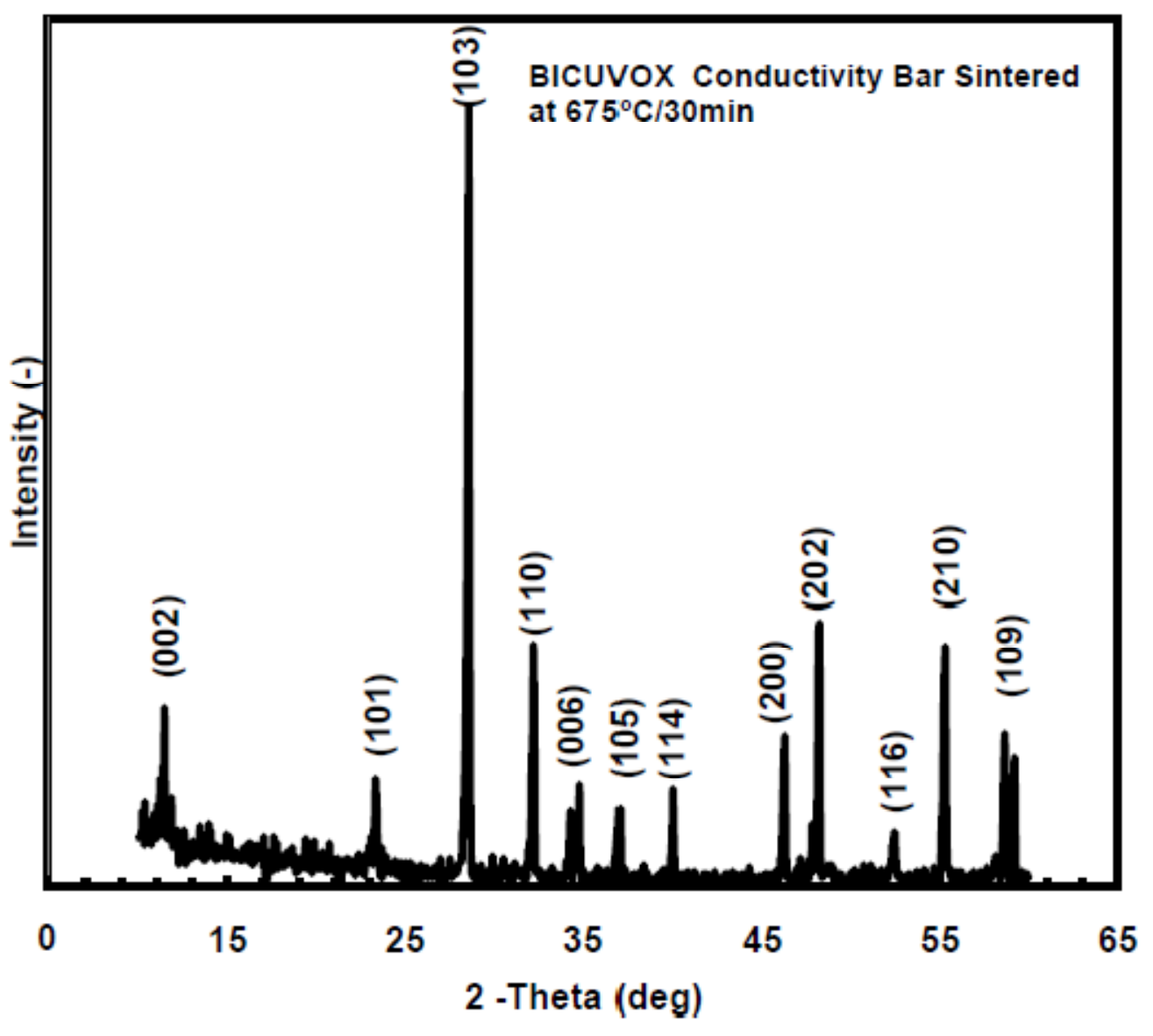

Figure 51: XRD pattern of the sintered conductivity bar at $675^{\circ} \mathrm{C} / 30 \mathrm{~min}$

As is shown in Figure 51, the XRD pattern of the conductivity bar sintered at $675^{\circ} \mathrm{C}$ for 30 minutes matches with the standard BICUVOX XRD pattern, with no trace of impurities. 
Figure 52 shows the obtained conductivities versus temperature for the samples containing different amounts of GDC and sintered at different conditions. As is shown in Figure 52, sintered samples at the temperature $675^{\circ} \mathrm{C}$ indicate higher conductivity compare to those sintered at higher temperature $\left(700^{\circ} \mathrm{C}, 750^{\circ} \mathrm{C}\right.$ and $\left.800^{\circ} \mathrm{C}\right)$. Samples containing nano GDC exhibit equal or lower conductivity compare to ones without GDC. Increasing the amount of GDC decreases the ionic conductivity of the samples. Presented data in Figure 52 are the average of three tested samples (the error bars are not shown).

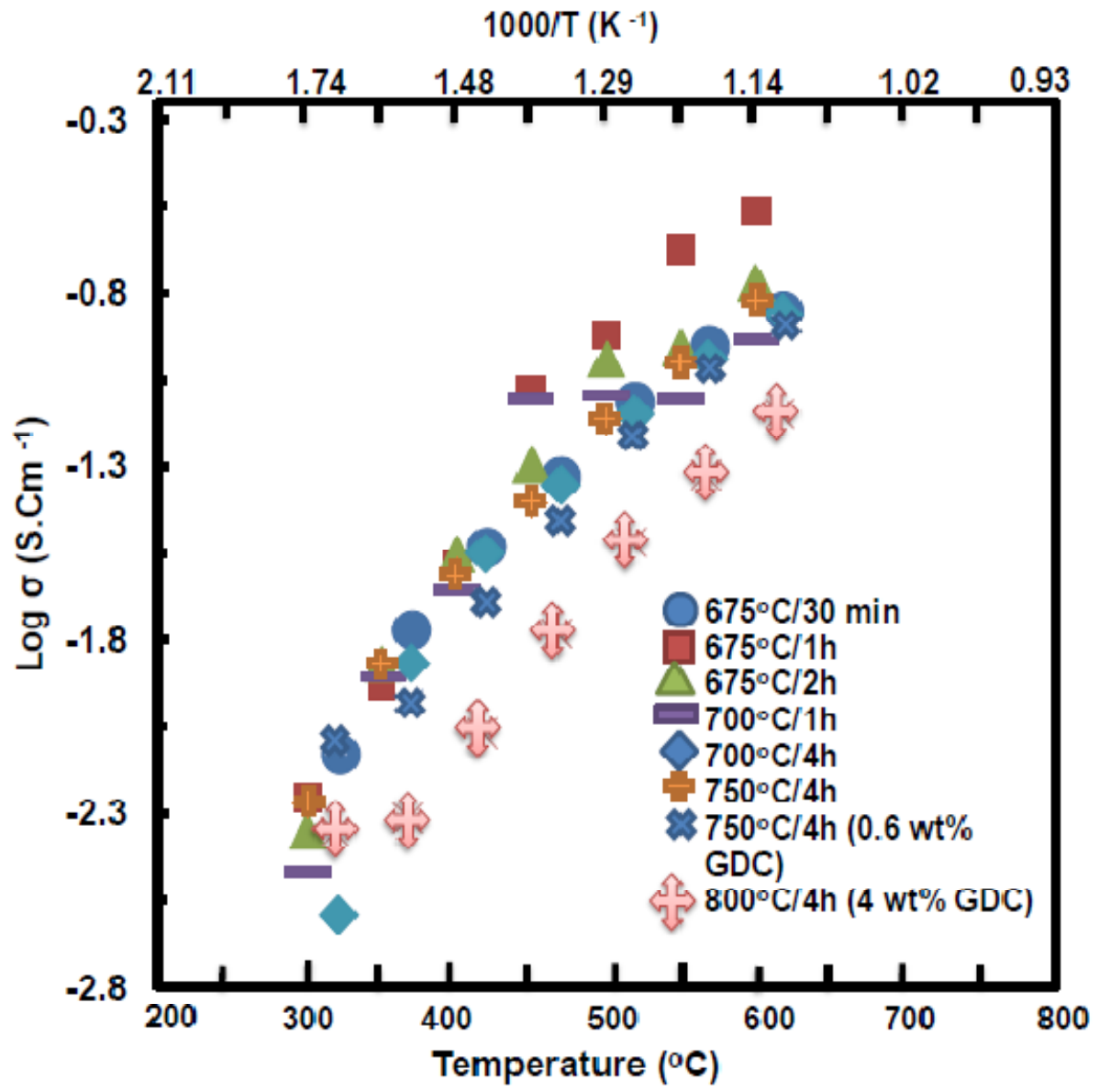

Figure 52: Conductivity versus temperature for the sintered samples at different sintering condition and different $\mathrm{wt} \%$ of nano powder GDC 
Higher conductivities at the lower temperatures $\left(<700^{\circ} \mathrm{C}\right)$ and shorter times $(<4 \mathrm{~h})$ can be attributed to the formation of a dense ceramics. As it is shown in Figure 52, the highest ionic conductivities were obtained by the samples sintered at lower temperatures and shorter times. These samples show smaller grain size compared to other sintering conditions. Steil et al. have shown that $\gamma^{\prime}$ phase, which is a less conductive (compared with $\gamma$-tetragonal phase) ordered structure, does not form for the samples with grain sizes less than a few micron. That is a higher number of grain boundaries is able to act as a clamp and hold the structure firmly from rotation and transforming to lower conductive phase. Therefore, samples with smaller grain size and higher density will have higher conductivity compared to other sintering conditions (Figure 52) [37].

The density and grain size of the sintered conductivity bars, fabricated with co-precipitation powder, was compared with others' published work in Table 8 . 
Table 8: Comparison of density and grain size obtained by co-precipitation method with other works

\begin{tabular}{c|c|c|c}
\hline Papers & $\begin{array}{c}\text { Sintering } \\
\text { Temp }\left({ }^{\circ} \mathrm{C}\right) / \text { Time(h) }\end{array}$ & $\begin{array}{c}\text { Theoretical } \\
\text { Density (\%) }\end{array}$ & $\begin{array}{c}\text { Avg. Grain } \\
\text { Size( }(\mathrm{mm})\end{array}$ \\
\hline $\begin{array}{c}\text { Co-precipitated BICUVOX } \\
\text { (This work) }\end{array}$ & $675^{\circ} \mathrm{C} / 1 \mathrm{~h}$ & $97.5 \%$ & $<1 \mu \mathrm{m}$ \\
\hline $\begin{array}{c}0.6 \text { wt \% GDC/BICUVOX } \\
\text { (This work) }\end{array}$ & $750^{\circ} \mathrm{C} / 4 \mathrm{~h}$ & $99 \%$ & $1-2.5 \mu \mathrm{m}$ \\
\hline Steil $^{(36)}$ & $750^{\circ} \mathrm{C} / 1 \mathrm{~h}$ & $97 \%$ & $10 \mu \mathrm{m}$ \\
\hline Simner $^{(3)}$ & $800^{\circ} \mathrm{C} / 10 \mathrm{~h}$ & $96.5 \%$ & $5-8 \mu \mathrm{m}$ \\
\hline
\end{tabular}

The electrical properties of the optimal samples produced in this work was compared to Steil, Simners, and Krock results (Figure 51 and Table 9). As it is shown, this work has reported the highest conductivity compared to other works, which can be attributed to higher density. More work must be done to prove if other factors are controlling.

Paydar et al. [1] have reported that the contribution of grain boundaries to the total resistance is lower for the samples with larger grain size, which is due to the lower density of grain boundaries. They also have reported that addition of $0.5-1 \mathrm{wt} \% \mathrm{ZrO}_{2}$ to BICUVOX increases the density of grain boundaries and as a result their contribution to the total conductivity is also more. This causes a reduction in total ion conductivity with respect to the single phase BICUVOX samples. Addition of GDC to BICUVOX matrix increases the density of grain boundaries, thus reduction in total conductivity can be attributed to higher contribution of grain boundaries to the total conductivity. 


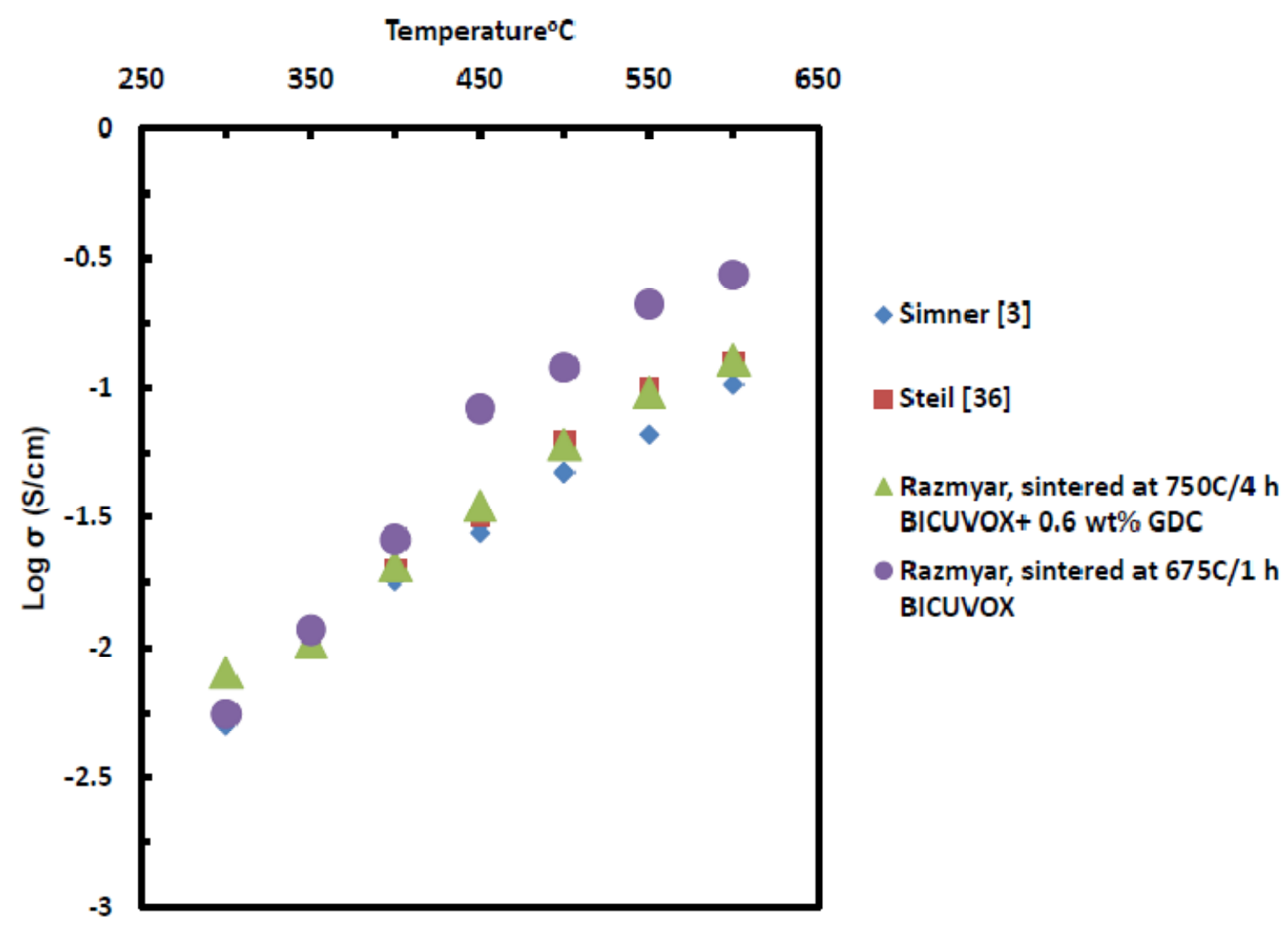

Figure 53: Comparison of obtained conductivity results with other work

Table 9: Comparison of conductivities and related densities of other works

\begin{tabular}{|c|c|c|c|c|}
\hline \multirow{2}{*}{ Sample/Ref. } & \multirow{2}{*}{$\begin{array}{l}\text { Density } \\
\left(\mathrm{g} / \mathrm{cm}^{3}\right)\end{array}$} & \multicolumn{3}{|c|}{ Conductivity (S.Cm $\left.{ }^{-1}\right)$} \\
\hline & & $350^{\circ} \mathrm{C}$ & $450{ }^{\circ} \mathrm{C}$ & $550^{\circ} \mathrm{C}$ \\
\hline BICUVOX/ (This Work) & 96.85 & 0.01 & 0.08 & 0.2 \\
\hline Simner [3] & 95 & 0.003 & 0.027 & 0.06 \\
\hline Steil [36] & 97 & 0.01 & 0.03 & 0.1 \\
\hline Krok [42] & 90 & 0.002 & 0.01 & 0.05 \\
\hline
\end{tabular}




\subsection{Mechanical Testing}

Ceramic membranes used in SOFC and SOEC applications may experience significant tensile stresses during manifolding/sealing and operation. Equibiaxial flexural strength measurement calculates the maximum stress that a test specimen is capable of sustaining when subject to flexure between two concentric rings. It is also known as ring-on-ring flexture test and it is a proven way to estimate the strength and deformation under multiple tension stresses. Elimination of specimen edge defects is one of the most important advantages of this method.

The following sections investigate the effects of different sintering conditions on mechanical strength at room temperature of BICUVOX ceramics. Also, the effects of addition of intergranular nano GDC on mechanical strength of sintered samples at $750^{\circ} \mathrm{C}$ was also studied.

\subsubsection{Experimental Procedure}

In order to measure monotonic equibiaxial flexural strengths of BICUVOX membranes (sintered at different times and temperatures), ASTM standard C1499-0336 [36 above was used to design a load and support fixture for concentric ring-on-ring experiment. Elimination of specimen edge defects is one of the most important advantages of this method. A schematic of the ring-on-ring loading set up is shown in Figure 54. 


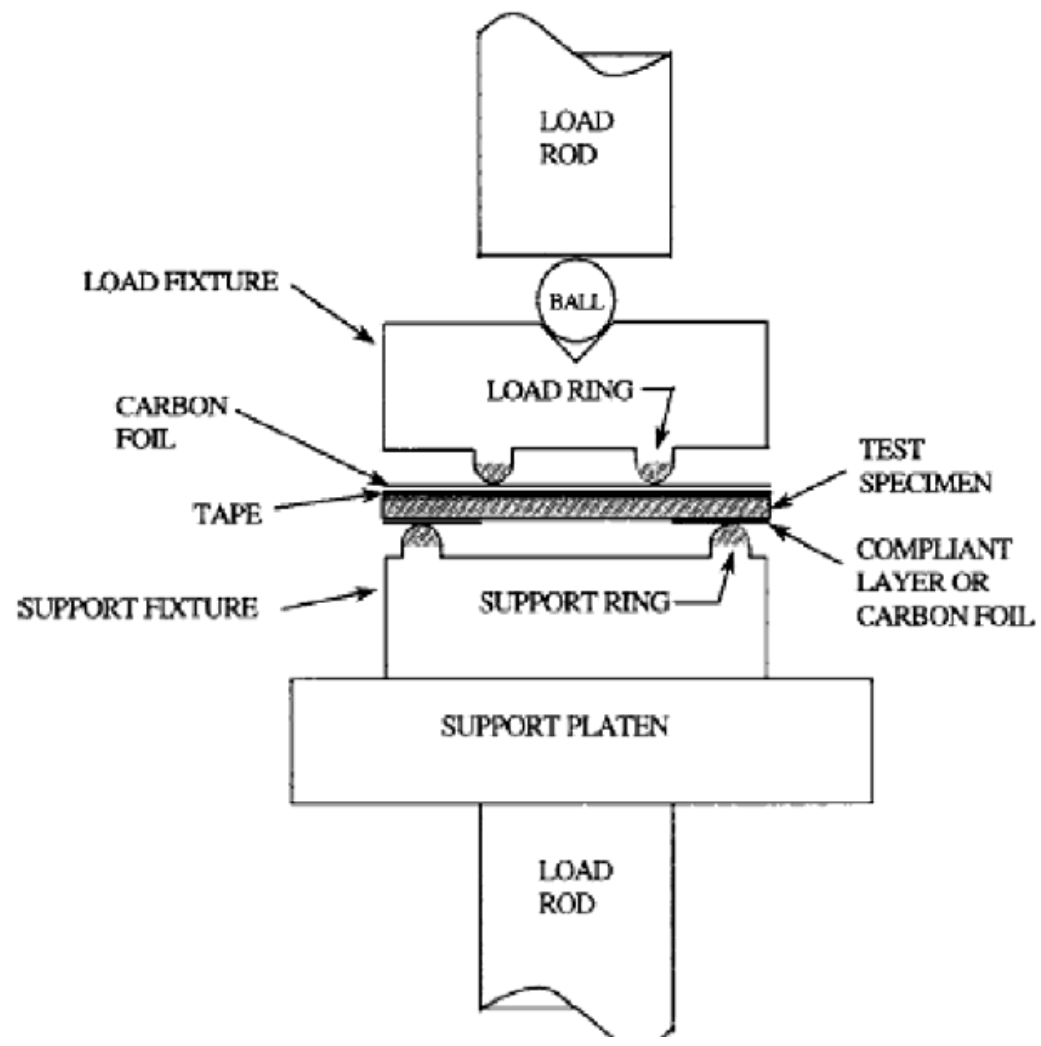

Figure 54: A schematic of the concentric ring-on-ring loading configuration [52].

The diameter of the loading ring $\left(\mathrm{D}_{\mathrm{L}}\right)$, support ring $\left(\mathrm{D}_{\mathrm{S}}\right)$ and test specimen $(\mathrm{D})$ was $5.92 \mathrm{~mm}$, $13 \mathrm{~mm}$, and $16 \mathrm{~mm}$, respectively. The test specimen thickness range is from $240 \mu \mathrm{m}$ to $1.3 \mathrm{~mm}$. In order to reduce the friction between compressive and tensile surfaces of the test specimen and the load and support ring, a sheet of Teflon tape $(\sim 89 \mu \mathrm{m})$ was placed between the mentioned surfaces. The effect of test specimen-ring misalignment was reduced by placing a sheet of high purity silicon rubber $(254 \mu \mathrm{m})$ between a test specimen and the support ring. 
Displacement rate and equibiaxial strength were calculated using Eq. 11 and Eq. 12, respectively.

$$
\delta \cong\left(\frac{D_{S}^{2}}{6 \mathrm{Eh}}\right) \sigma
$$

where $\delta$ is the displacement rate of the actuator or cross head in unit of $\mathrm{mm} / \mathrm{s}, \sigma$ is the maximum value of the nominal recommended stress rate occurring within the test specimen in unit of $\mathrm{MPa} / \mathrm{s}, \mathrm{D}_{\mathrm{S}}$ is the support ring diameter in $\mathrm{mm}, \mathrm{h}$ is the test specimen thickness, and $\mathrm{E}$ is the modulus of elasticity in units MPa.

By measuring the breaking load (F) equibiaxial strength $\left(\sigma_{f}\right)$ was calculated using equation 12 .

$$
\sigma_{\mathrm{f}}=\frac{3 \mathrm{~F}}{2 \pi \mathrm{h}^{2}}\left[(1-v) \frac{\mathrm{D}_{\mathrm{S}}^{2}-\mathrm{D}_{\mathrm{L}}^{2}}{2 \mathrm{D}^{2}}+(1+v) \ln \frac{\mathrm{D}_{\mathrm{S}}}{\mathrm{D}_{\mathrm{L}}}\right]
$$

where $v$ is the Poison's ratio. The elastic constant and estimated strength were chosen according to published data related as $\mathrm{E}=80 \mathrm{GPa}, \nu=0.31, \sigma_{\mathrm{f}}=83 \mathrm{MPa}$. The calculated Young's modulus (E) and equibiaxial strength $\left(\sigma_{f}\right)$ are related to aurivillius type-ferroelectric $\mathrm{Bi}_{1.75} \mathrm{Te}_{0.25} \mathrm{Sr}_{0.75} \mathrm{Na}_{0.25} \mathrm{Nb}_{2} \mathrm{O}_{9}$ (SBNTeN25), and equibiaxial strength of BICUVOX from Yaremchenko et al work, respectively $[4,53,54]$.

In order to obtain accurate data ( $\% 0.15$ to $\% 0.20)$, model 34 precision miniature load cell (Honeywell) was mounted on Instron series 3300 load frame. The load cell is able to record compression load force till $22.67 \mathrm{~kg}$ (Figure 55). 


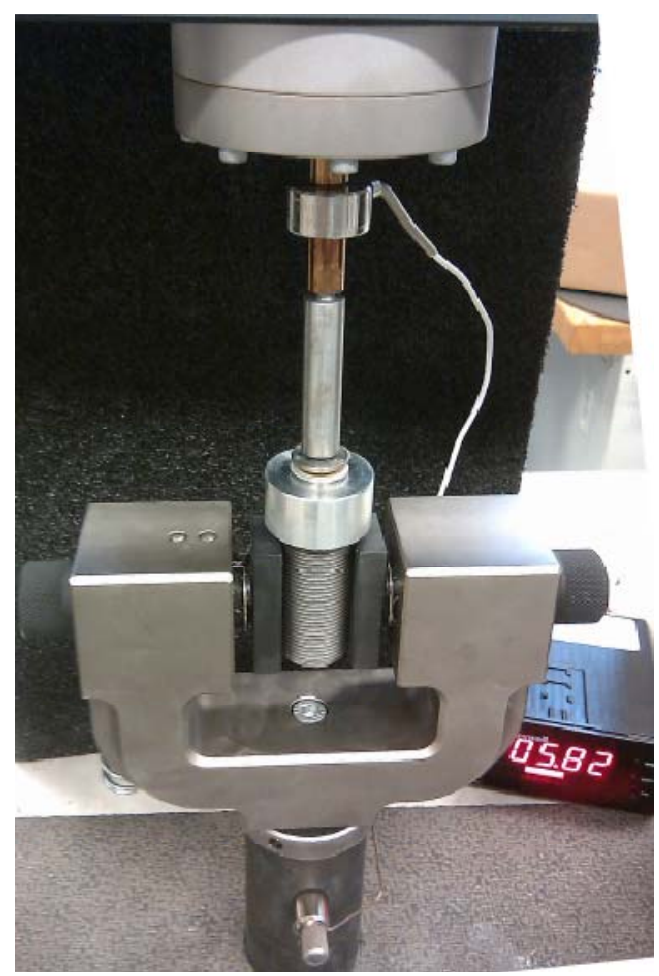

Figure 55: Load cell and fixture set up for equibiaxial flexural strength test

Preparation of BICUVOX and GDC-BICUVOX disk specimens were carried out using tape casting method.

According to ASTM standard C1499-03, in order to increase precision of the mechanical test, the test specimen thickness (h) should be in the calculated ranges from equation 13 . The dimensions of designated fixture and test specimens need to fir these criteria. Equations 13 and 14 were developed from plate theory.

$$
\frac{\mathrm{D}_{\mathrm{S}}}{10} \geq \mathrm{h} \geq \sqrt{2 \sigma_{\mathrm{f}} \mathrm{D}_{\mathrm{S}}^{2} / 3 \mathrm{E}}
$$


Equation 14 was used to determine the diameter of test specimen. The difference in diameter of test specimen and support ring divided by thickness of the sample need to be fit in the following equation:

$$
2 \leq \frac{\mathrm{D}-\mathrm{D}_{\mathrm{S}}}{\mathrm{h}} \leq 12
$$

Eq. 14

\subsubsection{Results}

In order to verify the accuracy of designed fixture, $17 \mathrm{~mm}$ alumina disks $\left(99.6 \% \mathrm{Al}_{2} \mathrm{O}_{3}\right)$ were fabricated and equibiaxial strength results $(2.54 \mu \mathrm{m} / \mathrm{s}$ loading $)$ were compared with the ones reported in ASTM C 1499-03 (Table 10). The equibiaxial strength was calculated using equation 12 and the alumina mechanical data was obtained from literature [55].The percent coefficient of variation is a normalized measure of dispersion of a probability distribution and was calculated from equation 15 .

Percent Coefficient of variation $=\% \mathrm{C} . \mathrm{V}=\frac{100 \times(\text { standard deviation })}{\text { Mean }}$

Table 10: Comparison of alumina mechanical data of this work with the ones reported in ASTM C 1499-03

\begin{tabular}{c|c|c|c} 
Material & $\begin{array}{c}\text { Specimen } \\
\text { Thickness }\end{array}$ & $\begin{array}{c}\text { Equibiaxial } \\
\text { Strength (MPa) }\end{array}$ & $\begin{array}{c}\text { Percent Coefficient of } \\
\text { Variation \% C.V }\end{array}$ \\
\hline $\begin{array}{c}99.6 \% \mathrm{Al}_{2} \mathrm{O}_{3} \mathrm{ASTM} \\
\text { Standard } \mathrm{C} 1499-03\end{array}$ & 0.4 & 540 & 7.6 \\
\hline $\begin{array}{c}99.6 \% \mathrm{Al}_{2} \mathrm{O}_{3} \text { (This } \\
\text { Work) }\end{array}$ & 0.4 & 536.09 & 11
\end{tabular}


Different sintering conditions were applied to investigate the effects of grain size and density on mechanical property of BICUVOX ceramics. Also, the effects of GDC ( $0.6 \mathrm{wt} \%)$ addition on improvement of mechanical property have been investigated (Table 11).

Table 11: Effects of sintering conditions and addition of GDC on mechanical properties of BICUVOX

\begin{tabular}{c|c|c|c|c} 
Sample & $\begin{array}{c}\text { Sintering } \\
\text { Condition }\end{array}$ & $\mathbf{h}(\mathbf{m m})$ & $\begin{array}{c}\text { Equibiaxial Strength } \\
(\mathbf{M P a})\end{array}$ & $\begin{array}{c}\text { Percent Coefficient of } \\
\text { Variation \% C.V }\end{array}$ \\
\hline BICUVOX.1 & $675^{\circ} \mathrm{C} / 1 \mathrm{~h}$ & 0.44 & 159.29 & 15.42 \\
\hline BICUVOX.1 & $700^{\circ} \mathrm{C} / 1 \mathrm{~h}$ & 0.45 & 138.99 & 23.18 \\
\hline BICUVOX.1 & $750^{\circ} \mathrm{C} / 4 \mathrm{~h}$ & 0.44 & 129.13 & 11.83 \\
\hline $0.6 \mathrm{wt} \%$ GDC/BICUVOX.1 & $750^{\circ} \mathrm{C} / 4 \mathrm{~h}$ & 0.44 & 134.18 & 7.37
\end{tabular}

Comparison of equibiaxial strength data verifies that sintered samples at lower temperatures and short times exhibit higher mechanical strength (Table 11). This can be attributed to higher density and smaller grain size achieved at these conditions. Considering the same sintering condition $\left(750^{\circ} \mathrm{C} / 4 \mathrm{~h}\right)$, fabricated samples with the addition of $0.6 \mathrm{wt} \%$ GDC exhibit higher mechanical strength. Addition of $0.6 \mathrm{wt} \%$ GDC to BICUVOX prevents the grain growth during the sintering and improves the mechanical properties. 


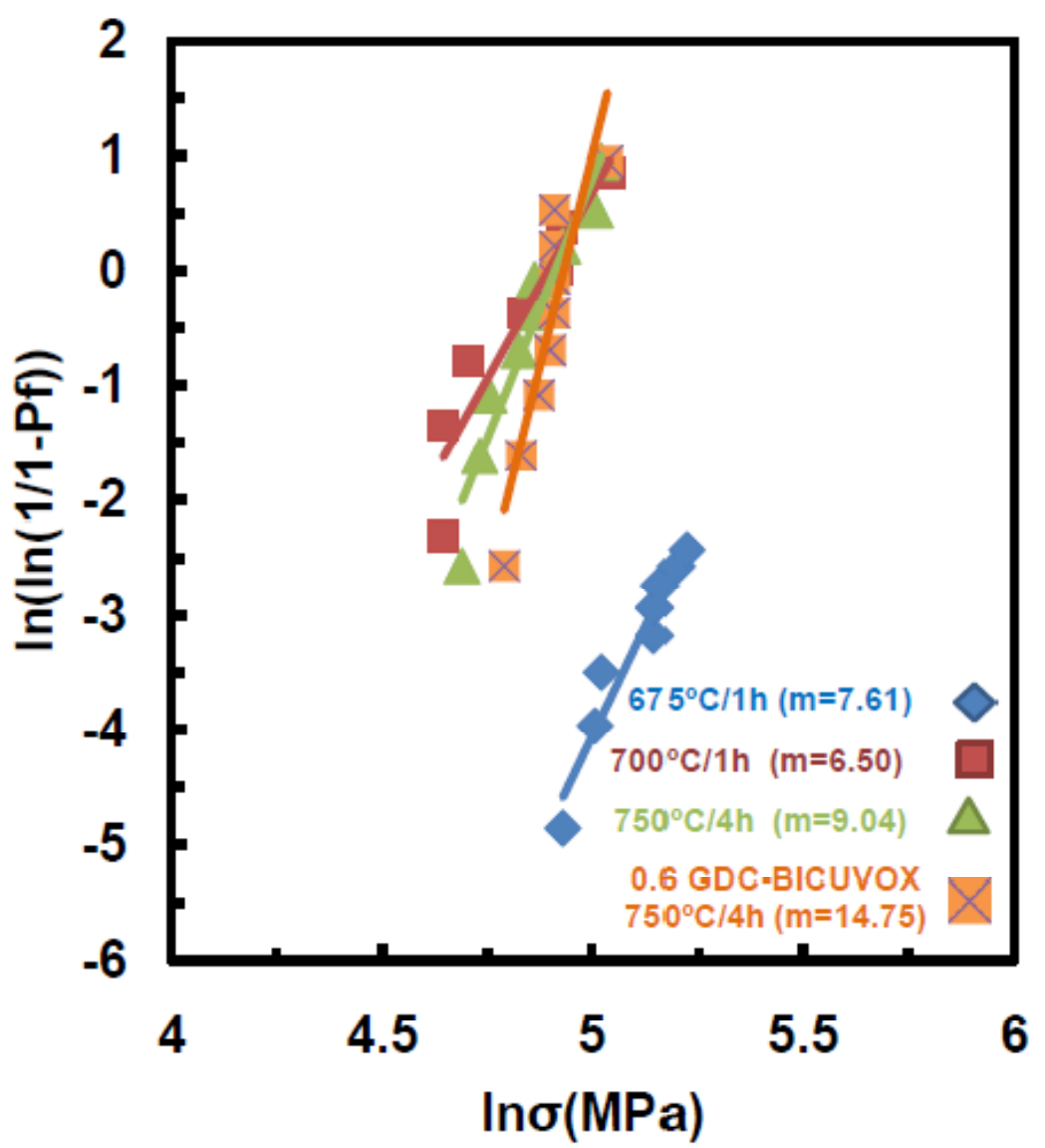

Figure 56: A Weibull plot showing the distribution of flexural strength for specimens sintered at different conditions.

The flexure breaking behavior of tested specimens was analyzed by using Weibull statistics (Figure 56). In order to have a good reliability and high yield of usable component, it is desired to have Weibull modulus close or greater than 10 [56]. Higher Weibul modulus means that there is a little variability in strength and that specimen has consistent microstructure and lower defect population. As it is shown in Figure 56, sintered samples at lower temperature $\left(<750^{\circ} \mathrm{C}\right)$ and shorter times $(<4 \mathrm{~h})$ show lower Weibull modulus. However, it is suggested that more samples be tested to achieve more accurate Weibull modulus. 
Table 12 compares the biaxial flexure strength of different oxide ceramics. The BICUVOX ceramic achieved by co-precipitation method, shows much higher mechanical strength $(60 \%$ greater) compare to the one obtained by Yaremchenko et al. [4] from standard solid state synthesis.

Table 12: Comparison of biaxial flexure strength of different oxide ceramics

\begin{tabular}{c|c|c} 
Sample & $\begin{array}{c}\text { Equibiaxial Strength } \\
\text { (MPa) }\end{array}$ & Ref. \\
\hline BICUVOX.1 & 159.29 & This work \\
\hline BICUVOX & $83 \pm 16$ & {$[4]$} \\
\hline Ni-YSZ & $95-133$ & {$[53]$} \\
\hline YSZ & 416 & {$[5]$} \\
\hline $10 G C O$ & 120 & {$[56]$} \\
\hline $20 G C O$ & 138 & {$[56]$} \\
\hline TZP & 378 & {$[56]$}
\end{tabular}

Figure 57 presents the failure patterns of the biaxial flexure strength test. Fracture patterns of tested specimens (Figure 58) do not follow of any failure patterns and proves the validity of the tests. 


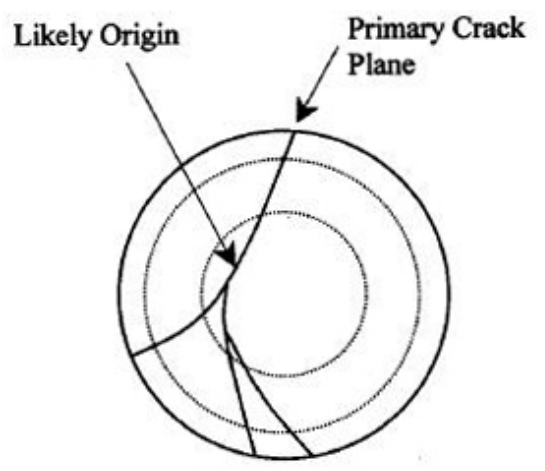

Low Energy - Low Strength Failure

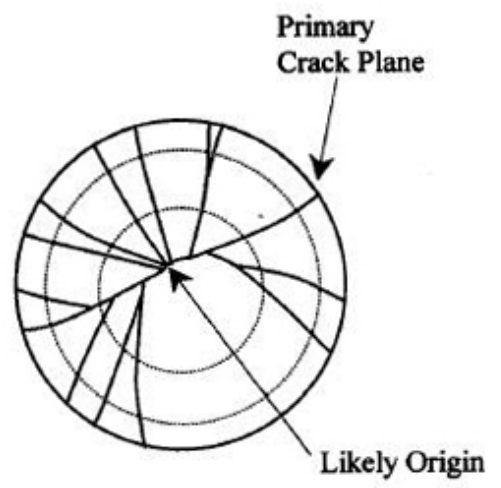

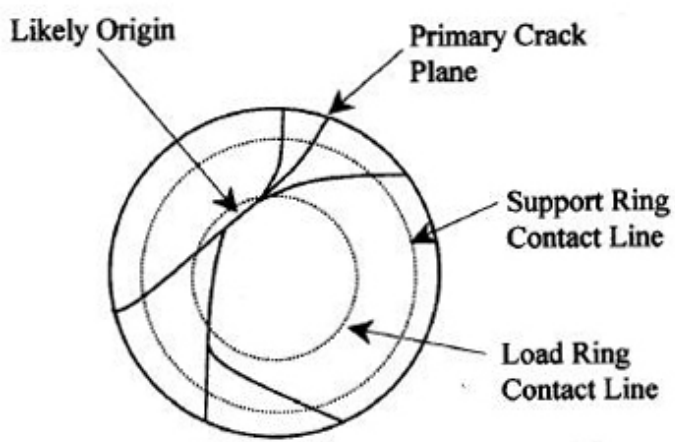

Medium Energy - Medium Strength Failure

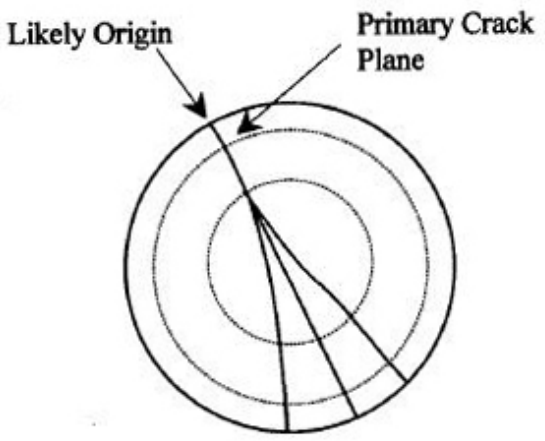

Figure 57: Illustrations of failure patterns in concentric ring test specimens
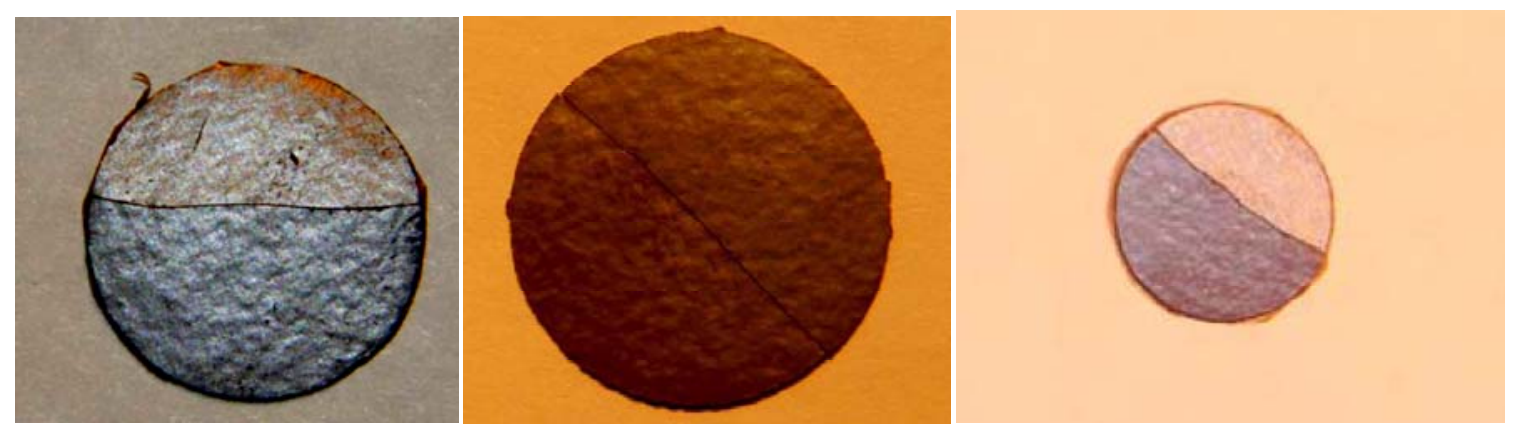

Figure 58: Fractured patterns of the tested samples 
The bumpy edges of the fractured surface shows that crack progress through the specimen is an intergranular fracture, which means fracture follow the grain boundaries of the sample (Figure 59). This might be related to microvoid nucleation and coalescence at inclusions along grain boundaries.

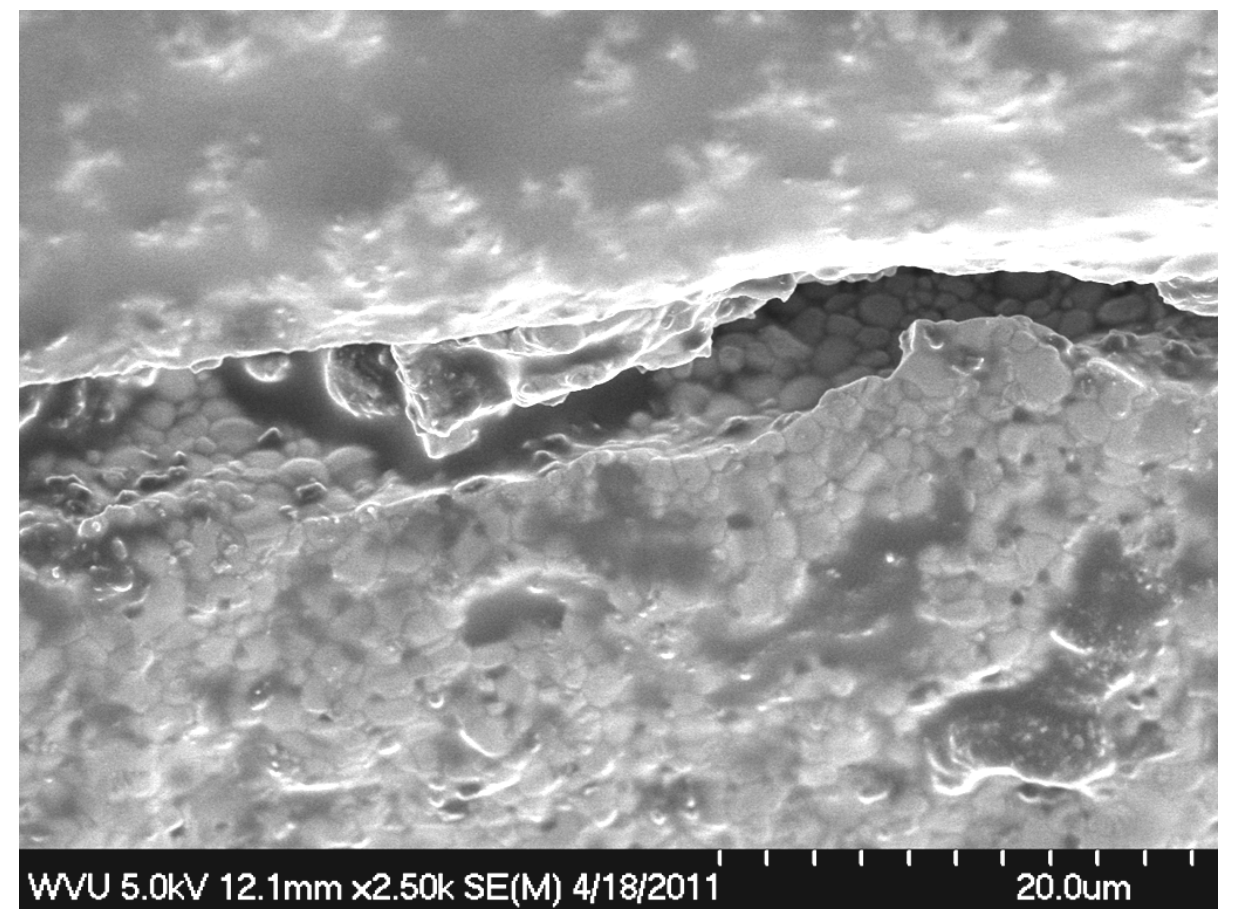

Figure 59: Intergranular crack growth in fractured surface

Figure 60 shows the crack progress into the grains and the straight line presents the intragranular fracture mechanism. 


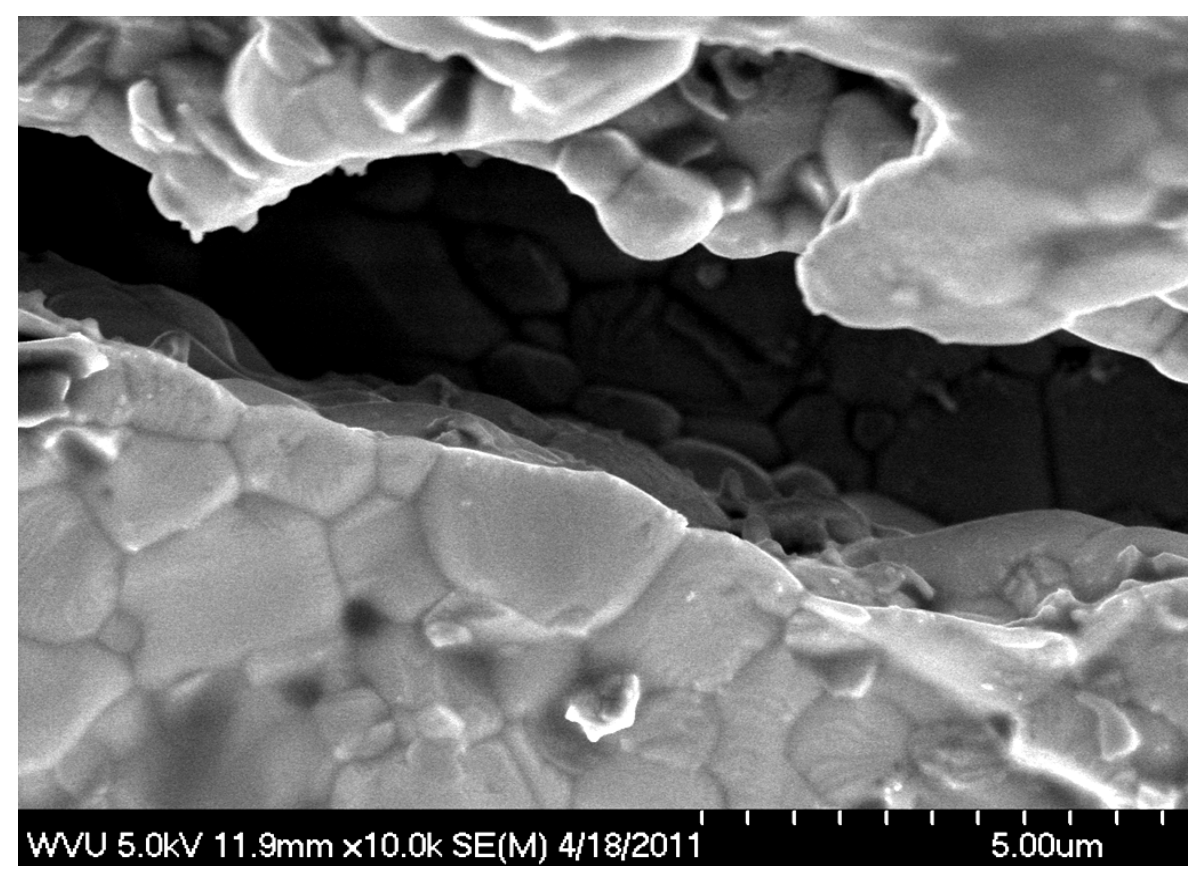

Figure 60: Intragranular crack growth in fractured surface

The top surface images of the fractured samples (Figure 61and Figure 62) confirm the mixed fracture mechanism (intragranular and intergranular) for the tested sample (fired at $675^{\circ} \mathrm{C} / 1 \mathrm{~h}$ ).
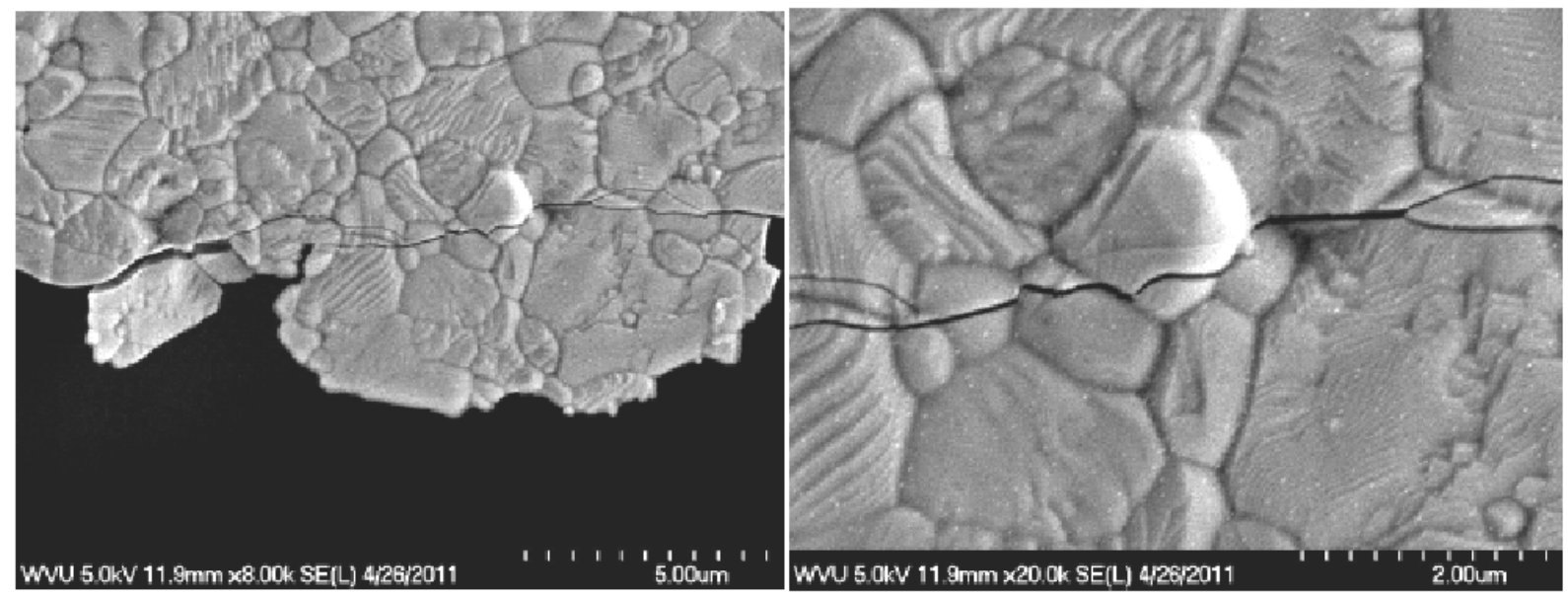

Figure 61: Intragranular crack growth in top surface 

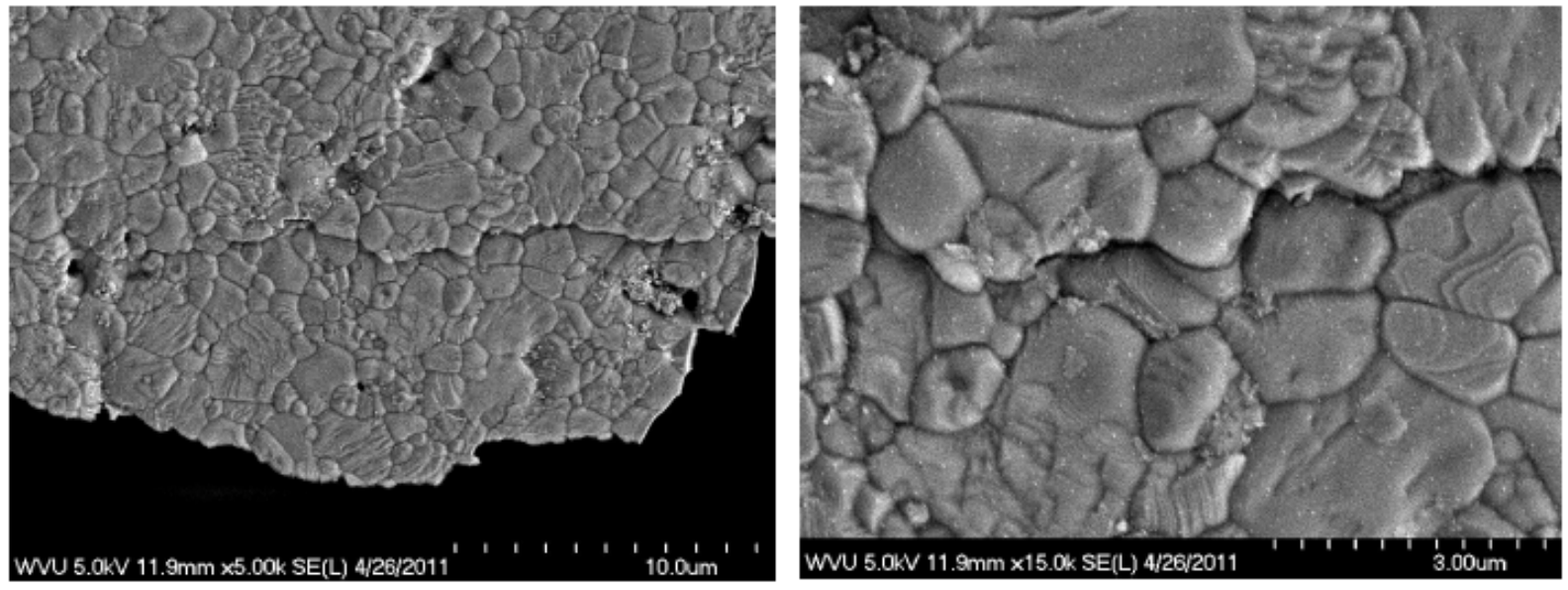

Figure 62: Intergranular crack growth in top surface

\subsection{Conclusions}

The highest conductivity was achieved for the samples fired at $675^{\circ} \mathrm{C} / 1 \mathrm{~h}$ for pure BICUVOX. Addition of $0.6 \mathrm{wt} \%$ GDC slightly decreased the ionic conductivity and further GDC addition up to $4 \mathrm{wt} \%$ lead to significant reduction in ionic conductivity. Dispersion of GDC particles to grain boundaries will increase the density of grain boundaries. Grain boundaries with higher density will contribute more to the total conductivity. Reduction in conductivity can be attributed to the higher contribution of grain boundaries to the total resistance.

Fired samples at lower temperatures $\left(<750^{\circ} \mathrm{C}\right)$ and shorter times $(<4 \mathrm{~h})$ exhibit higher mechanical strength, which is related to their higher density and smaller grain size achieved at these conditions. Addition of $0.6 \mathrm{wt} \%$ GDC to BICUVOX prevents the grain growth during the sintering and improves the mechanical properties. 
At the same sintering condition $\left(750^{\circ} \mathrm{C} / 4 \mathrm{~h}\right)$, the BICUVOX sample with $0.6 \mathrm{wt} \%$ addition of GDC shows $7 \%$ higher flextural strength compared to the one made of pure BICUVOX. $60 \%$ greater strength than the one reported by Yaremchenco et al [4] (83 MPa) was achieved. The achieved mechanical strength values are comparable to reduced Ni-YSZ supports for SOFCs (95-133 MPa) reported by Wang et al [53]. 


\section{Thesis Conclusion}

This work demonstrated a method of synthesizing submicron BICUVOX by co-precipitation synthesis. The co-precipitated powder was transformed to pure phase BICUVOX at lower calcination conditions than previously reported in literature $\left(500^{\circ} \mathrm{C} / 2 \mathrm{~h}\right)$, which is about $150^{\circ} \mathrm{C}$ below most other works. A thin BICUVOX membrane ( $250 \mu \mathrm{m}$ thick) was produced by firing at lower sintering temperature and shorter time $\left(675^{\circ} \mathrm{C} / 1 \mathrm{~h}\right)$. The produced membrane displays $97.5 \%$ theoretical density and grains size between $1-2 \mathrm{~mm}$ grain sizes. Grain size was also controlled by nanomaterial GDC powder, which pinned-grain growth and permitted densities improved to $\sim 99 \%$ theoretical density. Highest density BICUVOX samples displayed total conductivity of $0.20-0.25 \mathrm{~S} / \mathrm{cm}$ at $550^{\circ} \mathrm{C}$ (even with $0.6 \mathrm{wt} \%$ GDC) and the fabricated BICUVOX membranes showed $\sim 130-159 \mathrm{MPa}$ flextural strength. 


\section{Future work}

Recently a great deal of attention has been focused on texturing the electronic materials, which shows an anisotropy property within their crystal structures. The purpose of texturing is to access physical properties which are directly related to crystallographic orientation. TGG is one of the texturing mechanisms that increase volume fracture of texturing by growth of template particles at the expense of the finer matrix [57]. Measured conductivity for single crystal $\mathrm{Bi}_{4} \mathrm{~V}_{2} \mathrm{O}_{11}$, at the direction parallel to $\left(\mathrm{Bi}_{2} \mathrm{O}_{2}\right)^{+2}$, is three orders of magnitude larger than the one which is perpendicular to $\left(\mathrm{Bi}_{2} \mathrm{O}_{2}\right)^{+2}$ layers [58]. Also, BICUVOX single crystal shows ionic conductivity larger by two orders of magnitude in the direction parallel to the layer of intergrowth structure than in perpendicular direction [59]. Polycrystalline BICUVOX might show enhanced ionic conductivity by controlling its microstructure and orienting the grain growth process toward $<001>$ crystallography direction, thus the polycrystalline BICUVOX might show similar property to single crystal one. Increasing the ionic conductivity of BICUVOX ceramic will be investigated by texturing method. Platelet BICUVOX particles (obtained from MSS method) and sub-micron BICUVOX particles (from co-precipitation method) can be used as a template and matrix, respectively, during the Templated Grain Growth (TGG) process. TGG process includes the mechanical alignment of a relatively small volume fraction of the template particles within a ceramic matrix during green processing. 
With thermal treatment of the green ceramic, the template particles grow at the expense of the finer matrix powder in order to increase the volume fraction of textured material within the ceramic. Materials grain growth property can be controlled by seeding process. By seeding the matrix with other type of materials, which have the same structure as the matrix, the grain growth process will be controlled at the $<001>$ crystallography orientation. TGG results in texturing materials. At the end of sintering process, all of the grains will be aligned at $<001>$, as single crystal, so textured materials will indicate the same properties as a single crystal. By putting electrodes in the direction parallel to the layers of intergrowth structure of BICUVOX, high ionic conductivity larger by 50 to 100 orders of magnitude will be achieved.

More experiments need to be completed to characterize the phase that results in higher conductivity for the samples fired at lower temperature and shorter time.

For higher precision in mechanical testing, more experiments need to be run to drive actual BICUVOX mechanical data such as Young modulus and poisson's ratio.

More research needs to be completed in order to determine the exact effects of nano GDC particles in grain boundaries. It needs to be understood where the GDC particles sit in grain boundaries and whether they react or dissolve at grain boundaries. 


\section{References}

[1]. M. H. Paydar, A. M. Hadian, K. Shimanoe, N. Yamazoe. "Microstructure, mechanical properties and ionic conductivity of BICUVOX - $\mathrm{ZrO}_{2}$ composite solid electrolytes." Materials Science 37 (2002): $2273-2278$.

[2]. V.V. Kharton, F.M.B. Marques, A. Atkinson. "Transport properties of solid oxide electrolyte ceramics: a brief review." Solid State Ionic 174 (2004): 135-149.

[3]. S. P. Simner, D. Suarez-Sandoval, J. D. Mackenzie, and B. Dunn. "Synthesis, Densification, and Conductivity Characteristics of BICUVOX Oxygen-Ion-Conducting Ceramics." American Ceramic Society 80, no. 10 (1997): 2563-2568.

[4]. A.A Yaremchenko, V.V. Kharton, E.N. Naumvich F. M. B Marques. "Physicochemical and Transport Properties of BICUVOX-Based Ceramic." Journal of Electroceramics, 2000: 223-242.

[5]. A. Selcuk, A. Atkinson. "Strength and Toughness of Tape-Cast Yttria-Stabilized Zirconia." Journal of the American Ceramic Society 83, no. 8 (2000): 2029.

[6]. M. N. Rahaman, Ceramic Processing and Sintering. New York: Marcel.Dekker, 1995.

[7]. W. Jibo, J. Baofeng, Z. Xuefeng, C. You, Y. Weishen. "Effects of Synthesis Methods of BICUVOX.10 Membranes on Oxygen Permeation at Moderate Temperatures." Chinese Journal of Catalysis 30, no. 9 (2009): 926-932.

[8]. EG\&G Technical Services, Inc. . Fuel Cell Handbook. U.S. Department of Energy, 2004. 
[9]. E. J. D. Guire "Solid Oxide Fuel Cell." CSA. 2003.

http://www.csa.com/discoveryguides/fuecel/overview.php.

[10]. R. J. Kee, A. M. Dean, M. Lusk, and N. Sullivan. "Fundamental Chemistry and Physics of Direct-Oxidation in Solid-Oxide Fuel Cells." coloradofuelcellcenter. http://www.coloradofuelcellcenter.org/pages/projects/fundamental.html.

[11]. Charles Kittel,. Introduction to Solid State Physics . Wiley, 2005.

[12]. C. N. R. Rao, J. Gopalakrishnan. New Directions in Solid State Chemistry. Cambridge, 1997.

[13]. J. Kim, A. Manthiram. "Low Temperature Synthesis of Insertion Oxides for Lithium Batteries." Chemistry of Material 10 (1998): 2895-2909.

[14]. G. Mairesse, J.C. Boivin . "Recent Material Developments in Fast Oxide Ion Conductors." Chemistry of Material 10 (1998): 2870-2888.

[15]. A. R. West(Ed). "Solid State Chemistry and its Applications." John Wiley and Sons, Chap. 13. Chichester, 1984.

[16]. S. Yashonath, P. Padma Kumar. "Ionic Conduction in the Solid State." Chemical Sciences 118 (2006): 135-154.

[17]. A. Predith, A. Wilson. "Simulation of Oxygen Ion Ordering as a Result of Temperature Change." Parallel Scientific Computing 2002. http://beowulf.csail.mit.edu/18.337-2002/projects2002/a_wilson/18.337/18.337.htm.

[18]. P. Shuk, H. D. Wiemhofer, U. Guth", W. Gopeld, M. Greenblatt. "Oxide Ion Conducting Solid Electrolytes Based on $\mathrm{B}_{2} \mathrm{O}_{3}$." Solid State Ionics 89 (1996): 179-196. 
[19].University of Cambridge, Dissemination of IT for the Promotion of Materials Science (DoITPoMS). Edited by doitpoms@msm.cam.ac.uk. http://www.doitpoms.ac.uk/tlplib/fuelcells/sofc_electrolyte.php?printable $=1$.

[20]. M. Greenblatt and J. Yana. "Ionic conductivities of $\mathrm{Bi}_{4} \mathrm{~V}_{2-\mathrm{x}} \mathrm{M}_{\mathrm{x}} \mathrm{O}_{11-\mathrm{x} / 2}(\mathrm{M}=\mathrm{Ti}, \mathrm{Zr}, \mathrm{Sn}, \mathrm{Pb}) . "$ Solid State Ionics 81, no. 3-4 (1995): 225-233.

[21]. J. A. Kilner and S. J. Skinner. "Oxygen ion conductors." Materials Today 6, no. 3 (2003): 30-37.

[22]. http://abulafia.mt.ic.ac.uk/publications/theses/stanek/intorduction.pdf.

[23]. Crystal Structure Gallery. URL: http://staff.aist.go.jp/nomura-k/english/itscgallary-e.htm.

[24]. A. J. Jacobson. "Materials for Solid Oxide Fuel Cells." Chemistry of Materials 22 (2010): 660-674.

[25]. B. J. Wuenscha, K. W. Ebermana, C. Heremansa , E. M. Kua , P. Onnerud , E. M. E. Yeo, S. M. Haile, J. K. Stalick, J. D. Jorgensen. "Connection between Oxygen-Ion Conductivity of Pyrochlore Fuel-Cell Materials and Structural Change with Composition and Temperature." Solid State Ionics 129 (2003): 111-133.

[26]. S. Dutch Perovskite Structure. Natural and Applied Sciences. http://www.uwgb.edu/dutchs/Petrology/Perovskite\%20Structure.HTM.

[27]. N. Xu, , H. Zhao, X. Zhou, W. Wei, X. Lu, W. Ding, F. Li. "Dependence of critical radius of the cubic perovskite $\mathrm{ABO}_{3}$ oxides on the radius of $\mathrm{A}$ - and $\mathrm{B}$-site cations." International Journal of Hydrogen Energy 35 (2010): 7295-7301. 
[28]. N. M. Sammes, G. A. Tompsett, H. Nafe and F. Aldinger. "Bismuth Based Oxide Electrolytes Structure and Ionic Conductivity." Journal of European Ceramic Society 19 (1999): 1801-1826.

[29]. R. J. Cava "Perovskite Structure and Derivatives." Solid State Chemistry Research Group. http://www.princeton.edu/ cavalab/tutorials/public/structures/perovskites.html.

[30]. A. V. Akopjan, T. V. Serov, V. A. Dolgikh, E. I. Ardaschnikovaa and P. Lightfoot. "A New Anion Conductive Bismuth-Vanadium Oxyfluoride." Journal of Materials Chemistry 12, no. 5 (2002): 1490-1494.

[31]. Y.. V. Emel'yanova, R. R. Shafigina, E. S. Buyanova, V. M. Zhukovskii, V. M. Zainullina, and S. A. Petrova. "Oxide Ion Conductors of the BIMEVOX Family: Synthesis, Structure, and Conductivity." Russian Journal of Physical Chemistry 80, no. 11 (2006): 1725-1730.

[32]. G. Pasciak, J. Chmielowiec, P. Bujlo. "New Ceramic Superionic Materials for IT-SOFC Applications." Materials Science-Poland 23 (2005): 209-219.

[33].H.Y. Chena, L. Wua, C. Rena, Q.Z. Luob, Z.H. Xiea, X. Jianga. "The effect and mechanism of bismuth doped lead oxide on the performance of lead-acid batteries." Journal of Power Sources 95 (2001): 108-118.

[34].http://www.geocaching.com/seek/cache_details.aspx?guid=d987db33-569f-4271-a9f3d5be8a1b059a.

[35]. http://www.finishing.com/94/18.shtml. 
[36]. M.C. Steil, F. Ratajczak, E. Capoen, C. Pirovano, R.N. Vannier, G. Mairesse. "Thermal stability and preparation of dense membrane ceramics of BIMEVOX." Solid State Ionics, 2005: 2305-2312.

[37]. M. C. Steil, J. Fouletier, M. Kleitza and P. Labruneb. "BICOVOX: Sintering and Grain Size Dependence of the Electrical Properties." Journal of the European Ceramic Society 19 (1999): 815-818.

[38]. M.H. Paydar, A.M. Hadian , K. Shiamnoe, N. Yamazoe. "The effects of zirconia addition on sintering behavior, mechanical properties and ion conductivity of BICUVOX.1 material." Journal of the European Ceramic Society, 2001: 1825-1829.

[39]. B. Roy, Paul Anton Fuierer. "Molten Salt Synthesis of $\mathrm{Bi}_{4}\left(\mathrm{~V}_{0.85} \mathrm{Co}_{0.15}\right)_{2} \mathrm{O}_{11 \_\delta}$ (BICOVOX) Ceramic Powders." Journal of American Ceramic Society, 2009: 520-523.

[40]. P. I. Paulin F, M. R. Morelli, S.C. Maestrelli. "Bimevox type ionic conductors produced by melting process." Materials Research Innovations 3 (2000): 292-296.

[41]. T.S. Zhang, J. Ma, L.B. Kong. "Mechanochemical synthesis of nano-sized $\mathrm{Bi}_{2} \mathrm{~V}_{0.9} \mathrm{Cu}_{0.1}$ $\mathrm{O}_{5.35}$ powders." Journal of Materials Research, 2006: 71-74.

[42]. F. Krok, W. Bogusz, P Kurek. "Influence of prepration procedure on some physicalproperties of BICUVOX." Materials Science and Engineering B-Solid State Materials for Advanced Technology, 1973: 70-76.

[43]. M. Valant, D. Suvorov , R. C. Pullar ,K. Sarma , N. M. Alford. "A mechanism for lowtemperature sintering." Journal of the European Ceramic Society, 2006: 2777-2783. 
[44]. Larry, R. Department of Biology, Millersville University. http://rsb.info.nih.gov/ij/docs/pdfs/ImageJ.pdf (accessed 2007).

[45]. C.Vachon, M. Touboul and. "The Bi2O3-V2O5 System and Crystal Data About Some Bismuth Vanadates." Thermochemical Acta, 1988: 61-66.

[46]. A. Jankowski, J. Hayes, R. Smith, B. Reed. "Grain growth in bismuth coatings." Materials Science and Engineering, 2006: 106-108.

[47]. P. H. Borse, S. S. Yoon, J. S. Jang, J. S. Lee, T. E. Hong, E. D. Jeong. "Formation of Layered $\mathrm{Bi}_{5} \mathrm{Ti}_{3} \mathrm{FeO}_{15}$ Perovskite in $\mathrm{Bi}_{2} \mathrm{O}_{3}-\mathrm{TiO}_{2}-\mathrm{Fe}_{2} \mathrm{O}_{3}$ Containing System." Bulletin of the Korean Chemical Society 30 (2009): 3011.

[48]. P. I. Paulin F, M. R. Morelli, S.C. Maestrelli. "Bimevox type ionic conductors produced by melting process." Materials Research Innovations 3 (2000): 292-296.

[49]. T.S. Zhang, J. Ma, L.B. Kong. "Mechanochemical synthesis of nano-sized $\mathrm{Bi}_{2} \mathrm{~V}_{0.9} \mathrm{Cu}_{0.1}$ $\mathrm{O}_{5.35}$ powders." Journal of Materials Research, 2006: 71-74.

[50]. F. Krok, W. Bogusz, P Kurek. "Influence of prepration procedure on some physicalproperties of BICUVOX." Materials Science and Engineering B-Solid State Materials for Advanced Technology, 1993: 70-76.

[51]. M. G. Chourashiya and S. R. Bhardwaj, and L. D. Jadhav. "Fabrication of 10\%Gd-doped ceria (GDC)/NiO-GDC half." Solid State Electrochem, 2010: 1869-1875.

[52]. 1499-03, ASTM Standard C. Monotonic Equibiaxial Flexural Strength of Advanced Ceramics at Ambient Temperature. West Conshohocken, PA: American Society for Testing and Materials, 2003. 
[53]. Y. Wang, M.E. Walter , K. Sabolsky, M.M. Seabaugh. "Effects of powder sizes and reduction parameters on the strength of Ni-YSZ anodes." Solid State Ionics 177 (2006): 15171527.

[54]. B. Jimenez, P. Duran-Martin, R. J. Jimenez-Rioboo and R. Jimenez. "On the existence of a second phase transition in ferroelectrics with Aurivillius-type structure through the study of the Young's modulus." Journal of Physics, 2000: 3883-3895.

[55].http://accuratus.com/alumox.html.

[56]. A. Atkinson, A. Selcuk. "Mechanical behaviour of ceramic oxygen ion-conducting." Solid State Ionics 134 (2000): 59-66.

[57]. Y.Sakka, X. Zhu and. "Textured silicon nitride: processing and anisotropic properties." Science Technology Advance Materials 9 (2008): 47.

[58]. S. K. Kim, M. Miyayama. "Anisotropy in oxide ion conductivity of $\mathrm{Bi}_{4} \mathrm{~V}_{2-\mathrm{x}} \mathrm{Co}_{\mathrm{x}} \mathrm{O}_{11-\delta}$." Solid State Ionics 104 (1997): 295-302.

[59]. J. R. Dygas, P. Kurek and M. W. Breiter. "Structure- Dependent Impedance of BICUVOX." Electrochimica Acta, 1995: 1545-1550. 